\author{
UNIVERSIDADE DE SÃO PAULO (USP) \\ FACULDADE DE ARQUITETURA E URBANISMO (FAU) \\ Programa de Pós-Graduação em Arquitetura e Urbanismo
}

EDER FERREIRA DOS SANTOS

A INFLUÊNCIA DOS ESPECTROS DA LUZ EM USUÁRIOS RESIDENCIAIS

SÃO PAULO 


\section{A INFLUÊNCIA DOS ESPECTROS DA LUZ EM USUÁRIOS RESIDENCIAIS}

Dissertação de mestrado apresentada à Faculdade de Arquitetura e Urbanismo da Universidade de São Paulo, como requisito parcial para obtenção do grau de Mestre.

Área de concentração: Tecnologia da Arquitetura

Orientador: Prof. Dr. Leonardo Marques Monteiro

EXEMPLAR REVISADO E ALTERADO EM RELAÇÃO À VERSÃO ORIGINAL, SOB RESPONSABILIDADE DO(A) AUTOR(A) E ANUÊNCIA DO(A) ORIENTADOR(A). A versão original, em formato digital, ficará arquivada na Biblioteca da Faculdade.

São Paulo, 05/07/2017

SÃO PAULO 


\section{DEDICATÓRIA}

Dedico esse trabalho à minha família, a qual me inspira e me proporciona a energia que preciso para ir além dos meus próprios limites, com a qual eu sempre sonhei e hoje é o meu alicerce, que estrutura meus sonhos, meus planos, meus objetivos e minha vida.

Dedico também à minha profissão, a qual me possibilita estar o tempo todo analisando e entendendo o espaço e olhando para o bem-estar de seus usuários. 


\section{AGRADECIMENTOS}

Em primeiro lugar a Deus, que me proporciona saúde e paz para levantar dia após dia e seguir em frente, em uma jornada cheia de benções e em seguida minha esposa e companheira que me apoiou desde o início deste trabalho e a qual sabe dos obstáculos e das superações para chegar até aqui, além dos meus filhos, Victoria, Sophia e o recém-chegado Enzo, os quais me inspiram e me fortalecem.

Um especial agradecimento ao Prof. Dr. Leonardo M. Monteiro, meu orientador que sempre me deu livre direção e apoio ao longo dessa jornada.

Agradeço à Juliana Iwashita, que me ajudou com o empréstimo dos equipamentos utilizados em campo, além de ouvir e apoiar os planejamentos realizados, à Fernanda Falcão que me incentivou e apoiou ao longo dessa jornada e à Paula Carnelós, que segurou o fardo dos trabalhos profissionais em andamento durante a reta final.

Agradecimento especial também ao PhD Mark S. Rea e PhD Mariana G. Figueiró, ambos diretores do Lighting Research Center no Rensselaer Polytechnic Institute, Troy, NY, EUA, que me cederam gentilmente as bases de cálculo da metodologia utilizada, sem a qual esse trabalho não seria possível e À professora de física técnica ambiental, Laura Bellia, do Departamento de Engenharia Industrial da Universidade Frederico II, Napole, Itália, que se interessou pelo trabalho e fez essa ponte possível.

Agradeço também a todos os participantes da pesquisa, amigos, familiares e voluntários, que toparam participar das pesquisas realizadas em campo e gentilmente abriram suas casas e se interessaram pela seriedade da pesquisa realizada. 


\section{RESUMO}

Este estudo tem como objetivo introduzir ao leitor a influência da luz sobre os usuários residenciais, mostrando que o avanço das tecnologias ao longo da história e o acesso à iluminação artificial elétrica proporcionaram maior conforto às atividades relacionadas a sua moradia. Novas tecnologias, mais econômicas do ponto de vista energético, possibilitaram acesso a maiores quantidades de luz pelos usuários com diferentes tons de luz branca, permitindo uma maior escolha, porém podendo influenciar na produção do hormônio melatonina, o qual regula o relógio biológico, provocando distúrbios diversos. $\mathrm{O}$ trabalho de campo foi realizado em residências, dividido em duas linhas de raciocínio, sendo o primeiro à leitura em uma amostra de residências aleatórias e o segundo com base em uma residência utilizada como modelo. Entretanto, nesse último caso foram alteradas as tecnologias empregadas. Em ambos os casos foram feitas medições na sala de estar em frente à televisão. Esses estudos foram fundamentados no método de Circadian Stimulus (Rea M.S., 2005, 2011), baseado em diversos estudos laboratoriais, que demostraram a influência da luz sobre a produção de melatonina, onde foi empregado nos dois procedimentos adotados. Conclui-se que, apesar da estimativa dos níveis de supressão encontrados serem baixas, as tecnologias com temperaturas de cor mais elevadas, ou seja, luzes mais brancas, tem índices de inibição maiores e devem ser evitadas, assim como as quantidades de luz praticadas para os ambientes residenciais devem ser cuidadosamente dimensionadas. Esse trabalho não tem caráter conclusivo e sim introduz uma metodologia que ainda está em fase final de estudos, porém pode contribuir para apontar diretrizes até então pouco abordadas na prática profissional e terem o intuito de orientar os usuários finais.

Palavras Chave: melatonina, ritmo circadiano, iluminação artificial, ambiente residencial, projeto de arquitetura 


\begin{abstract}
This study aims to introduce the reader to the influence of light on residential users, showing that the advancement of technologies throughout history and access to electric artificial lighting have provided greater comfort to the activities related to their homes. New technologies, more economically energetic, allowed access to greater amounts of light by users with different white light tones, allowing a wide choice, but may influence the production of the hormone melatonin, which regulates the biological clock, causing many disturbances. Fieldwork was carried out in residences, divided into two lines of reasoning, the first to be read in a sample of random households and the second based on a residence used as a model. However, in the latter case, the technologies employed were altered. In both cases measurements were taken in the living room in front of the television. These studies were based on the Circadian Stimulus method (Rea M.S., 2005, 2011), based on several laboratory studies, which demonstrated the influence of light on the production of melatonin, where it was used in the two adopted procedures. It is concluded that, although estimates of suppression levels found are low, technologies with higher color temperatures, meaning whiter lights, have higher inhibition rates and should be avoided, as well as the amounts of light practiced for residential environments must be carefully dimensioned. This work does not have a conclusive character but rather introduces a methodology that is still in the final phase of studies, but it can contribute to point out guidelines that have not been approached in the professional practice and are intended to guide end users.
\end{abstract}

Keywords: melatonin, circadian rhythm, artificial lighting, residential environment, architectural design. 


\section{LISTA DE GRÁFICOS}

Gráfico 1 - Por Original Horst Frank, com algumas modificações por Jailbird.

Tradução da versão de Alebergen. - Obra derivada de

image:Electromagnetic_spectrum-es.svg, 15:39, 5 May 2011., CC BY-SA 3.0,

https://commons. wikimedia.org/w/index.php?curid=18122584 26

Gráfico 2 - secreção de metatonina e cortisol (adaptado de Touitou, 2003).

Gráfico 3 - Adaptado de Figueiro 2012

Gráfico 4 - Adaptado de Bellia 2013

Gráfico 5 - Teste simples de reflexão, executado com equipamento com

espectrômetro Konica Minolta CL500A a $20 \mathrm{~cm}$ da superfície citada. 39

Gráfico 6 - Traduzido de Rea 2005

Gráfico 7 - Gráficos de resumo do procedimento 1 - Residências aleatórias. .54

Gráfico 8 - Gráficos de resumo do procedimento 2 - residência modelo. 60

Gráfico 9 - Gráficos de resumo da equalização de níveis de iluminância para a residência modelo. 


\section{LISTA DE TABELAS}

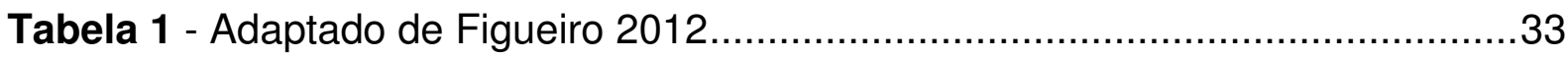

Tabela 2 - Tabela de iluminâncias para residências da antiga NBR5413.................37

Tabela 3 - Fonte: Plano Decenal de Expansão de Energia 2024 - Ministério de Minas e Energia, Empresa de Pesquisa Energégica .........................................42

Tabela 4 - Fonte: Plano Decenal de Expansão de Energia 2024 - Ministério de Minas e Energia, Empresa de Pesquisa Energégica ..........................................42

Tabela 5 - Procedimento 1 Luzes acesas + TV ligada........................................51

Tabela 6 - Procedimento 1 Luzes acesas + TV desligada ..................................52

Tabela 7 - Procedimento 1 Luzes apagadas + TV ligada ....................................53

Tabela 8 - Residência modelo - Luzes acesas + TV ligada ………......................57

Tabela 9 - Residência modelo - Luzes acesas + TV desligada ………………....58

Tabela 10 - Residência modelo - Luzes acesas + TV ligada - sem o vidro da luminária (lâmpadas expostas).

Tabela 11 - Residência modelo - Luzes apagadas + TV ligada e condição de tudo desligado.

Tabela 12 - Residência modelo equalização de níveis de iluminância (lux) Luzes acesas + TV desligada para 30lx 63

Tabela 13 - Residência modelo equalização de níveis de iluminância (lux) Luzes acesas + TV desligada para 60lx

Tabela 14 - Residência modelo equalização de níveis de iluminância (lux) Luzes acesas + TV desligada para 90lx

Tabela 15 - Residência modelo equalização de níveis de iluminância (lux) Luzes acesas + TV desligada para $1201 x$ 


\section{LISTA DE FIGURAS}

Figura 1 - llustração de artefato de madeira, pedra e tira de couro para produção de fogo. Imagem de: http://pt.wikihow.com/Fazer-Fogo-Sem-Fósforo-ou-Isqueiro. 17

Figura 2 - Lamparina de pedra calcária achada numa mina inglês, remontante há cerca de 10.000anos. (Natale Bonali, 2001)

Figura 3 - Sinopse figurada da evolução da lucerna de cerâmica entre os séculos VI A.C e I D.C. (Natale Bonali, 2001).

Figura 4 - Lucernas de bronze, dotadas de argolas para uso manual e, ao mesmo tempo, de corrente para uso pênsil. Museu Romano-Alemão de Mainz. (Natale Bonali, 2001) 18

Figura 5 - Lucerna etrusca Séc III A.C., $58 \mathrm{~cm}$ de diâmetro. 16 bicos para mechas. (Natale Bonali, 2001)

Figura 6 - Rudimentar castiçal de pedra calcárea incorporando lucerna, base e arrimo. Cerca de 3000 anos A.C. (Natale Bonali, 2001)

Figura 7 - Castiçal de bronze exibindo Sileno encostado numa árvore. Os dois ramos terminam com pequenas bandejas onde posam as lucernas. Século $1^{\circ}$ D.C. Museu Nacional de Nápoles. (Natale Bonali, 2001) 18

Figura 8 - Três candelabros etruscos, em bronze, dos séculos V/IV, descobertos na cidade de Vulci. Bases triangulares postas sobre 3 patas de animal. No cume pequenas bandejas aptas a receberem lucernas ou velas. Museu Etrusco-gregoriano Roma. (Natale Bonali, 2001)

Figura 9 - Candelabro Judaíco, "Menorah" fabricado em Essen em época mais recente em fiel consonância com as indicações contidas no Êxodus. (Natale Bonali, 2001)

Figura 10 - Coroa ardente conforme um afresco na Igreja de São Lourenço em Roma. (Natale Bonali, 2001)

Figura 11 - Gravura de M. Zombini, que mostra um "lanterneiro" no cumprimento de sua tarefa. Biblioteca Correr, Veneza. (Natale Bonali, 2001)

Figura 12 - Representação gráfica em detalhes dos principais componentes da lâmpada de Argand, com destaque para o reservatório, o canudo, o queimador e o botão regulador da chama. (Natale Bonali, 2001). 
Figura 13 - Patente da lâmpada de arco voltaico de Elihu Thomson, de 1882.

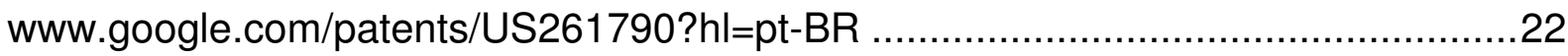

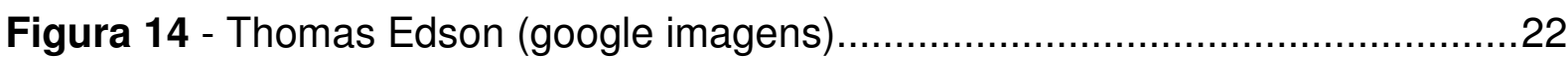

Figura 15 - Recriação do experimento de 1907 de HJ Round na observação da eletroluminescência de um ponto de contato com um carborundum (silicone carbide) crystal. (en.wikipedia.org/wiki/H._J._Round, 2017) .23

Figura 16 - Esquema de anatomia do olho humano com ampliação das células da retina. 27

Figura 17 - Ciclo circadiano humano 29

Figura 18 - Experimento realizado usando luz vermelha durante a noite, na casa de repouso Saint Francis, em Stella Niagara, NY 31

Figura 19 - Medições realizadas com espectrometro Everfine SPIC-200 a 1m 40

Figura 20 - Fonte: ABILUX (Associação Brasileira da Industria de lluminação) 2012

Figura 21 - Esquema de medição de campo adotada no procedimento 1 .50

Figura 22 - Dimensões e registro fotogrático da residência adotada como modelo .56 Figura 23 - Registro fotográfico do candelabro improvisado na residência modelo .61 


\section{Sumário}

1 Introdução...

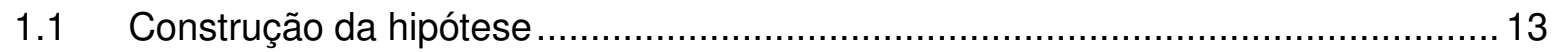

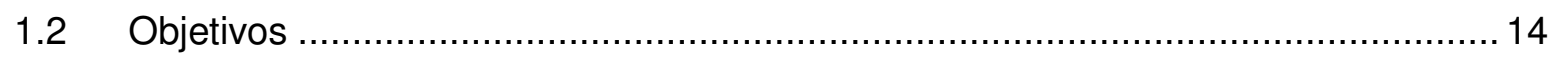

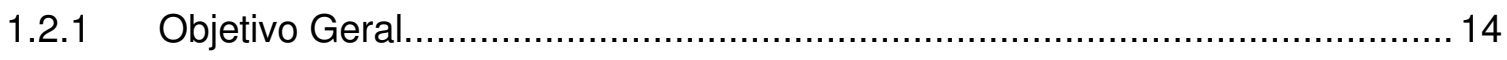

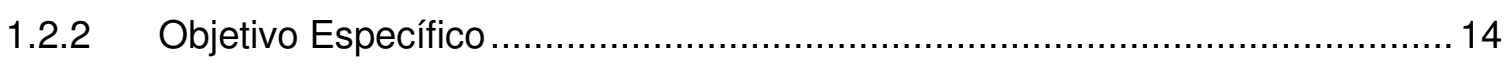

1.3 Estruturação da metodologia de pesquisa ..................................................... 14

2 A luz artificial - do fogo ao led ................................................................ 16

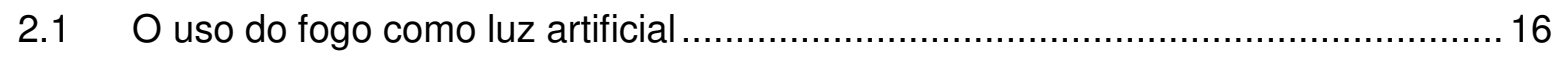

2.2 O uso do gás como luz artificial no século XVIII ............................................... 20

2.3 O uso da eletricidade com luz artificial no século XIV ....................................... 21

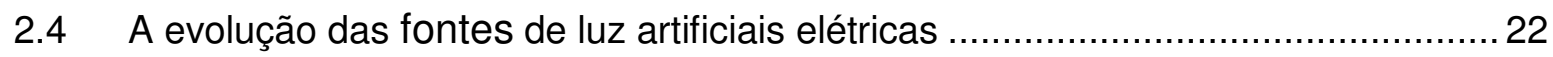

3 A relação entre a luz e olho humano.......................................................... 25

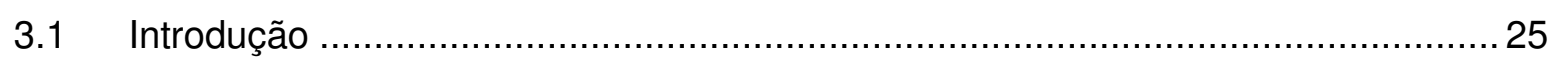

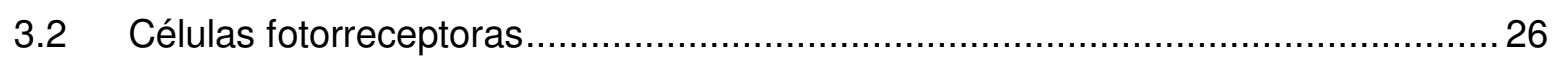

3.3 O efeito da iluminação no ritmo circadiano ................................................... 28

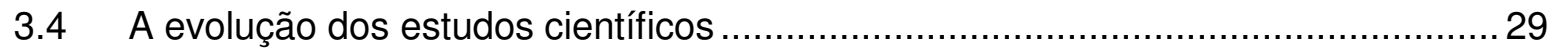

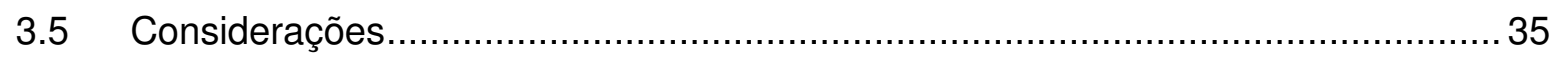

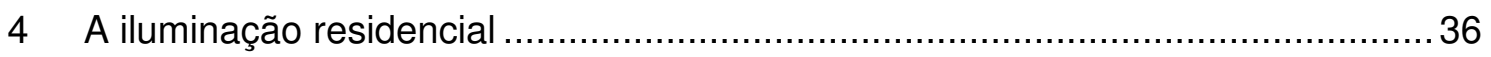

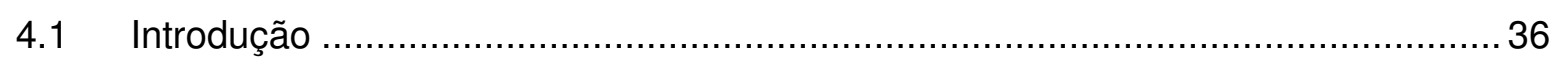

4.2 Níveis de iluminância para ambientes residenciais............................................ 36

4.3 Similaridades e diversidades na iluminação de residências....................................38

4.4 Tendências das tecnologias empregadas em residências no Brasil. ...................... 41

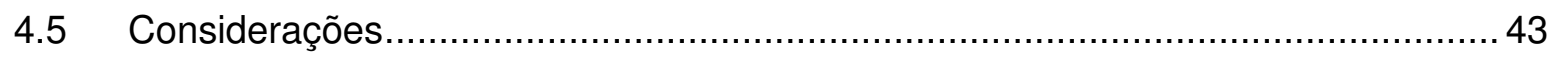

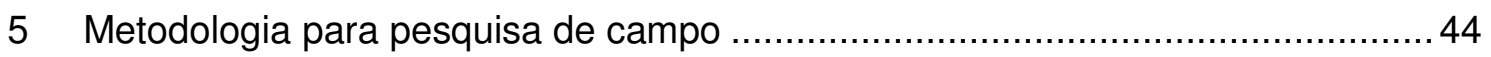

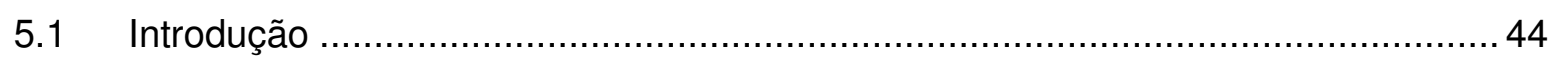

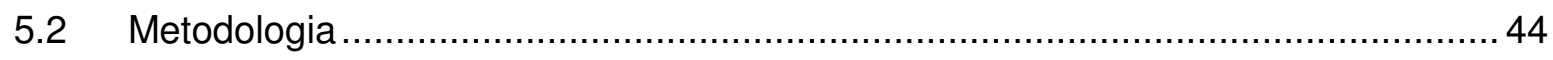

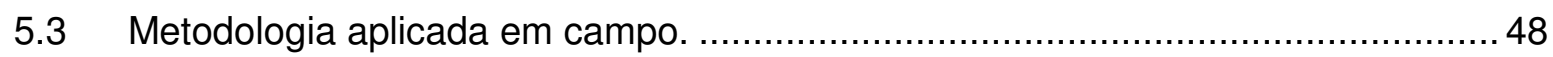

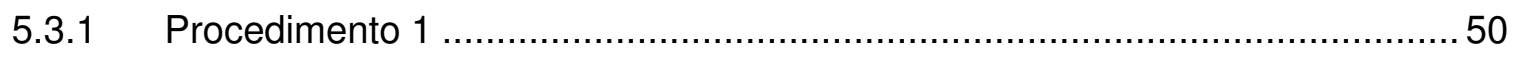

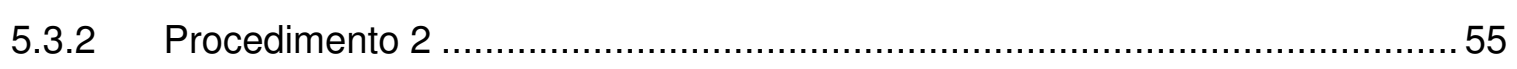

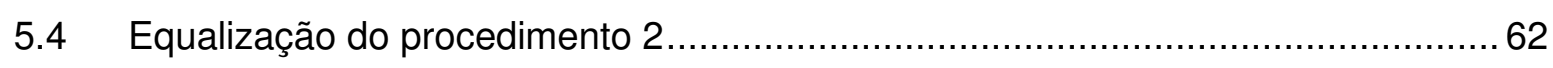

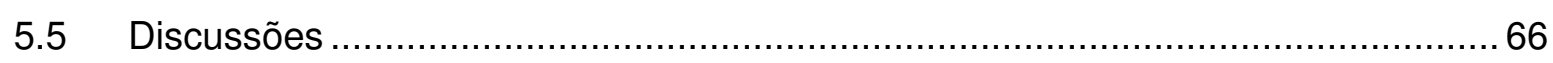

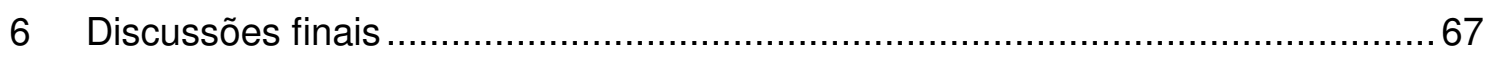

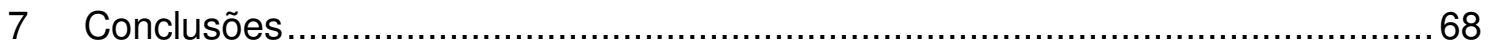

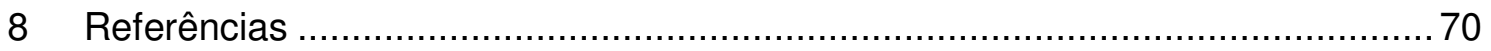

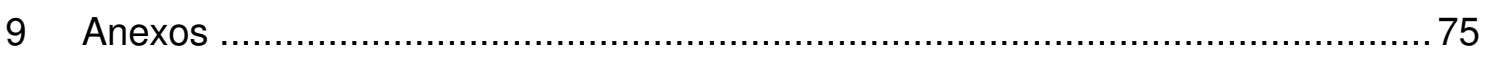


A história da iluminação artificial elétrica é significativamente curta quando comparada com a história da humanidade, por isso este estudo busca uma análise do impacto que a luz elétrica trouxe ao ser humano, principalmente quando analisamos o uso dessa luz no período de ausência da luz natural.

Há milênios o homem domina o fogo e consequentemente o utiliza-o como fonte de luz artificial, possibilitando um prolongamento de suas atividades, tendo em vista que na ausência de luz natural o ser humano perde o sentido da visão e fica limitado aos seus demais estímulos.

Esse prolongamento das atividades poderia ser considerado uma anomalia ao ciclo natural praticado anteriormente, para o qual o corpo humano foi biologicamente programado para funcionar. Entretanto o uso do fogo como luz artificial acontece ao longo de milênios e seria capaz que o homem já tivesse se adaptado a ele se analisarmos que a energia eletromagnética emitida pelo fogo está dentro de uma porção que aparentemente não interfere demasiadamente no seu repouso.

Uma breve e sucinta análise histórica nos faz entender que, após o advento da luz elétrica, o homem passou viver sob uma quantidade de luz muito acima do que estava acostumado até então. Esse é o foco de quase todos os estudos que buscam entender a influência da luz no comportamento, saúde e bem-estar humano.

Aqui faremos mais um estudo que busca entender como as novas tecnologias estão se relacionando com o ser humano dentro dos termos acima citados, contribuindo para futuras pesquisas e para a prática profissional em geral.

Os estudos que relacionam a luz do dia com a atividade humana também relacionam o estado de repouso, porém aqui faremos um estudo focado na influência da luz em residências partindo do princípio que os indivíduos tiveram suas atividades regulares ao longo do dia, sendo expostos à luz natural direta ou indiretamente mesmo que em tempo curto. 


\subsection{CONSTRUÇÃo DA HIPÓTESE}

Não nos cabe aqui realizar um estudo sobre as diversas tipologias de arquitetura, porém partimos do princípio que residências, de uma forma geral, têm ambientes fechados, suportados de alguma forma por aberturas por onde provem luz natural em alguma quantidade suficiente para que, durante o dia, não necessitem ser iluminadas total ou parcialmente por iluminação artificial. Certamente a diversidade de tipologias de residências que se possa imaginar nos levaria aos extremos dessa hipótese, sabendo que existem algumas completamente permeáveis pela luz e outras excessivamente enclausuradas.

Independentemente dessa questão, podemos incorporar também que o ser humano tem atividades diversas ao longo do dia, a depender de sua idade, sexo, religião, cultura, localização, e todas as demais diversidades provindas das relações e natureza humanas. Isso faz com que saibamos da complexidade das análises de exposição do ser humano à radiação solar ao longo do dia e, estudos segmentados são aplicáveis ao entendimento dessa rotina.

Sabendo-se também que, ao longo da noite, em tese os seres humanos devem ter o seu ciclo de repouso, culminando em um processo de adaptação até atingir o repouso total, o sono e que, também variações seriam aplicáveis, como indivíduos que exercem o seu trabalho ou qualquer outra atividade no período noturno. Entretanto, a estado de repouso humano está intrinsicamente ligado aos padrões de dia e noite, claro e escuro, luz e ausência dela, também chamado de ciclo circadiano'.

A partir da análise acima e fazendo um recorte específico, porém abrangente, decidiu-se estudar a influência que a luz pode ter na residência das pessoas, local no qual esse período de adaptação e repouso costuma acontecer, principalmente no momento onde se tem um maior acesso às novas tecnologias de iluminação elétrica que emitem uma luz muito diferente, tanto em termos de seleção da radiação como em intensidade, da luz do fogo, o qual foi utilizado por um período muito longo da história como luz artificial.

\footnotetext{
1 Do latin circa dien; circa=cerca de; dien = dia. Ritmo biológico com o período de aproximadamente 24 horas. CIE 2014
} 


\subsection{OBjetivos}

\subsubsection{Objetivo Geral}

Entender como a luz artificial em residências pode influenciar na qualidade e profundidade do repouso de seus usuários, através de um método que tenha embasamento científico, mas que possa dar direções para a boa prática profissional.

\subsubsection{Objetivo Específico}

Analisar a quantidade de supressão de melatonina que um indivíduo pode ter em sua residência graças as tecnologias aplicadas para a iluminação artificial, independente da diversidade de possibilidades que os espaços possam apresentar e das atividades exercidas.

Desmitificar a informação de aplicação isolada das tecnologias frente a sua relação com as variáveis do tipo de ambiente estudado, ou seja, entender o real impacto que os tipos de tecnologia empregadas na iluminação somadas as variantes dos ambientes tem sobre o ciclo biológico de seus usuários.

\subsection{ESTRUTURAÇÃo dA METOdOLOGIA DE PESQUISA}

Frente ao objeto e ao indivíduo de estudo dessa pesquisa, respectivamente a residência e seu usuário, a estruturação dessa dissertação busca o raciocínio retilíneo do pensamento científico, estruturando a hipótese e levantando as questões e os devidos conhecimentos sobre elas.

Assume-se então que, a diversidade de residências prováveis e como elas podem ser iluminadas é demasiadamente vasta para ser categorizada, porém os espectros provindos das fontes de luz artificial, mesmo após sua interação através dos espaços tão distintos, tem similaridade e podem dar indicadores e orientações para sua aplicação. 
Enquanto isso a análise biológica do indivíduo é demasiadamente complexa que exigiria estudos laboratoriais com variantes devidamente travadas e/ou controladas para que se tivesse resultados confiáveis, utilizando da coleta de plasma através da saliva ou amostra de sangue para as devidas evidências, porém resultando em um distanciamento da possível prática profissional sugerida e almejada.

Dessa forma o trabalho foi estruturado pelos capítulos abaixo descritos e suas finalidades.

O capítulo 2 faz, de forma sucinta e objetiva, um resgate de como a luz artificial foi usada ao longo da história, buscando um entendimento dos hábitos dos indivíduos e a relação das tecnologias usadas ao longo da história recente.

Em seguida, o capítulo 3 almeja mostrar o entendimento sobre a luz e sua relação com os seres humanos, abordando as respostas visuais e principalmente não visuais que ela proporciona.

Logo após, o capítulo 4 aborda as similaridades e diversidades dentro do objeto de estudo, a residência.

Por fim, o capítulo cinco aborda a metodologia e sua aplicação em campo, mostrando os resultados obtidos através dos métodos escolhidos baseados nos objetivos dessa pesquisa, seguido pelo sexto e sétimo capítulos que irão abordar as discussões a serem consideradas e as conclusões cabíveis. 
"As evidências que indicam o controle do fogo, o qual já existia de forma natural, datam de 400.000 anos atrás, com evidências de uso regular bem posteriores. A rotina de uso doméstico do fogo começou por volta de 50 a 100mil anos atrás, o que pode ter influenciado na evolução do ser humano para a tolerância da poluição do ar, causada pela queima de combustíveis fósseis ou vegetais em ambientes fechados." (David M.J.S. Bowman et al. 2009.)

\subsection{O USO DO FOGO COMO LUZ ARTIFICIAL}

Apesar de historicamente o fogo estar diretamente ligado à evolução humana, para esse trabalho nos concentraremos na importância que este teve como primeira luz artificial, possibilitando a extensão de suas atividades após o pôr do sol.

Até este momento o homem vivia como qualquer outro animal na natureza, respeitando as capacidades e relações que seu organismo tem com a luz natural, estando em atividade ao longo do dia e em repouso durante a ausência de luz.

É importante citarmos que, ao se referir à luz artificial estamos falando sempre de algo que nos possibilita ter a capacidade da visão no momento em que há deficiência ou ausência total da luz natural e que, ao longo de sua existência, sua função sempre foi a mesma, o que muda é a forma como ela é produzida, podendo associar isso sempre a uma tecnologia de base que a torna possível.

O fogo empregado no uso de luz artificial era difícil de ser produzido, utilizandose do atrito de gravetos ou minerais para gerar faíscas. "Pouco a pouco, o primitivo arbusto ardente foi transformando-se num arrematado artefato. Foram selecionadas madeiras resinosas que, desfiadas em tiras, vinham amarradas com cipós e espargidas de piches e resinas. Os artefatos tiveram grande difusão, primeiramente junto a babilonenses, fenícios e egípcios, alastrando-se em seguida junto a todos os povos da história antiga". (Natale Bonali, 2001)

$\mathrm{Na}$ substituição das madeiras e atritos, foram descobertos os óleos combustíveis de animais e vegetais, com precisão histórica indefinida, que eram 
utilizados em antigas lucernas (ou lamparinas) de pedra com cavidades naturais ou devidamente escavadas.

A mais arcaica das lamparinas descobertas remonta a cerca de 20.000 anos, descoberta no sul da França pelo arqueólogo francês Emil Reviere. (Natale Bonali, 2001)

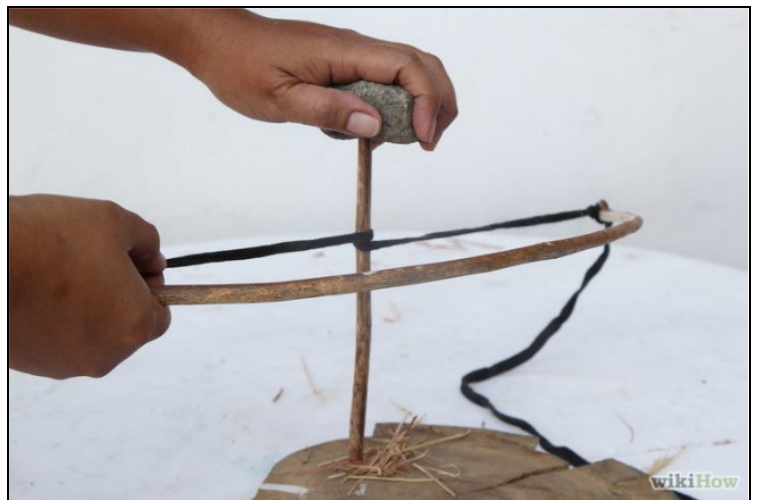

Figura 1 - llustração de artefato de madeira, pedra e tira de couro para produção de fogo. Imagem de: http://pt.wikihow.com/Fazer-Fogo-Sem-Fósforo-ou-Isqueiro

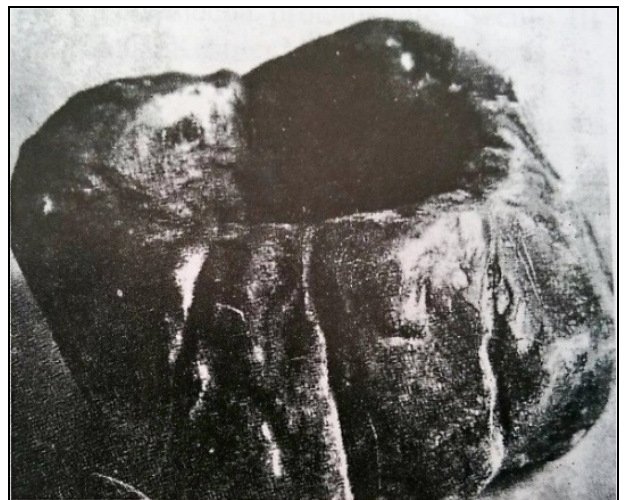

Figura 2 - Lamparina de pedra calcária achada numa mina inglesa, remontante há cerca de 10.000anos. (Natale Bonali, 2001)

A história relativamente recente das lamparinas e tochas tradicionais é rica e interessante, porém a ser relatada de forma breve nesse trabalho. As tochas ao longo da história deixaram de ser manuais e passaram a estar nas paredes de grandes áreas, foros públicos e anfiteatros, como em Roma, no circo Máximo e o Coliseu.

As lucernas ou lamparinas a princípio para uso manual, para que o homem pudesse levar a sua luz consigo, também foram feitas para uso pênsil, iluminando ambientes. Estas foram feitas de vários materiais ao longo da história, desde o barro até o metal e foram usadas das mais diversas formas. 


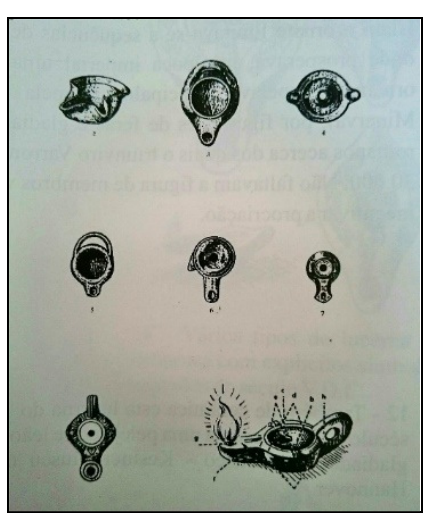

Figura 3 - Sinopse figurada da evolução da lucerna de cerâmica entre os séculos VI A.C e I D.C. (Natale Bonali, 2001)

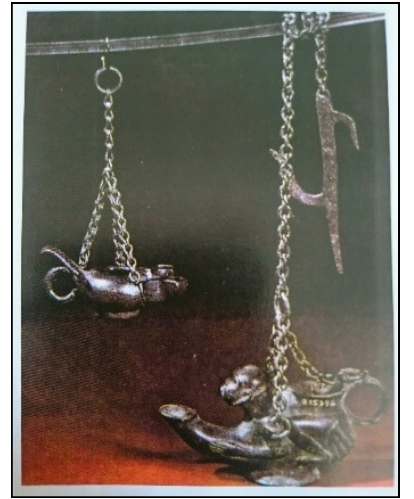

Figura 4 - Lucernas de bronze dotadas de argolas para uso manual e, ao mesmo tempo, de corrente para uso pênsil. Museu Romano-Alemão de Mainz. (Natale Bonali, 2001)

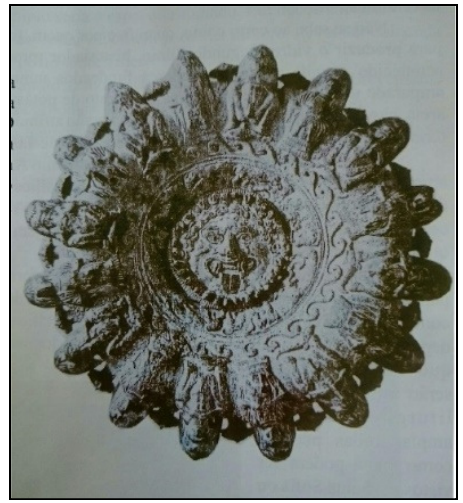

Figura 5 - Lucerna etrusca Séc III A.C., $58 \mathrm{~cm}$ de diâmetro. 16 bicos para mechas. (Natale Bonali, 2001)

Os castiçais nasceram da junção de apoios criados para as lucernas manuais, uma vez que os homens perceberam que, quanto mais alta a luz, mais amplo o espaço iluminado. Na Grécia as casas abastadas faziam questão de ostentar sofisticados castiçais com as efígies dos deuses do Olimpo.

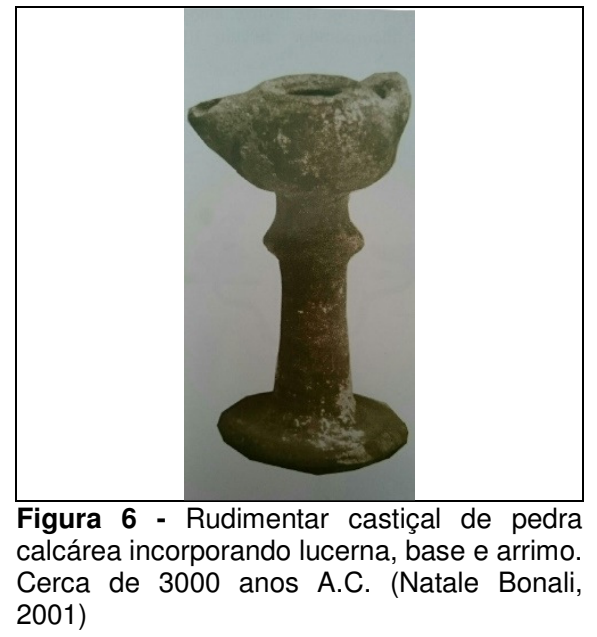

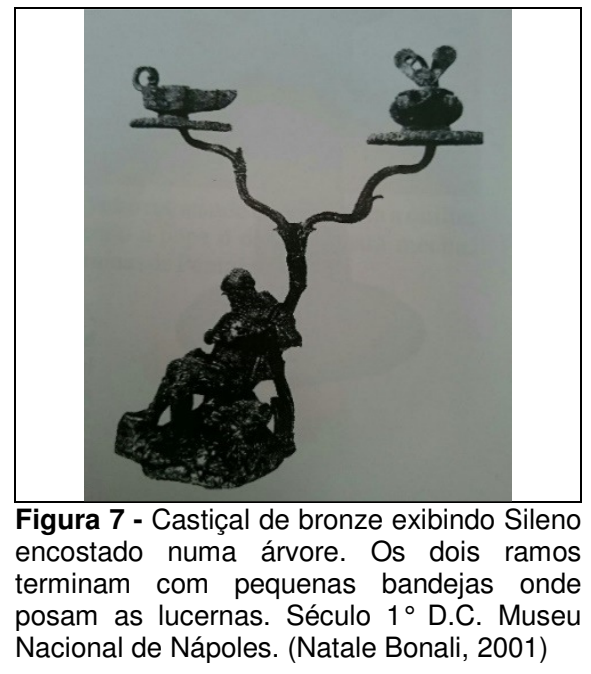

Sugere-se que as primeiras velas tenham surgido por volta de 2.000 anos A.C., onde cordões de cânhamos foram revestidos com breu, logo endurecida. Apesar de simplório, o processo resultava em artefatos de contornos irregulares, que mais tarde evoluíram para a produção através de imersão de cordões em cilindros com sebo líquido ou cera de abelha. As velas logo substituíram as lucernas sobre os castiçais.

Os candelabros derivaram dos castiçais, porém com maior altura e por comportar um maior número de fontes luminosas. No princípio também comportavam lucernas, porém logo adotaram a vela como fonte luminosa. 


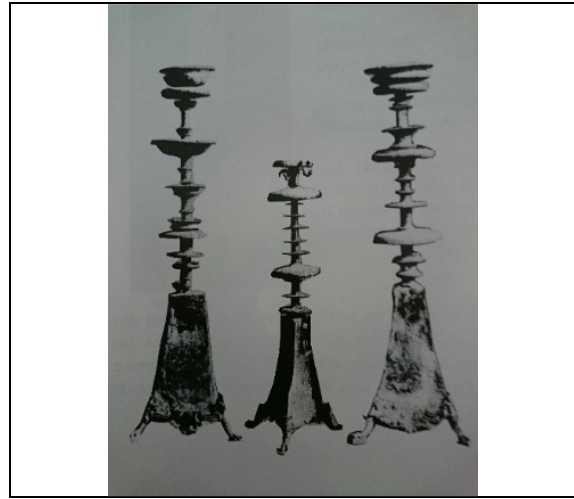

Figura 8 - Três candelabros etruscos, em bronze, dos séculos V/IV, descobertos na cidade de Vulci. Bases triangulares postas sobre 3 patas de animal. No cume pequenas bandejas aptas a receberem lucernas ou velas. Museu Etruscogregoriano Roma. (Natale Bonali, 2001)

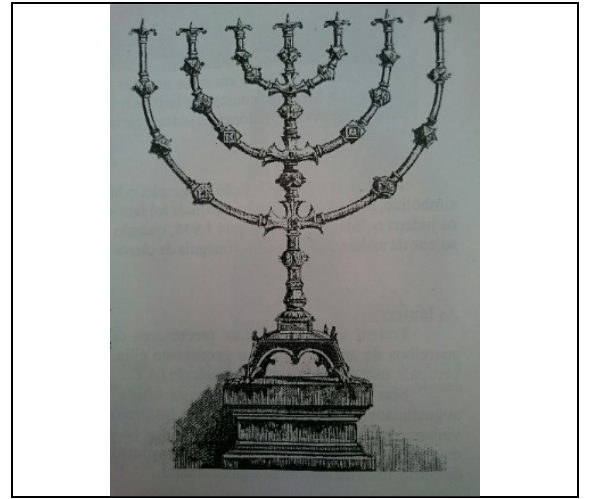

Figura 9 - Candelabro Judaíco, "Menorah" fabricado em Essen em época mais recente em fiel consonância com as indicações contidas no Êxodus. (Natale Bonali, 2001)

Em determinado momento na história, os candelabros passaram a ser pênseis, sendo apelidados de "coroa ardente" ou "aro de fogo". Eram feitos de aros longos com espigões para se colocar as velas. Esse aparelho teve ampla difusão nos templos, onde segundo a suma papal "Liber pontificalis" conseguia criar uma aura de misticismo como a atmosfera simbólica da "Jerusalém".

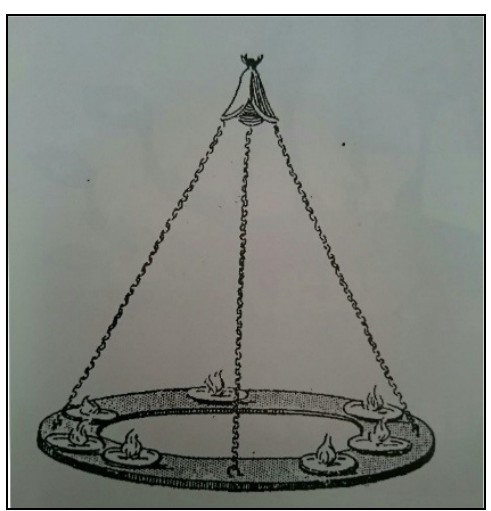

Figura 10 - Coroa ardente conforme um afresco na Igreja de São Lourenço em Roma. (Natale Bonali, 2001)

Durante toda a idade média, entrando pela era moderna até o final do século $\mathrm{XVII}$, inúmeras tipologias de candelabros, pedestais e lanternas foram criadas e utilizadas para os mais variados fins, porém sempre se utilizando da mesma tecnologia, a vela ou o óleo animal ou vegetal.

Bem no início do século XVIII, a iluminação pública estava restrita aos principais locais das cidades seguindo uma programação racional, através de lanternas de rua, 
as quais eram alimentadas por óleos vegetais cujo consumo era mais lento, porém em detrimento a quantidade de luz.

Em 1.760 as lanternas, que eram fixadas nas paredes das casas, ganharam um avanço tecnológico importante, um pequeno espelho côncavo de metal polido, que melhorava a distribuição luminosa da chama gerada. Essas eram alimentadas pelos lanterneiros. Curiosamente tal incumbência não era desempenhada em noites de luar.

Em 1.783 surge a lâmpada de Argand, após milhares de anos sem evolução tecnológica significativa, a qual utilizava de um vidro de dupla camada de ar para triplicar o poder de iluminação da chama. A lâmpada de Argand, apesar de bem difundida, não chegou a tomar grandes proporções devido ao aparecimento do gás no final do século XVIII.
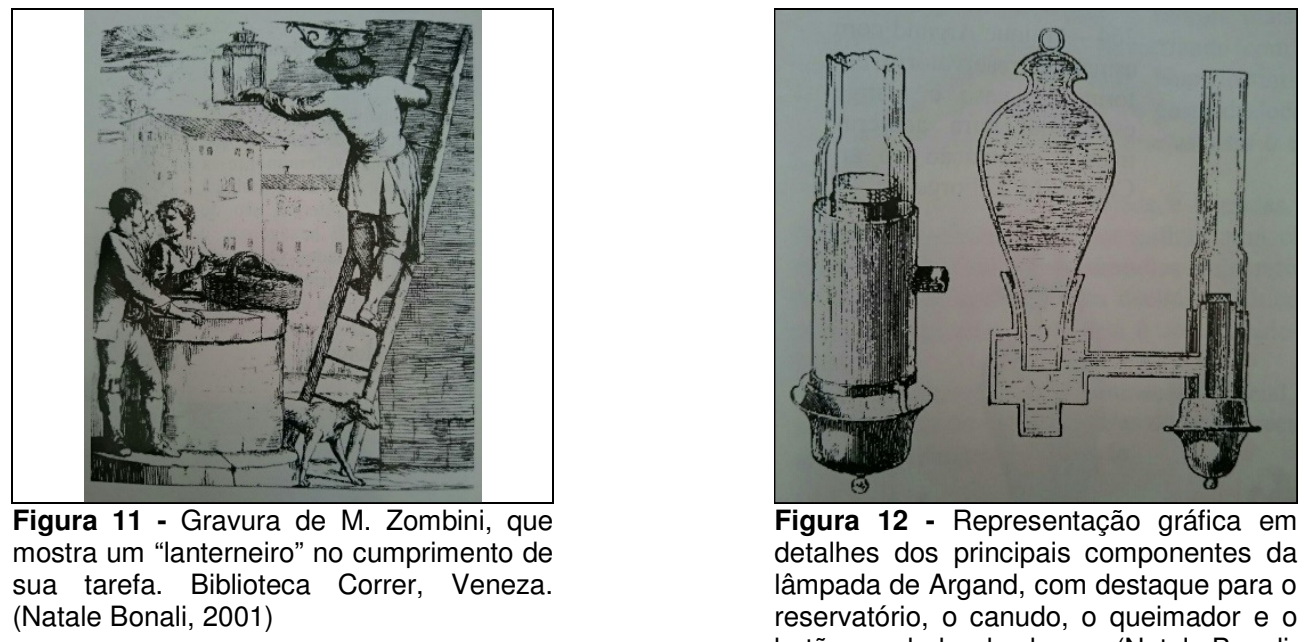

Figura 12 - Representação gráfica em detalhes dos principais componentes da lâmpada de Argand, com destaque para o reservatório, o canudo, o queimador e o botão regulador da chama. (Natale Bonali, 2001)

\subsection{O USO DO GÁS COMO LUZ ARTIFICIAL NO SÉCULO XVIII}

O gás aeriforme obtido pela destilação do carvão fóssil e descoberto no final do século XVII por J.J. Becker, só foi utilizado na iluminação no final do século XVIII pelo inglês Willian Murdoch o qual logrou-se por descobrir o modo de armazená-lo em um reservatório dito gasômetro. Willian iluminou sua casa e sua fábrica em Redruth através de uma canalização complexa feita de tubos de cobre. Frente a complexidade de implantação e ao perigo de explosões limitou-se o uso de tal tecnologia para o uso residencial. 
O número de gasômetros expandiu-se rapidamente para atender a iluminação de áreas e espaços fechados públicos. Londres inaugurou em 1.807 a primeira instalação pública permanente iluminando a rua de Pall Mall, feito logo imitado por outros centros urbanos do velho continente.

"Em 1.819, o diário alemão "Kolimische Zeitung" com relação a iluminação a gás, publicava: "As lâmpadas desta inatural iluminação são muito perigosas podendo explodir a qualquer momento. Ademais, a luz é demasiada inibindo os cavalos, incentivando os ladrões e facilitando a indecência" (Natale Bonali, 2001)

No final do século XIV, ápice da tecnologia a gás, os aparelhos ganhavam o "bico Auer", que era agregado com algodão embebido de óxidos que diminuíam as possibilidades de explosão e possibilitava virar a chama para baixo pela primeira vez na história.

\subsection{O USO DA ELETRICIDADE COM LUZ ARTIFICIAL NO SÉCULO XIV}

Apenas no final do século XIX que a energia elétrica viria a ser usada na iluminação pública, substituindo as fontes de luz geradas através da queima de combustíveis animais ou vegetais ou de gases.

Em 1876 o Russo Pavel Yablochkov criou o primeiro modelo de lâmpada de arco voltaico, patenteando em Paris um tipo de "vela elétrica" (Patente francesa $n^{\circ}$ 112024). O primeiro uso público do sistema de Yablochkov foi em outubro de 1877 no Halle Marengo, utilizando 6 "velas elétricas".

No final do século XIX, a lâmpada de arco voltaico foi patenteada nos Estados Unidos pelo Engenheiro elétrico Elihu Thomson, que nasceu em Manchester Inglaterra em 1853 e mudou-se com sua família para os Estados Unidos em 1858. Por volta de 1880 ele fundou a Thomson-Houston Electric Company a qual, em 1892 se fundiu com a Edison General Electric Company para formar a General Eletric Company. A lâmpada de arco voltaico é a tecnologia predecessora das atuais lâmpadas de descarga, conhecidas como lâmpada de sódio, de mercúrio e vapor metálico. (en.wikipedia.org/wiki/Elihu_Thomson; 2017) 


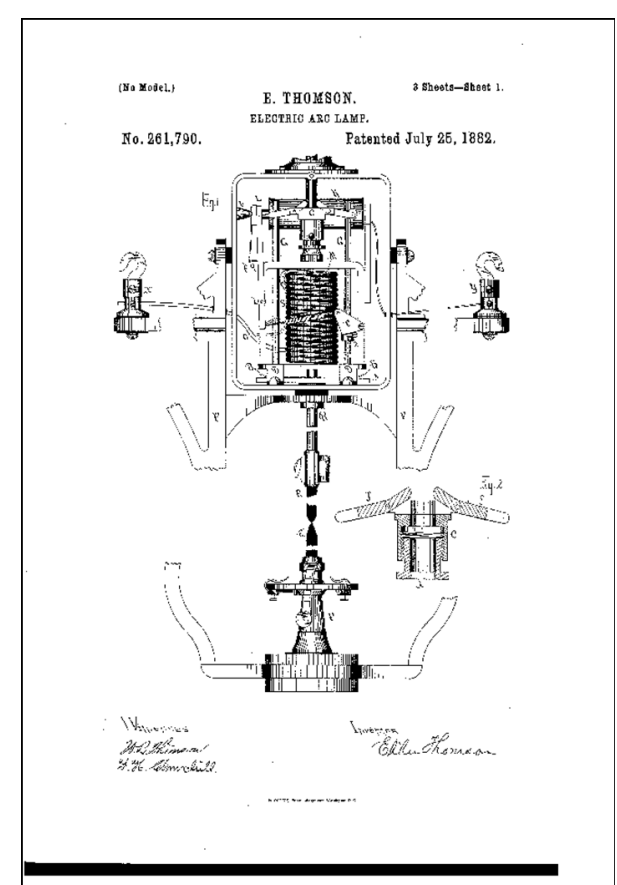

Figura 13 - Patente da lâmpada de arco voltaico de Elihu Thomson, de 1882 www.google.com/patents/US261790?hl=pt-BR

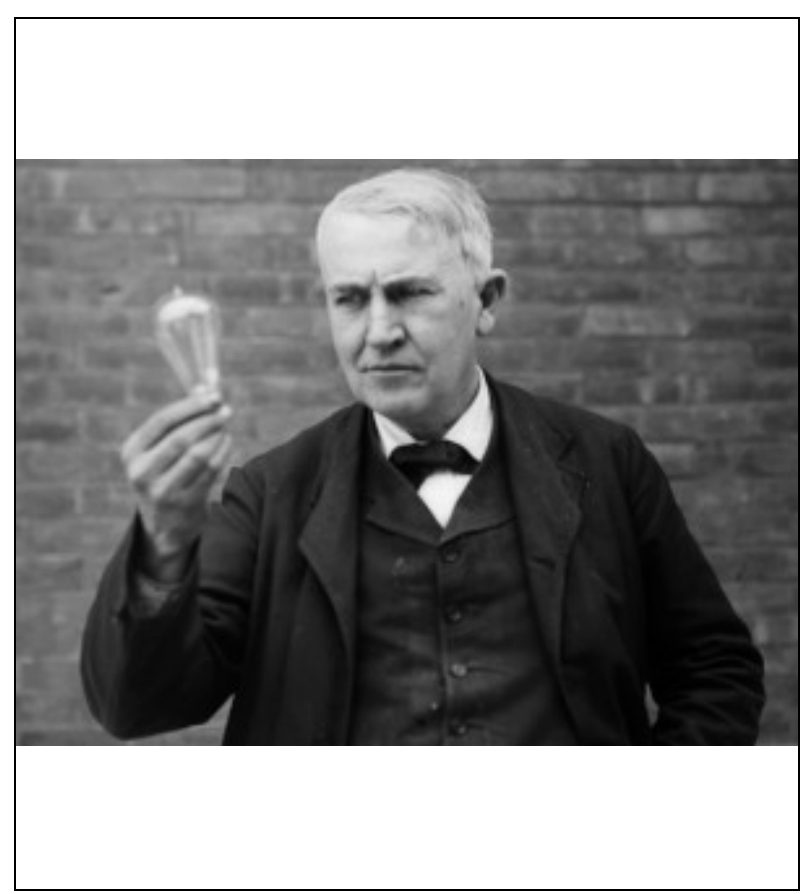

Figura 14 - Thomas Edson (google imagens)

Em 1879, Thomas Alva Edison consegui estabilizar e aumentar a vida útil de lâmpadas elétricas utilizando um filamento fino de carvão em alto vácuo. Logo consegue melhor, aprimorar e comercializar em grande escala a lâmpada incandescente. Em 1802 o químico britânico Humphry Davy construiu a primeira fonte luminosa com um filamento de platina, utilizando o efeito joule, observado quando um resistor é aquecido pela passagem de uma corrente elétrica a ponto de emitir luz visível. Outros 21 inventores construíram lâmpadas incandescentes antes de Edison.

\subsection{A EVOLUÇÃo dAS FONTES DE LUZ ARTIFICIAIS ELÉTRICAS}

Ao longo do século $\mathrm{XX}$, as duas tecnologias utilizadas para a geração de luz artificial elétrica, a lâmpada incandescente e as lâmpadas de arco voltaico evoluíram e iluminaram o mundo pouco a pouco. A incandescente ganhou melhores filamentos e gases inertes em seu interior, assim como as lâmpadas de arco voltaico dariam origem as lâmpadas fluorescentes e as lâmpadas de descarga, utilizando de alguns metais como base geração de energia luminosa, como o mercúrio e o sódio. 
Ambas tecnologias iluminaram o último século e se desdobraram em centenas de tipologias e formatos de lâmpadas, de diferentes intensidades e potências que foram empregadas nos mais diversos usos.

Diferente do que se imagina, a terceira e mais cotada tecnologia, com potencial sucessora de qualquer fonte de luz elétrica existente foi descoberta em 1907 pelo engenheiro e capitão Inglês Henry Joseph Round, que foi o primeiro a reportar a observação do fenômeno da eletroluminescência, princípio básico da tecnologia dos diodos emissores de luz (LED, do inglês Lighting Emithing Diode). (en.wikipedia.org/wiki/H.J.Round, 2017)

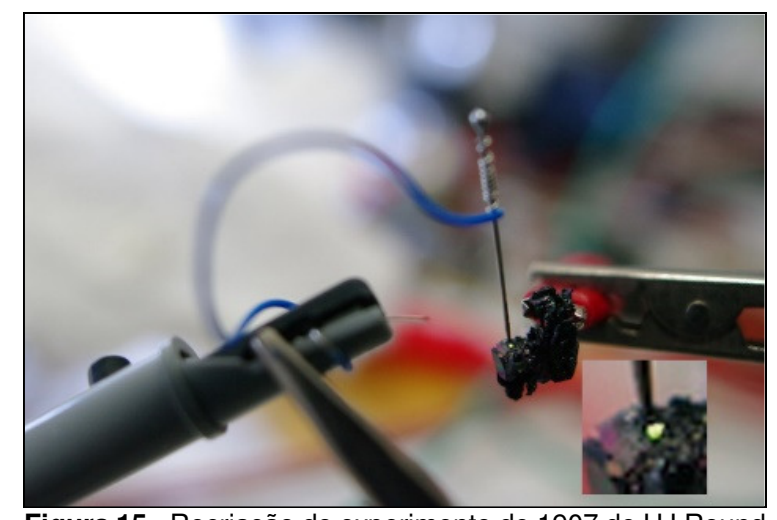

Figura 15 - Recriação do experimento de 1907 de HJ Round na observação da eletroluminescência de um ponto de contato com um carborundum (silicone carbide) crystal. (en.wikipedia.org/wiki/H._J._Round, 2017)

Após muitos anos sem evolução, em 1962 seria patenteado o primeiro LED na cor vermelha, tecnologia que hoje é cotada para a substituição de todas as fontes de luz até agora citadas.

O princípio de funcionamento do LED é basicamente matéria dopada de cargas positivas e negativas (catodo e anodo) através da qual, durante a passagem de corrente elétrica, há liberação de fótons gerando assim espectro de radiação visível, a luz.

Durante mais de 30 anos apenas LEDs vermelhos e verdes foram usados como sinalização de baixa intensidade em equipamentos eletrônicos, porém em 1994 o LED de alto brilho azul baseado em Índium Galium e Nitrato (InGaN) foi desenvolvido por Shuji Nkamura da Nichia Corporation em paralelo com Isamu Akasaki e Hiroshi Amano em Nagoya. Os três receberam em 2014 o prêmio Nobel em Física por sua invenção 
que possibilitara o uso dos LEDs em iluminação geral e arquitetural com baixo consumo de energia. (en.wikipedia.org/wiki/Light-emitting_diode)

Após uma transição para o uso da energia elétrica como fonte de luz artificial, os LEDs são potencialmente cotados para a substituição das tecnologias existentes por vários motivos. Para este estudo, vale ressaltar alguns mais importantes e de fácil assimilação, como o baixo consumo de energia frente as tecnologias mais eficientes existentes atualmente, ao ser de descarte ecologicamente correto por não possuir substâncias tóxicas ao meio ambiente como metais pesados e a sua flexibilidade de aplicação devido ao seu tamanho diminuto, possibilitando montagens nas mais variadas formas possíveis.

Para fecharmos este capítulo cujo intuito é relatar de forma sucinta, porém não menos importante, a relação do homem com a luz artificial ao longo de sua história e como as diferenças tecnologias evoluíram e foram utilizadas, coloca-se a reflexão sobre a quantidade de luz efetiva que se usou ao longo da história para se iluminar os ambientes de forma artificial.

Acreditamos que a energia elétrica trouxe também o uso exagerado de luz, além de outras questões que levantaremos ao longo dos próximos capítulos. 


\subsection{INTRODUÇÃo}

Neste capítulo faremos uma introdução dos princípios básicos da luz, porém direcionando o pensamento na relação que a luz tem com o ser humano, pensando física e fisiologicamente, onde podemos fazer uma simples analogia da luz como mensagem, a qual sempre precisa de um locutor e um receptor, a qual sem qualquer um dos dois não faria sentindo e não existiria como tal, se tornando totalmente dependente um do outro.

A luz é algo aparentemente simples, pois desde a existência de qualquer consciência do homem existe a visão, função intrinsicamente ligada a luz.

Mark Rea escreveu um artigo intitulado "O lúmen visto em uma nova luz: fazendo distinções entre luz, iluminação e neurociência”" , onde faz uma sagaz jornada em como atualmente a ciência aborda a luz por pontos diferentes, muitas vezes isolados por interesses ou até mesmo por falta de conhecimento. Tais pontos são: a física da luz, o processo de iluminar e a neurociência, sendo esta última a que aborda como o corpo recebe e reage a luz.

Assim como a mensagem não pode sequer ser imaginada e presente sem ambos, locutor e receptor, assim é a luz, não pode existir sem sua fonte de emissão, seu meio de transmissão e seu receptor. Para entendermos efetivamente a relação do homem com a luz temos que pensar nestes pontos como parte de um único processo, podendo sim isolá-los para estudo, mas sabendo que um não existe sem o outro.

Primeiramente vamos entender o que é luz.

Luz: energia radiante capaz de excitar o sistema visual humano (CIE, 2014; IESNA, 2006). A radiação visível ocupa a região de comprimento de onda delimitada pela UV (Ultravioleta) e IR (Infravermelho), ficando entre aproximadamente $400 \mathrm{e}$ 750nm. Esses limites não são nítidos (IES, 2011).

\footnotetext{
2 Titulo original: The lumen seen in a new light: Making distinctions between light, lighting and neuroscience. MS Rea PhD. Lighting Res. Technol. 2015; Vol. 47: 256-280
} 
$\mathrm{Na}$ definição de luz já temos o conceito de interdependência, pois quando falamos em energia irradiada podemos pensar em uma fonte de energia e a mesma sendo emanada em alguma direção através de um meio e, quando falamos de visível, estamos criando uma dependência e uma segregação onde, apenas uma parte dessa energia ativa determinados receptores para se tornar visível dentro do olho humano.

Abaixo vemos uma ilustração que mostra como a energia radiante do sol é classificada e qual parte desta realmente é considerada como luz.

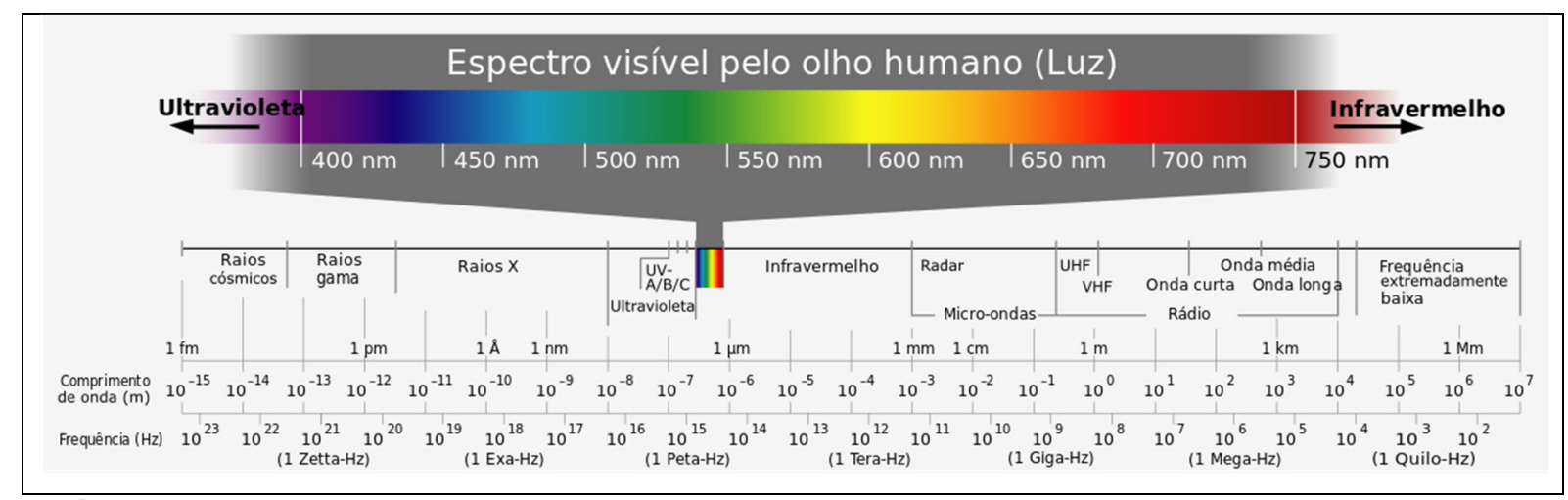

Gráfico 1 - Por Original Horst Frank, com algumas modificações por Jailbird. Tradução da versão de Alebergen. - Obra derivada de image:Electromagnetic_spectrum-es.svg, 15:39, 5 May 2011., CC BY-SA 3.0,

https://commons. wikimedia.org/w/index.php?curid=18122584

No capítulo anterior vimos como a luz artificial evoluiu ao longo da história, porém é importante citar que a luz artificial é uma forma de se reproduzir a luz natural, o Sol, a qual o homem está biologicamente apto a receber.

\subsection{CÉLULAS FOTORRECEPTORAS}

A retina no olho humano é composta por algumas células fotorreceptoras, as quais são responsáveis cada uma pela transformação em pulsos eletromagnéticos que serão transportados pelo nervo óptico à zonas específicas dentro do cérebro para a obtenção das respostas visuais e não visuais.

Assim como a dupla função associada ao ouvido (audição e equilíbrio), nos mamíferos o olho também tem dupla função, uma delas a de detecção da radiação óptica e formação da imagem (visão) assim como respostas ligadas a regulação do ciclo diário (ciclo circadiano), neuro endocrinológico (influência nas células cerebrais que controlam a produção de hormônios para o corpo) e neuro comportamental 
(resultados observados no comportamento através da produção de determinados hormônios).

O efeito não visual da radiação óptica é a habilidade de reiniciar o relógio biológico interno baseado no ciclo diário da luz natural, ou seja, o estimulo à produção de hormônios diurnos ou noturnos é dado pela exposição (dia) ou não (noite) de determinadas células no olho humano aos espectrodas da radiação eletromagnética.

Abaixo esquema de posicionamento do olho humano, a direita da imagem podemos ver cones e bastonetes, todos conectados a células ganglionárias.

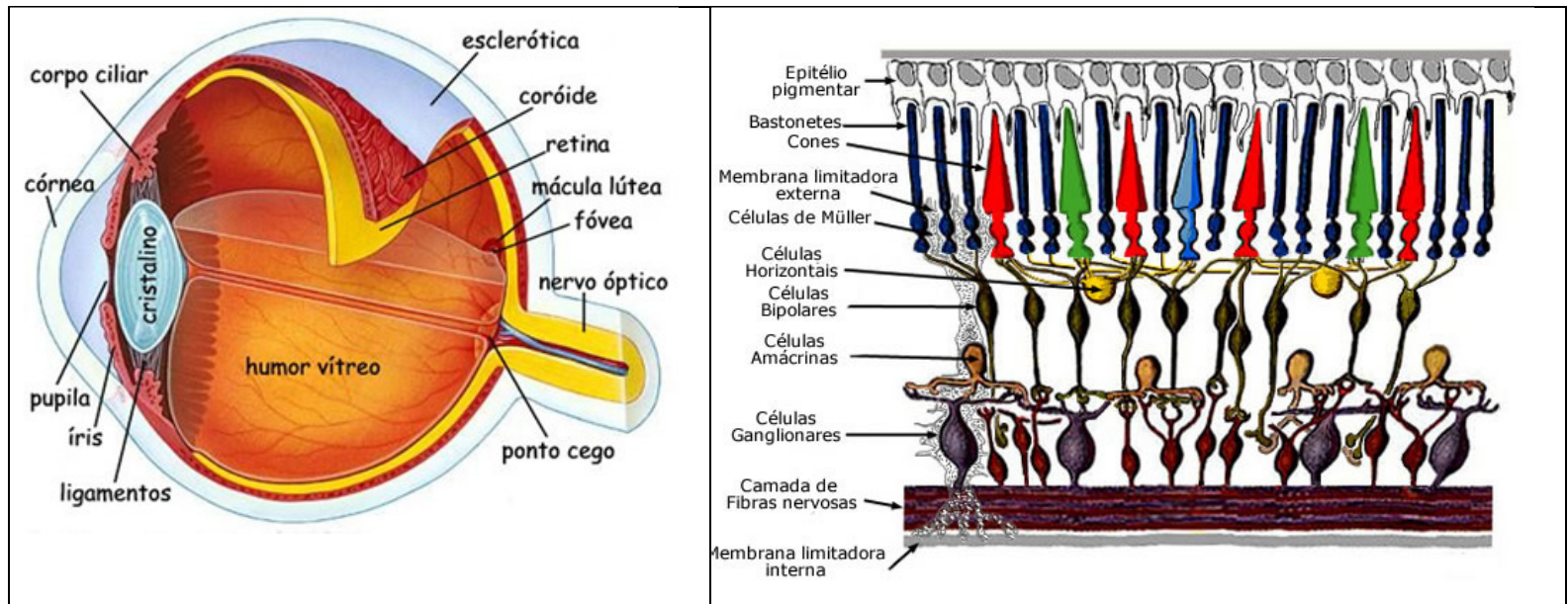

Figura 16 - Esquema de anatomia do olho humano com ampliação das células da retina.

Até a pouco tempo, apenas quatro células fotossensíveis presentes da retina eram conhecidas. Os cones, responsáveis pela interpretação das cores, divididos entre 3 tipos que são os curtos, médios e longos, com picos de sensibilidade em azul, verde e vermelho respectivamente e os bastonetes, sensíveis a baixos índices de radiação (baixos níveis de iluminância), e responsáveis pela leitura brilho.

Recentemente um novo tipo de célula fotorreceptora denominadas células ganglionárias retinais intrinsicamente fotossensíveis (ipRGCs) 3 foi descoberta (Berson D.M. 2002) e essas são responsáveis pela regulação do sistema neuro endocrinológico, ou seja, responsável pela regulação da produção dos hormônios que regulam o ciclo circadiano do indivíduo. Tais células representam apenas de 1 a 3\%

\footnotetext{
${ }^{3}$ do inglês intrinsically photosensitive retinal ganglion cells
} 
do total das células ganglionares, porém formam uma rede em toda retina que recebe a energia óptica e tem um canal exclusivo de ligação no nervo óptico ao núcleo supraquiasmático (SCN), o qual faz o papel de "marca-passo" do sistema circadiano, marcando o ciclo dia e noite para as diversas regiões do cérebro, incluindo o hipotálamo, responsável pela regulação da produção de hormônios como a melatonina e a cortisona.

A maior ação espectral da radiação visível para as células fotossensíveis está entre 459 e 484nm (luz azul), onde a ausência de radiação ativa a produção de melatonina que é o neuro hormônio responsável por iniciar o ciclo de repouso do corpo humano, desativando o sistema digestivo e reduzindo a pressão arterial e a temperatura corporal. $\mathrm{Na}$ presença de radiação temos principalmente a produção de cortisol, responsável pelo bom stress e ativação dos sistemas digestivos e cardiovasculares (Lighting Handbook, 2011).

\subsection{O EFEITO DA ILUMINAÇÃO NO RITMO CIRCADIANO}

O ciclo circadiano tem adaptação diária, sendo assim a influência do histórico das exposições a diferentes tipos de espectro de radiação óptica é relativamente pequeno, ficando a critério da exposição diária a maior influência. Isso significa que a o ritmo biológico de cada indivíduo é regulado constantemente e por diversos fatores que irão influenciar o sistema, como o espectro de radiação óptica e a sua magnitude, ou seja, a quantidade de energia absorvida, o tempo de exposição e em que horário do dia esse tempo de exposição aconteceu. Quanto maior for a exposição à radiação óptica durante o dia menor será a sensibilidade do sistema circadiano durante a noite.

Tudo isso gera uma nova reflexão a respeito do comportamento dos indivíduos em relação a regulação do seu ciclo biológico diário, pois cada um pode ter um regulador influenciado tanto pela carga de luz (natural ou artificial) que ele recebe durante o dia e até que hora ele recebe tal carga, ou em que horário ele tem uma maior exposição. Isso diferirá o horário de repouso de cada indivíduo e não necessariamente está relacionado a qualidade de tal repouso e sim ao início da produção do hormônio melatonina que induz o corpo ao relaxamento e ao repouso. 
Abaixo uma relação aproximada dos horários de funcionamento biológico do corpo que está ligado ao sistema circadiano, lembrando que os indivíduos diferem neste funcionamento sendo inclusive categorizados como matutinos ou vespertinos, tendo relógios biológicos ligeiramente atrasados ou avançados respectivamente.

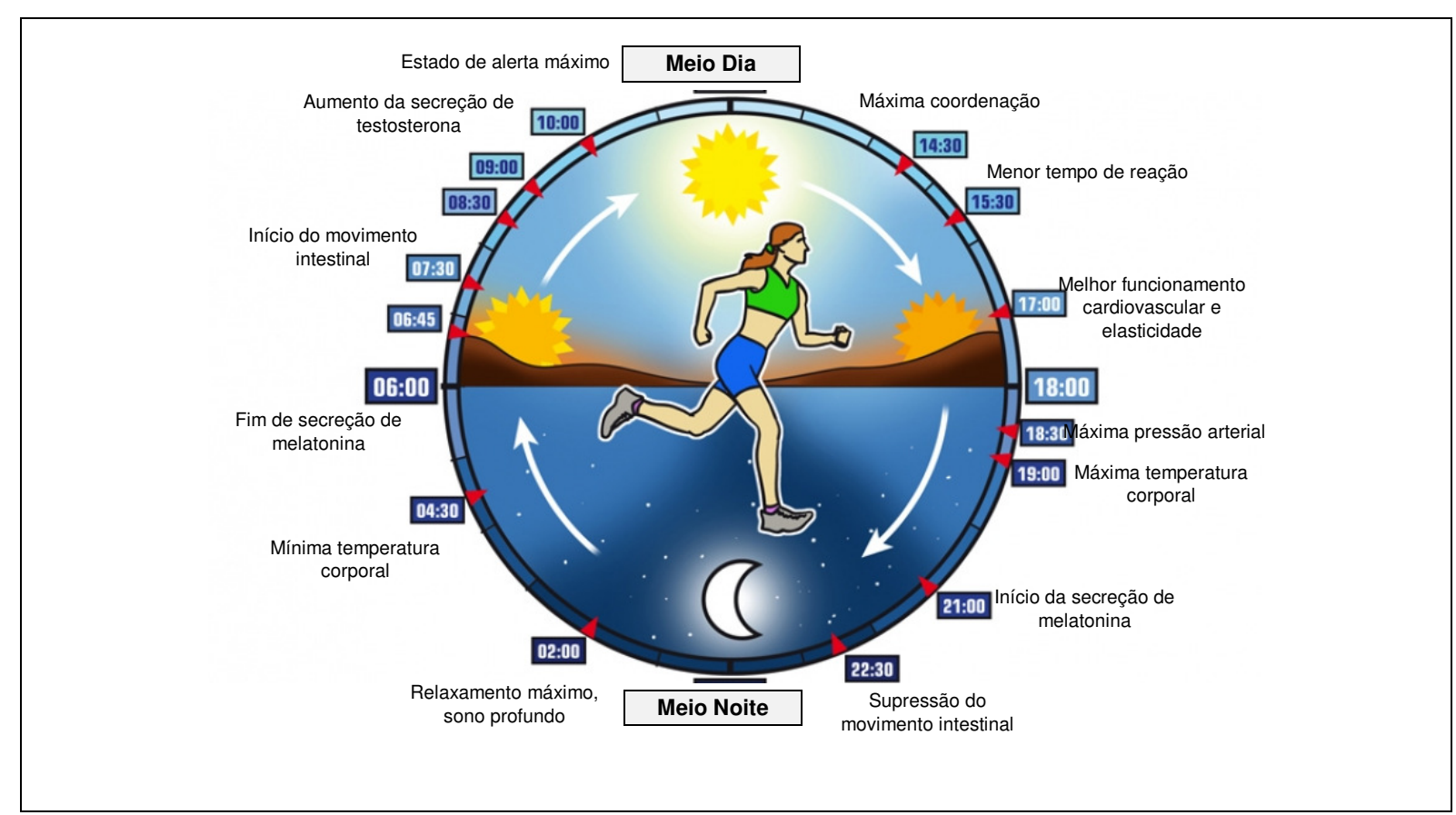

Figura 17 - Ciclo circadiano humano

Todos as exposições feitas acima estão relatadas no livro Lighting Handbook, 10 Edição de 2011, o qual é uma síntese de diversos artigos e estudos científicos produzidos até então sobre esse tema.

\subsection{A EVOLUÇão dos EStUdoS CIENTIFICOS}

Os primeiros estudos da influência do espectro da luz sobre o ciclo circadiano nos seres vivos são do final dos anos 70 e início dos anos 80 , desenvolvidos por diversos cientistas (Binbley 1975, Levy 1980, Brainard 1983, entre outros) em diversos tipos de animais, onde o foco era entender as oscilações de produção de melatonina pela glândula pineal.

No início dos anos 2000 que foram efetivamente descobertas as ligações das células ganglionárias e seu pigmento melanopsin (Brainard 2001; Thapan 2001) no equilíbrio da produção não apenas da melatonina, mas de outros neuro hormônios e 
neuro peptídeo responsáveis pelo balanço das atividades noturnas e diurnas humanas, assim como pelo crescimento, humor, alerta e repouso.

Desde então foram publicados inúmeros artigos com pesquisas laboratoriais ou de campo, que buscam sempre elucidar a influência do espectro da luz sobre o ciclo circadiano humano.

Em artigo publicado em maio de 2003 por Yvan Touitou, intitulado "Reprodutibilidade dos ritmos circadianos de sérum cortisol e melatonina em indivíduos saudáveis", apesar de estar totalmente relacionado com o meio médico para analisar a capacidade e estabilidade de repetição dos ciclos circadianos em indivíduos, mostra elucidativamente a relação entre a produção de cortisol e melatonina em 31 homens entre 20 e 30 anos, estudantes de medicina.

Esses indivíduos foram colocados em um ritmo definido para as medições hormonais, estando em repouso entre $23 \mathrm{hs} \mathrm{e} 08 \mathrm{hs}$ e em atividade das $08 \mathrm{hs}$ às $23 \mathrm{hs}$. As medições foram feitas com intervalos de $3 \mathrm{hs}$ entre $11 \mathrm{hs}$ e $23 \mathrm{hs}$ e de hora em hora das $23 \mathrm{hs}$ às $08 \mathrm{hs}$, através de cateter. No período de repouso os indivíduos não foram acordados para a coleta de amostras e repousaram em um local com menos de 30lx (sem descrição da fonte de luz e seu espectro) e utilizando veda olhos. Hábitos com não fumar e não ingerir bebidas alcoólicas foram observadores, entre outros.

Veja abaixo a relação de produção da melatonina e do cortisol apresentado pelo artigo acima descrito.

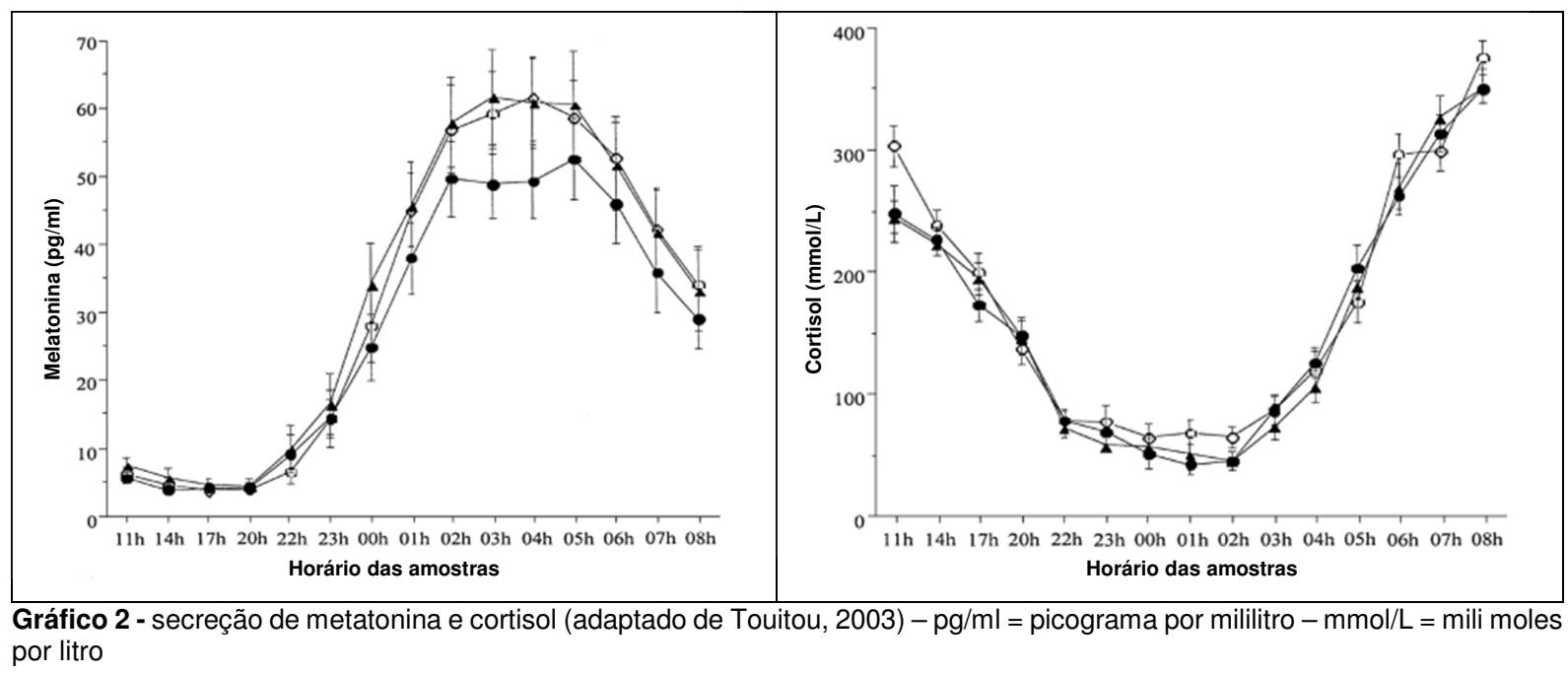


Em 2005 foi publicado por Mark Rea um artigo intitulado "Um Modelo de fototransdução pelo sistema circadiano humano, que relata e sintetiza em um método sugerido para a verificação, baseada em artigos científicos de inúmeros e renomados autores até aquele momento, do nível de supressão de melatonina e consequentemente do desequilíbrio do sistema circadiano. Em 2011 um novo artigo foi publicado citando uma evolução da metodologia, considerando e refinando as variáveis do método.

Esse método matemático proposto denominado como cálculo de CS (Circacian Stimulus) e do CLa (Cincadian Light) será usado como base da pesquisa de campo que será abordada neste trabalho.

Em 2008 foi realizada pesquisa de campo na casa de repouso St. Francis, em Stella Niagara, NY - EUA e foi chefiada pela Eng. Kimberly Mercier, citada naquele momento como diretora do Lighting Design Inovations, em Calgary, Canadá, onde a iluminação existente era baseada em lâmpadas fluorescentes tubulares, a qual ficavam acesas durante a noite para monitoramentos dos 32 quartos divididos em andares diferente e que abrigavam uma população de idosos dividida entre saudáveis e portadores de demência, separadas por andar. Foram adicionados filtros vermelhos em 1/6 das lâmpadas existentes, as quais ficavam acesas durante o período de repouso, desligando as demais lâmpadas.

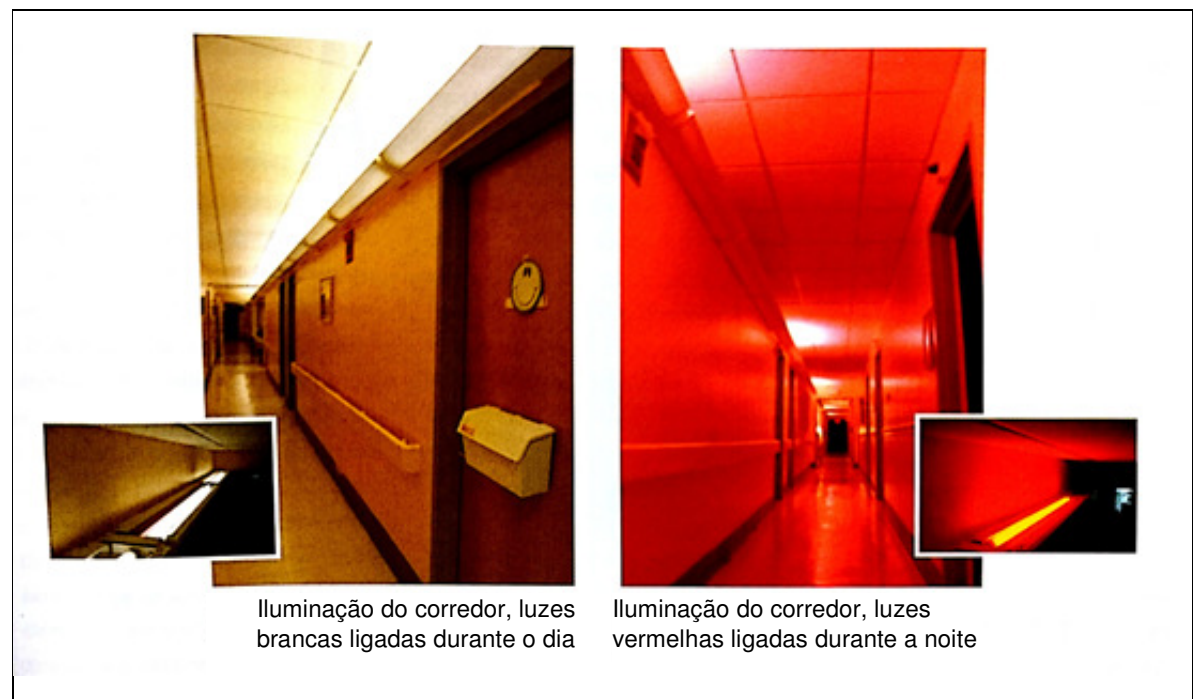

Figura 18 - Experimento realizado usando luz vermelha durante a noite, na casa de repouso Saint Francis, em Stella Niagara, NY 
Após a troca do sistema de iluminação, notou-se que os residentes aumentaram o tempo de sono durante a noite e reduziram os cochilos durante o dia. Tais resultados eram esperados pelo time de projetistas. Outros benefícios inesperados foram observados como a redução de períodos de doenças como gripes e resfriados, redução de pesadelos e redução de incidência de insônia. Alucinações cessaram, a diminuição de comportamentos agressivos a melhoria da lucidez e o aumento da participação em atividades sociais pelos residentes.

Os autores concluem que os resultados observados suportam a hipótese que a luz alinhada com o estimulo apropriado do sistema circadiano melhora a saúde e o bem-estar de idosos e pacientes de demência em casas de repouso e que os mecanismos utilizados ajudam na redução do consumo de energia.

Em artigo publicado em fevereiro de 2012, Figueiró demonstra através de experimento onde, 12 indivíduos foram expostos a lpads com 100\% de brilho, das $23 \mathrm{hs}$ às $01 \mathrm{hs}$, onde foram divididos em 3 grupos, o $1^{\circ}$ usando óculos com filtro laranja onde radiação abaixo de $525 \mathrm{~nm}$ era aproximadamente $=0,02^{\circ} \mathrm{sem}$ uso de qualquer interferência e o $3^{\circ}$ grupo usando óculos equipados com LED de luz azul provendo $401 x$ de 470nm na córnea.

O resultado foi que, para os indivíduos usando óculos com LED azul, a supressão de melatonina após $1 \mathrm{~h}$ foi de $48 \% \pm 4 \%$ e após $2 \mathrm{~h}$ de $66 \% \pm 4 \%$, enquanto para os indivíduos com apenas o tablet após $1 \mathrm{~h}$ foi de $7 \% \pm 4 \%$ e após $2 \mathrm{~h}$ de $23 \%$ $\pm 6 \%$. Para os indivíduos usando os óculos laranja não houve supressão de melatonina.

Os resultados foram obtidos através de medição através de amostras de saliva e foram comparados com o procedimento sugerido por Rea e seus colegas (Rea et al., 2005, 2010, 2011). Veja tabela abaixo dos resultados publicados. 
Condições de iluminação (iluminância fotópica em lux e $\mathrm{CL}_{\mathrm{A}}$ medidos com o "dimesimeter"), supressão da melatonina prevista (CS) e medição da supressão de melatonina após 1h e 2h de exposição.

\begin{tabular}{|c|c|c|c|c|c|}
\hline & & $\begin{array}{c}\text { Iluminância } \\
\text { fotópica (lux) }\end{array}$ & $\mathrm{CL}_{\mathrm{A}}$ & $\mathrm{CS}^{\mathrm{b}}$ & $\begin{array}{l}\text { Supressão } \\
\text { medida (\%) }\end{array}$ \\
\hline \multirow[t]{3}{*}{$1 \mathrm{~h}$} & Tablets + LEDs azuis & $59 \pm 5.0$ & $648 \pm 4.9$ & $0.46 \pm 0.0013$ & $48 \pm 4$ \\
\hline & $\begin{array}{l}\text { Tablet + óculos com } \\
\text { lentes laranjas }^{\text {a }}\end{array}$ & $9.8 \pm 1.9$ & $1.5 \pm 0.31$ & $0.0017 \pm 0.0004$ & NA \\
\hline & Apenas o Tablet & $18 \pm 3.8$ & $19 \pm 4.6$ & $0.03 \pm 0.0066$ & $7.0 \pm 4$ \\
\hline \multirow[t]{3}{*}{$2 \mathrm{~h}$} & Tablets + LEDs azuis & $57 \pm 3.8$ & $645 \pm 3.4$ & NA & $66 \pm 4$ \\
\hline & $\begin{array}{l}\text { Tablet + óculos com } \\
\text { lentes laranjas }^{\mathrm{a}}\end{array}$ & $9.9 \pm 1.6$ & $1.5 \pm 0.29$ & NA & NA \\
\hline & Apenas o Tablet & $16 \pm 2.7$ & $17 \pm 3.51$ & NA & $23 \pm 6$ \\
\hline
\end{tabular}

NA: Não aplicável

a O tablet com a condição do óculos laranja foi usado como controle de escuro.

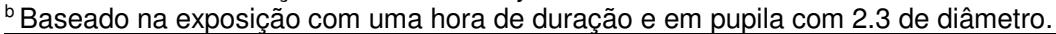

Tabela 1 - Adaptado de Figueiro 2012

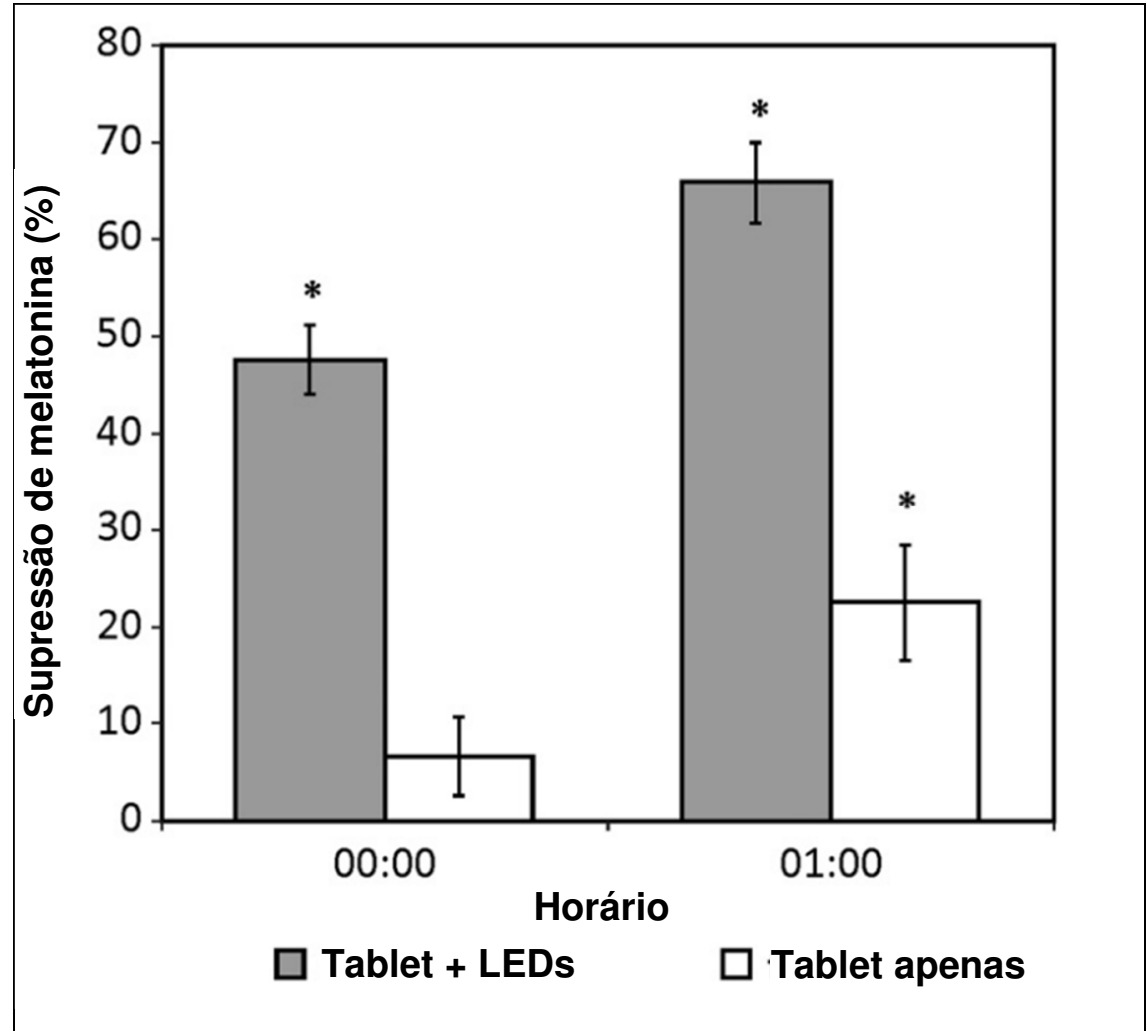

Gráfico 3 - Adaptado de Figueiro 2012

Artigos como esse incentivam aos fabricantes de gadgets a implementarem em seus hardwares e softwares maneiras de inibir a emissão de determinados espectros de luz no período de repouso. A Apple incorporou recentemente em seu sistema operacional mobile a função de "luz noturna", a qual reduz a intensidade da tela e 
muda a equalização das emissões entre as cores primárias RGB resultando em temperaturas de cor mais baixas, reduzindo a emissão de luz azul. Antes mesmo dessa implementação, aplicativos como o Twilight entre outros disponíveis para Android já faziam essa função. O software para computador PC intitulado f.lux também seguem com mesmo intuito, controlando a temperatura de cor dos monitores automaticamente ao longo do dia, seguindo o ciclo da luz circadiana.

Em maio de 2013 o artigo de título "lluminação artificial de ambientes internos: predição dos efeitos circadianos de diferentes distribuições espectrais de energia", desenvolvido por Bellia e seus amigos através do departamento de Psicologia da Segunda Universidade de Nápoles na Itália, utilizou a metodologia proposta por Rea e seus colegas (Rea 2005) para analisar se os valores de supressão proposta em um ambiente controlado, comparando fontes de luz de LED e fluorescente, entre temperaturas de cor entre $2700 \mathrm{~K}$ e $6500 \mathrm{~K}$.

Concluíram então que os valores de CS para exposição acima de 600lx tinha pouca variação, enquanto para níveis entre 50 e 200lx, variações a cada $501 x$ resultaram em variações significativas de CS. Concluíram também que, segundo o método, variações entre $2900 \mathrm{~K}$ e $4200 \mathrm{~K}$ não resultam em consideráveis variações de CS.

Foram feitas análises de CS tanto baseadas nas medições executadas como com base nas distribuições espectrais apresentadas pelos fornecedores das fontes de luz. Abaixo a ilustração das variações de CS apresentadas nesse artigo.

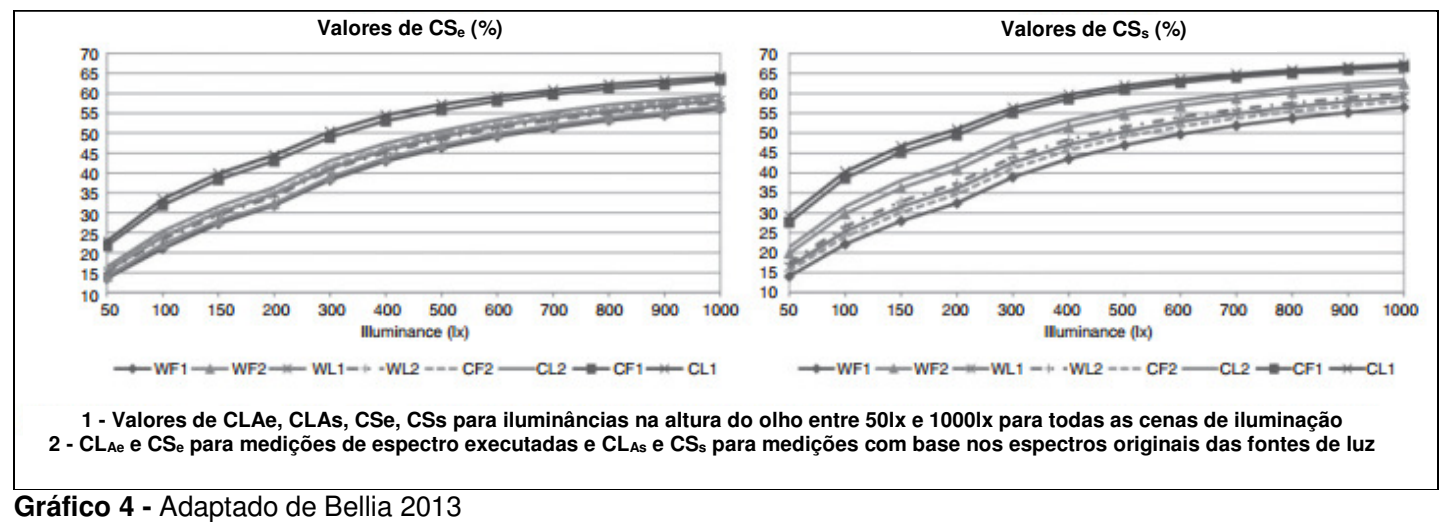




\subsection{CONSIDERAÇÕES}

Dentro do apresentado e pesquisado, se vê uma evolução considerável dentro dos estudos iniciados a aproximadamente $1 / 4$ de século, onde diversos autores, através de pesquisas laboratoriais com variantes controladas e também pesquisas de campo levaram e sintetizam, mesmo que com lacunas a serem preenchidas, que a supressão da produção de melatonina difere entre os tipos de radiação gerada pelos diferentes tipos de fontes de luz artificial, porém que são factíveis e reais.

Exemplo disso é o número de fabricantes lançando no mercado produtos com teóricas funções ligadas ao correto estímulo do ciclo circadiano. Citamos como exemplo a Inglesa Halcyon, a Holandesa Philips e a brasileira Luxion entre inúmeras outras empresas.

Além de nos preocuparmos com os tipos de fontes de luz no ambiente também temos que se ater aos equipamentos eletrônicos que emitem luz, como televisores, monitores, tablets, celulares, etc, que podem também emitir comprimentos de onda que impactem no desequilíbrio do ciclo circadiano. 


\subsection{INTRODUÇÃo}

Do ponto de vista arquitetônico, a residência tem uma diversidade inimaginável se pararmos para pensar que, mesmo para construções padronizadas poderá haver para diferentes usuários, diferentes mobiliários, acabamentos, usos e não menos importante, diferentes tipos de iluminação.

Partindo desta análise, começamos a entender que padronizações instituídas para iluminação de ambientes desse tipo são tentativas de se balizar algo para que profissionais e usuários tenham parâmetros para a projeção de seus ambientes.

Esse capítulo trata de uma simples, mas importante análise para revelar os espaços a serem trabalhados e sua complexidade em confronto com os estudos realizados, os quais são geralmente feitos em laboratórios com variáveis bem controladas, principalmente no que se refere a construção e ao dimensionamento do espaço.

No capítulo de número 2 desta dissertação, vimos que a luz artificial evoluiu para a iluminação dos ambientes e constatamos que ao longo da história temos baixos níveis de energia luminosa de uma única fonte de luz, o fogo, o qual tem espectro de luz similar à de fontes de filamento, com picos de energia próximos ao infravermelho.

\subsection{NíveIS DE ILUMINÂNCIA PARA AMBIENTES RESIDENCIAIS.}

Quando se trata de ambientes tão divergentes como o residencial, onde não apenas as 3 dimensões são totalmente variáveis, mas também o tempo, o uso e as preferências das pessoas que parecem divergir bastante a depender da idade, do local, dos traços culturais e sociais, fica difícil acreditar que possa existir uma padronização de níveis de iluminação, principalmente quando estão baseados apenas em iluminância, grandeza não visível ao olho humano, mas sim uma forma de avaliação a quantidade de energia luminosa que está chegando nas superfícies dos ambientes. 
Atualmente o Brasil segue a norma internacional ISO 8995-1 de 2002, apresentada pelo site da ABNT como NBR ISO 8995-1 2013, a qual não cita valores referenciais de iluminância para ambiente residenciais, focando apenas em ambientes de trabalho. Sua antecessora, a NBR 5413 de 1982 com correções em 1990 disponibilizava níveis de iluminância para ambientes residenciais os quais estão relacionados abaixo.

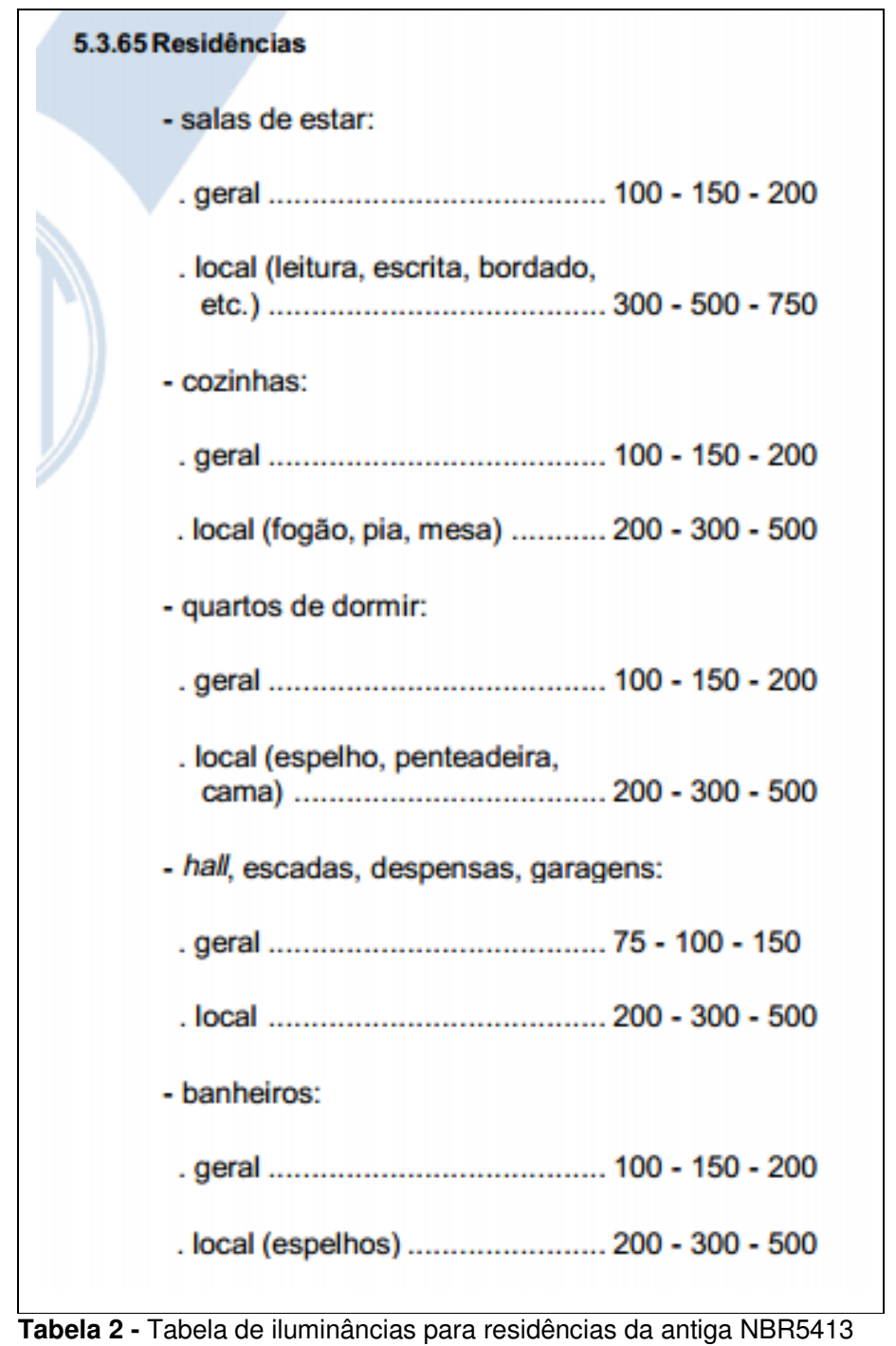

É coerente que, por se tratar de um espaço de usos e representações formais tão diferentes, que a norma internacional (ISO CIE 8995-1 2002) não cite níveis de iluminância para ambientes residenciais. A análise qualitativa em detrimento da quantitativa parece muito mais importante para este tipo de ambiente e a citação de níveis de forma generalizada sem uma análise mais detalhada das variações do ambiente e das tarefas em um mesmo ambiente parece necessária. 
O capítulo 33 do Lighting Handbook traz, de forma detalhada, cada ambiente e tipo de atividade e, além de citar os níveis de iluminação necessários, indica critérios como a possível aplicação de luz natural, a possibilidade de superfícies veladores, iluminância horizontal e vertical, etc. Convém que, de forma geral, a maioria dos níveis de iluminância vertical para ambientes internos recomendados estão variando em torno dos 50lux.

Cabe aqui entender que, o objetivo desse estudo não é abordar as técnicas e diretrizes para o projeto de iluminação residencial e sim entender como que a iluminação é utilizada em residências de forma geral, ou seja, aquela praticada com ou sem orientação profissional e como pode interferir no ciclo circadiano de seus ocupantes.

\subsection{SIMILARIDADES E DIVERSIDADES NA ILUMINAÇÃO DE RESIDÊNCIAS.}

Para entendermos melhor a iluminação em residências, vamos primeiro entender com a luz se comporta no ambiente.

Em primeiro lugar sabemos que, os materiais empregados na arquitetura de forma geral, sejam eles opacos ou translúcidos, não modificam a frequência das ondas eletromagnéticas emitidas pela fonte de luz, apenas podem absorver (superfícies opacas) ou filtrar (superfícies translúcidas) parte do espectro eletromagnético, mudando a equalização da energia original produzida pela fonte de luz devolvida ao ambiente. 


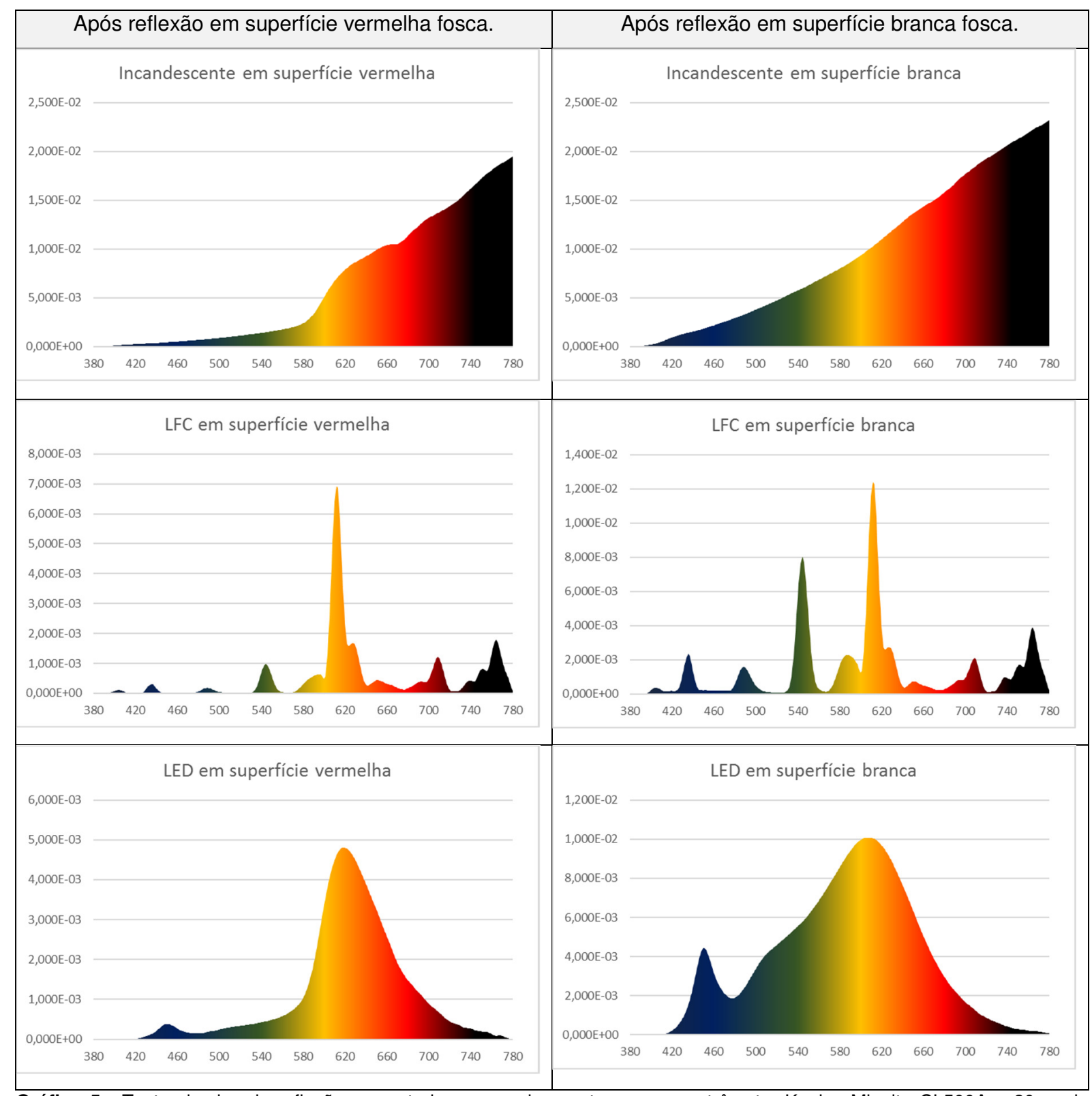

Gráfico 5 - Teste simples de reflexão, executado com equipamento com espectrômetro Konica Minolta CL500A a $20 \mathrm{~cm}$ da superfície citada.

Sendo assim, apesar da diversidade de materiais empregados nos ambientes residenciais, temos que avaliar a quantidade de energia e a equalização do espectro eletromagnético que está chegando efetivamente no olho do observador, a qual pode chegar de forma direta, ou seja, vindo diretamente da fonte de luz, ou de forma indireta, sendo filtrada ou refletida pelas superfícies do ambiente e dos objetos que 0 compõem. Portanto a diversidade dos materiais pode sim influenciar no ciclo circadiano uma vez que eles podem reduzir, filtrar ou redirecionar a energia produzida por uma fonte de luz no usuário. 
Porém, apesar da capacidade da diversidade dos materiais de interferirem no espectro original da fonte de luz, temos que entender a própria fonte de luz como similaridade, uma vez que estas estão embasadas em determinadas tecnologias que geram energia eletromagnética dentro dos comprimentos de onda visíveis.

A diversidade de fontes de luz que são comercializadas que, para facilitar o entendimento iremos tratar aqui apenas como lâmpadas, é demasiadamente grande, porém estas são suportadas por apenas 3 tipos de tecnologia que emitem radiação dentro do espectro visível, sendo essas as lâmpadas de filamento, as lâmpadas de descarga (fluorescentes ou vapores metálicos) e as lâmpadas de LED (diodo emissor de luz).

Abaixo exemplo de espectros eletromagnéticos emitidos por fontes de luz nas 3 tecnologias.

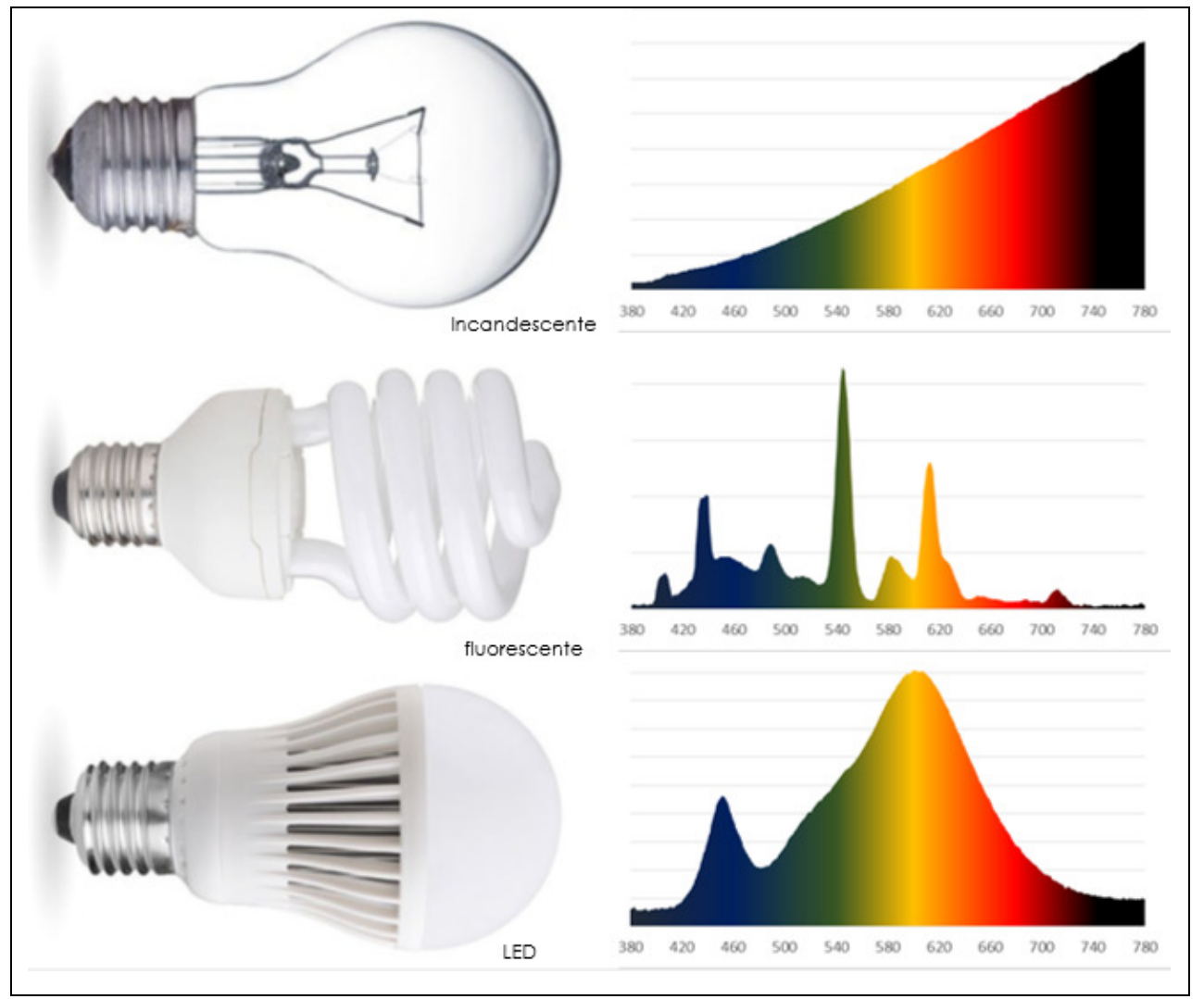

Figura 19 - Medições realizadas com espectrometro Everfine SPIC-200 a 1m.

Desta forma entendemos que, apesar de utilizarmos basicamente 3 tipos de tecnologia em residências, apresentando distribuições espectrais bem diferentes, 
temos que entender como o ambiente irá filtrar essa energia e como a luz efetivamente chegará nos usuários.

\subsection{TENDÊNCIAS DAS TECNOLOGIAS EMPREGADAS EM RESIDÊNCIAS NO BRASIL.}

Segundo matéria do Jornal Hoje publicada em 30/06/2016, intitulada "Lâmpadas incandescentes deixam o comércio nesta quinta-feira (30)", o uso residencial de lâmpadas incandescentes naquele momento seria de menos de $30 \%$, sendo que em 2010 representava $70 \%$ das residências brasileiras.

Seguindo o exemplo de outros países, em dezembro de 2010 os Ministérios de Minas e Energia, da Ciência e Tecnologia e do Desenvolvimento, Industria e Comércio emitiram a portaria interministerial de número 1007, com o título de "Regulamentação específica que define os níveis mínimos de eficiência energética para lâmpadas incandescentes", cujo objetivo era banir gradativamente as lâmpadas incandescentes do mercado até 2016.

A Abilux (Associação brasileira das indústrias de iluminação) publicou em 2012 o consumo de lâmpadas residenciais em 2011, que mostra claramente que as lâmpadas de incandescentes estavam sendo substituídas até então pelas lâmpadas fluorescentes compactas, indicando que o final da produção das lâmpadas incandescentes abriria o mercado para a penetração dos LEDs naquele momento.

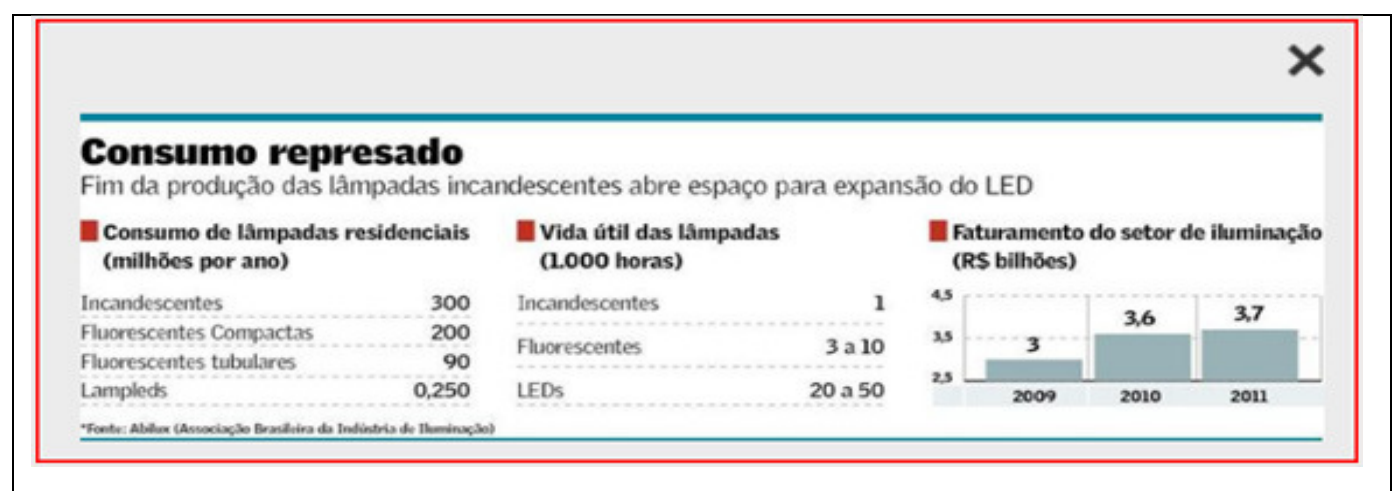

Figura 20 - Fonte: ABILUX (Associação Brasileira da Industria de lluminação) 2012 
Hoje já fica difícil encontrar lâmpadas de filamento em home center, reflexo da redução de custo das lâmpadas de LED, do aumento do custo da energia e da portaria interministerial acima citada.

O estudo apresentado no Plano Decenal de Energia 2024 elaborado pela EPE (Empresa de Pesquisa Energética) sob demanda do Ministério de Minas e Energia mostra informações que confirmam os números apresentados pela Abilux.

Abaixo a projeção de domicílio no Brasil

\begin{tabular}{|c|c|c|c|c|c|c|}
\hline \multirow{3}{*}{ Ano } & \multicolumn{6}{|c|}{ Projeção do número de domicílios } \\
\hline & Norte & Nordeste & Sudeste & Sul & Centro-Oeste & Brasil \\
\hline & \multicolumn{6}{|c|}{ mil unidades } \\
\hline 2015 & 4.671 & 17.082 & 29.017 & 10.240 & 5.190 & 66.201 \\
\hline 2020 & 5.194 & 18.541 & 31.742 & 11.135 & 5.865 & 72.478 \\
\hline \multirow[t]{2}{*}{2024} & 5.584 & 19.649 & 33.820 & 11.767 & 6.372 & 77.192 \\
\hline & \multicolumn{6}{|c|}{ Variação (\% ao ano) } \\
\hline 2015-2019 & 2,1 & 1,7 & 1,8 & 1,7 & 2,5 & 1,8 \\
\hline $2020-2024$ & 1,8 & 1,5 & 1,6 & 1,4 & 2,1 & 1,6 \\
\hline \multirow[t]{2}{*}{$2015-2024$} & 2,0 & 1,6 & 1,7 & 1,6 & 2,3 & 1,7 \\
\hline & \multicolumn{6}{|c|}{ Estrutura de Participação (\%) } \\
\hline 2015 & 7,1 & 25,8 & 43,8 & 15,5 & 7,8 & 100 \\
\hline 2020 & 7,2 & 25,6 & 43,8 & 15,4 & 8,1 & 100 \\
\hline 2024 & 7,2 & 25,5 & 43,8 & 15,2 & 8,3 & 100 \\
\hline
\end{tabular}

Tabela 3 - Fonte: Plano Decenal de Expansão de Energia 2024 - Ministério de Minas e Energia, Empresa de Pesquisa Energégica

E a posse média de equipamentos, que cita também o número de lâmpadas por domicílio.

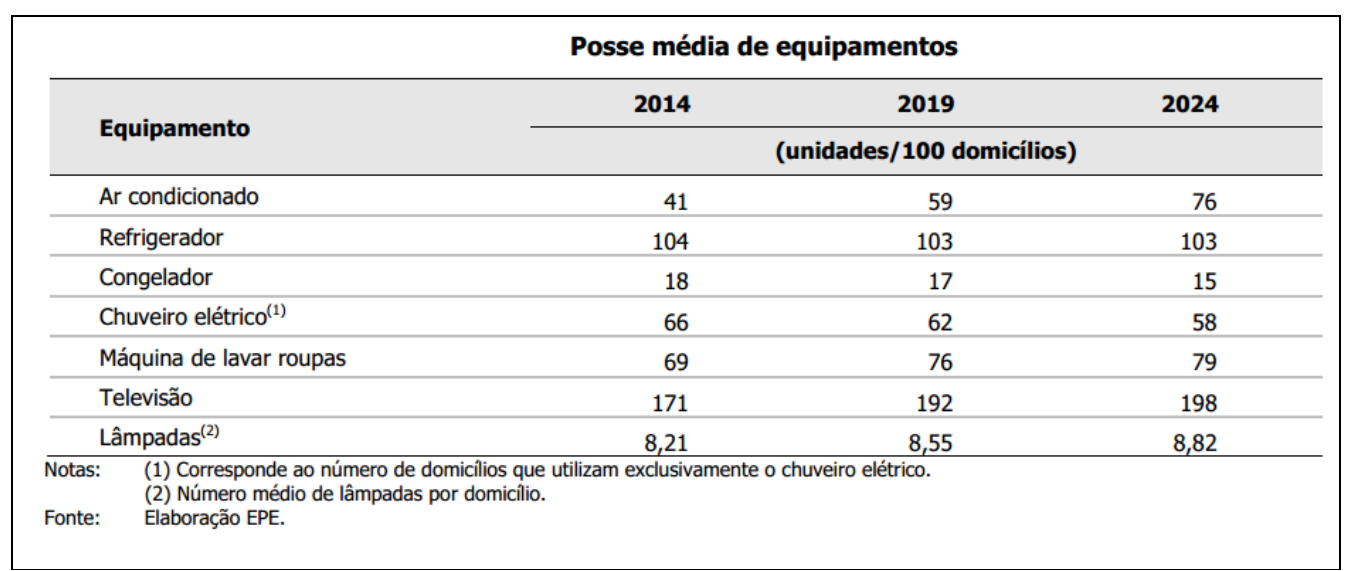

Tabela 4 - Fonte: Plano Decenal de Expansão de Energia 2024 - Ministério de Minas e Energia, Empresa de Pesquisa Energégica 
Fazendo as contas de 2014/2015, temos 66.201 domicílios vezes 8,55 lâmpadas por domicílio chegamos a um número de 543.510,21 lâmpadas em domicílios no Brasil em 2015.

Frente aos avanços da tecnologia LED, a rápida redução de custo, ao menor consumo e maior durabilidade quando comparado com lâmpadas fluorescentes compactas, a tendência é que em um futuro próximo os LEDs sejam a única tecnologia comercializada para esse nicho. As lâmpadas de LED também têm a vantagem de poderem ser descartadas em lixo comum, diferente das lâmpadas fluorescentes compactas que possuem metais pesados (mercúrio) e tem que ser descartada de forma apropriada.

Dessa forma conseguimos entender a quantidade média de lâmpadas por residência no brasil e a tendência para o tipo de tecnologia que será empregado em um futuro próximo.

\subsection{Considerações}

O intuito do capítulo 4 não é mostrar como se deve fazer um projeto de iluminação e sim como as residências são iluminadas com ou sem a ajuda de um profissional de iluminação e como essa iluminação interage como ambiente e chega aos olhos do observador, além de entender quais são os tipos de lâmpadas empregadas.

Entendendo qual o tipo de lâmpada empregada conseguimos ter uma ideia dos espectros que os usuários tendem a usar, o que nos dá base para uma análise do impacto em seu ciclo circadiano. 


\subsection{INTRODUÇÃo}

Frente ao aumento da demanda e do consumo de luz artificial a partir da utilização da luz elétrica e, conforme novas tecnologias, mais econômicas e eficientes são colocadas do mercado, este estudo visa analisar e entender como que esse aumento pode influenciar no relógio biológico dos indivíduos em suas casas.

Apesar do processo de influência da luz ser um ciclo completo e estar relacionado com as atividades biologicamente programadas nos seres humanos ao longo do dia e da noite, através da presença e ausência de luz, este trabalho está focado na análise do momento de repouso, onde, a partir do momento onde naturalmente teríamos ausência de luz, a noite, como a luz artificial interfere na produção de melatonina, hormônio responsável pelo estimulo do repouso e em que proporção essa supressão acontece.

Essa análise é feita em conjunto com habitat, tendo o foco na influência da arquitetura, na qual a iluminação está incorporada e como podemos entender o quanto as residências das pessoas e suas escolhas por fontes de luz podem influenciar de forma positiva ou negativa seu ciclo natural de atividade e repouso.

\subsection{Metodologia}

Os inúmeros artigos e suas metodologias estudados normalmente produzem pesquisas laboratoriais com controle rígido da atividade diária dos usuários e coleta de amostras de sangue e/ou saliva após controladas exposições a fontes de luz determinadas.

Após análise cuidadosa dos métodos a procedimentos observados e, frente a diversidade e pouca praticamente nenhuma padronização dos ambientes a serem estudados nessa pesquisa, que são as residências das pessoas com seus usos e formas muitos distintas, ficava difícil, custosa e aparentemente imprecisa a pesquisa de campo praticada com a obtenção das amostras biológicas acima citadas e, o 
levantamento e análise de questionários necessitariam de amostrar muito elevadas e seriam muito suscetíveis a fatores colaterais da rotina diária dos participantes, dificultando a relação real da ação da supressão de melatonina com a de outros fatores externos.

Desta forma a busca por um modelo matemático que expressasse as respostas biológicas que já foram testadas em quantidade satisfatória resultou na aplicação do método e cálculo do CLa (Lux circadiano) e CS (estimulo circadiano), desenvolvido conforme mencionado no capítulo 3 e melhor explicado abaixo, por Mark Rea e seus colegas, a partir da análise dos artigos relevantes, coerentes e não coerentes da análise das células ganglionárias e da resposta do melanopsin, somadas a ação conjunta de cones e bastonetes.

Segundo o Artigo de Rea e seus colegas publicado em 2005, ele faz uma analogia de todos os estudos feitos nos últimos 25 anos (anterior àquele ano) relacionados a sensibilidade do ciclo circadiano medido através da luz suprimindo a produção de melatonina. Ele cita os artigos de Levy (já citado aqui anteriormente) que foi o primeiro a descobrir que o sistema circadiano humano era fotossensível e que suprimia a produção de melatonina. Cita também outros artigos que demonstraram os primeiros estudos realizados por ele mesmo, por Brainard e por Figueiró, que demonstravam sinais de que cones e bastonetes não eram os principais responsáveis por regular o ciclo circadiano através da supressão da melatonina, se referindo a descoberta da células ganglionárias intrinsicamente fotossensíveis presentes na retina (ipRGCs) e aos estudos realizados por Brainard 2001, e Thapan 2001, colocando que há um consenso de que a máxima ação espectral para a supressão da melatonina está entre 440 e 500nm do espectro de radiação eletromagnética.

Em seu trabalho ele faz referência aos artigos ligados a neurofisiologia, a eletrofisiologia e a genética, citando os estudos de D.M. Berson 2002, I. Provencio 2002, R.G. Foster 1991, S. Hattar 2002, S. Panda 2002 respectivamente, buscando embasar seu modelo proposto, o qual busca na diversidade dos estudos realizados as respostas mais condizentes e que se transformariam posteriormente em variáveis da equação proposta. 
Abaixo a fórmula apresentada por Rea em seu modelo de 2005 e suas variáveis.

$$
\begin{aligned}
& \begin{aligned}
\mathrm{CS}= & {\left[\left(a_{1} \int M_{\lambda} P_{\lambda} d \lambda-b_{1}\right) \triangleleft a_{2}\right.} \\
& \left.\times\left(\int S_{\lambda} P_{\lambda} d \lambda-k \int V_{10 \lambda} P_{\lambda} d \lambda\right)-b_{2}\right]-a_{3}\left(1-e^{\frac{\mid v_{\lambda} P_{\lambda} d \lambda}{\text { rodSat }}}\right)
\end{aligned} \\
& \text { for } \int S_{\lambda} P_{\lambda} d \lambda-k \int V_{10 \lambda} P_{\lambda} d \lambda \geq 0 \\
& \mathrm{CS}=a_{1} \int M_{\lambda} P_{\lambda} d \lambda-b_{1} \\
& \text { for } \int S_{\lambda} P_{\lambda} d \lambda-k \int V_{10 \lambda} P_{\lambda} d \lambda<0
\end{aligned}
$$

Onde:

$\checkmark$ é um diodo matemático que, indica a capacidade que os cones têm de inibir ou não, a depender da quantidade de energia recebida, a comunicação de parte das células ipRGCs do núcleo supraquiasmático. SCN, chamada de função B - Y (blue - yellow), segundo os estudos de M.A. Belenky 2004 e H. Kolb 2004.

$M_{\lambda}$ é a função espectral da melanopsina contida nas ipRGCs com pico em 480nm proposta por V.C. Smith e seus colegas em 2003.

$V_{10 \lambda}$ é a função de eficiência espectral do campo visual ampliado dos cones longos e médios (L+M) proposto pela Comissão Internacional de lluminação (CIE) em 1978 e abordada por J. Schanda em 2002.

$V_{\lambda}^{\prime}$ é a função de eficiência espectral dos bastonetes, também colocado pela CIE em 1978.

$S_{\lambda}$ é a função espectral dos cones curtos (S) estudada e apresentada por V.C. Smith em 1974.

$P_{\lambda}$ é a irradiância no olho $\left(\mathrm{W} / \mathrm{m}^{2} / \mathrm{nm}\right)$

Os parâmetros $K=0,31$ a1 $=0,285$, a2 $=0,2$ e a3=0,72 representam as interações entre os tipos de fotorreceptores.

As constantes $b 1=0,01, b 2=0,001$ e rodSat $=6.5$ refletem os limiares dinâmicos característicos da relação entre os níveis de saturação entre os cones $S$ e as células amácrinas, os quais ajustam os limites de resposta do sistema circadiano.

CS (circadian stimulus) estimulo circadiano

Neste artigo Rea mostra a comparação que fez entre os diversos autores que pesquisaram a supressão de melatonina e a linha de atuação do sistema CS, conforme podemos ver no gráfico abaixo. 


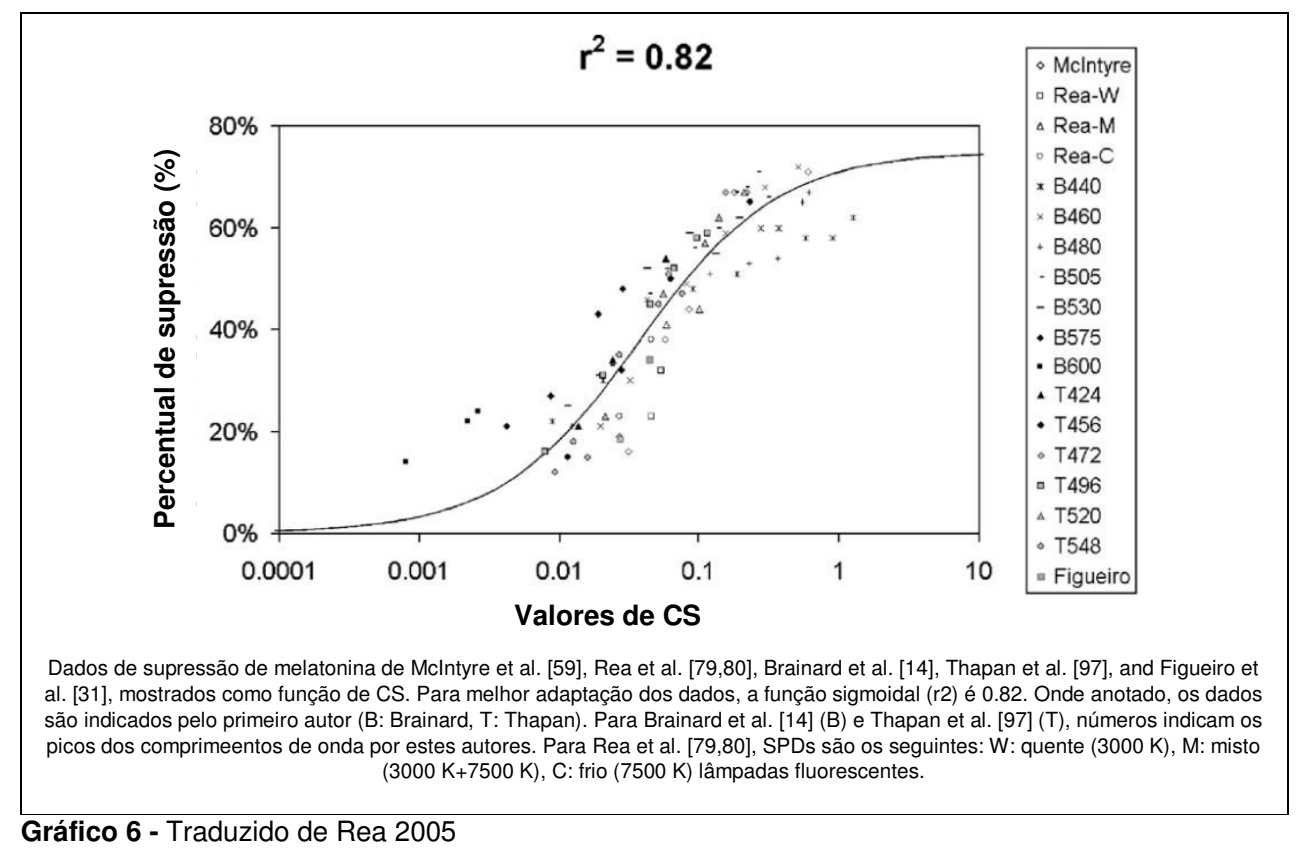

Em 2007 uma errata foi publicada dizendo que as formulas não haviam sido exibidas corretamente, trazendo a correção conforme abaixo.

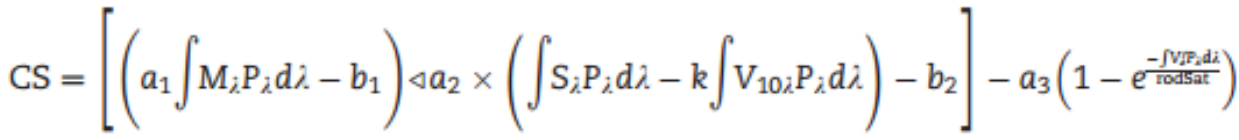

$$
\begin{aligned}
& \text { for } \int S_{\lambda} P_{\lambda} d \lambda-k \int V_{10 \lambda} P_{\lambda} d \lambda \geq 0 \\
& \mathrm{CS}=a_{1} \int \mathrm{M}_{\lambda} \mathrm{P}_{\lambda} d \lambda-b_{1} \\
& \text { for } \int S_{\lambda} P_{\lambda} d \lambda-k \int V_{10 \lambda} P_{\lambda} d \lambda<0
\end{aligned}
$$

Em 2011, um novo artigo foi publicado por Rea e seus amigos, mostrando uma evolução dos métodos aplicados e introduzindo o CLa (circadian light). A formula apresentada nesse novo artigo é a apresentada a seguir: 


$$
C L_{A}=\left\{\begin{aligned}
1622\left[\int M c_{\lambda} E_{\lambda} \mathrm{d} \lambda+\right. & \left.\left(a_{\mathrm{b}-\mathrm{y}}\left(\int \frac{S_{\lambda}}{m p_{\lambda}} E_{\lambda} \mathrm{d} \lambda-k \int \frac{V_{\lambda}}{m p_{\lambda}} E_{\lambda} \mathrm{d} \lambda\right)-a_{\text {rod }}\left(1-e^{\frac{-\int v_{\lambda}^{\prime} E_{\lambda} \mathrm{d} \mathrm{d}}{\text { Rodsat }}}\right)\right)\right] \\
& \text { if } \int \frac{S_{\lambda}}{m p_{\lambda}} E_{\lambda} \mathrm{d} \lambda-k \int \frac{V_{\lambda}}{m p_{\lambda}} E_{\lambda} \mathrm{d} \lambda \geq 0 \\
1622 \int M c_{\lambda} E_{\lambda} \mathrm{d} \lambda \quad & \text { if } \int \frac{S_{\lambda}}{m p_{\lambda}} E_{\lambda} \mathrm{d} \lambda-k \int \frac{V_{\lambda}}{m p_{\lambda}} E_{\lambda} \mathrm{d} \lambda<0
\end{aligned}\right.
$$

Onde:

CLa: (circadian light) constante 1622, define a normalização da CLa quanto o corpo negro a 2856K em 1000lux tem um CLa de 1000.

$E_{\lambda}$ :distribuição espectral da fonte de luz

$M c_{\lambda}$ : é a função espectral da melanopsina com a correção da transmitância do cristalino.

$S_{\lambda}$ : é a função espectral dos cones curtos (S)

$m p_{\lambda}$ : é transmitância do pigmento macular.

$V_{\lambda}$ : é a função de eficiência luminosa fotópica.

$V_{\lambda}$ : é a função de eficiência luminosa escotópica

$K=0,2616$

$a_{b-y}=0,6201$

$a_{\text {rod }}=3.2347$

Gentilmente foram cedidos por Mark Rea e Mariana Figueiro planilha em Excel com os cálculos acima citados, com os parâmetros ajustados e imputados conforme a ilustração dos artigos e suas erratas publicadas.

\subsection{Metodologia aplicada em CAMPo.}

Uma vez definido o modelo de embasamento teórico, as medições práticas foram definidas para levantar, em um número aleatório de residências, uma vez que o intuito não é, para essas medições, de se obter dados estatísticos e sim mostrar que a variação das tipologias citadas já no capítulo 4 é presente e podem influenciar nos resultados, mesmo que a similaridade das fontes de luz seja um fator comum a ser considerado, obtendo-se então os limites encontrados nas amostras e em quais condições. 
Uma segunda pesquisa paralela foi utilizar uma das residências medidas como modelo, para que se pudesse travar as variantes que o ambiente pode apresentar e medir diferentes tipos de fontes de luz com diferentes temperaturas de cor, para que se tenha uma relação real de um ambiente residencial. É sabido que, mesmo utilizando de uma residência como modelo, as variações de proporção das dimensões e acabamentos do ambiente, a posição das fontes de luz e a tipologia da luminária usada interferirão significativamente na quantidade de energia que chega nos olhos dos observadores, demonstrando novamente que a primeira parte de medições em residências aleatórias é necessária e que mostra a complexidade que há nesse tipo de uso e se ter uma amostra de residências reais e seus resultados.

Para os dois procedimentos aplicados em campo acima citados, a complexidade do uso da residência e o dinamismo de seus ocupantes, seja pela larga gama de atividades que podem ser exercidas e, mesmo em cada uma dessas atividades o posicionamento do usuário e seu foco de visão pode ser variado, escolheu-se uma posição e uma atividade que permitisse fazer uma validação, tanto da energia que provém das fontes de luz como da energia de um gadget, até o momento, muito utilizado em residências por um período longo, a televisão. Em ambos os casos, foram utilizados: 1 espectrofotômetro de iluminância Konica Minolta, modelo CL500A, com precisão de $1 \mathrm{~nm}$ e calibragem automática, 1 trena eletrônica Bosch GLM50 Professional e 1 celular para simples registro fotográfico do ambiente. Para maiores detalhes dos ambientes levantados veja anexo no final deste trabalho. 


\subsubsection{Procedimento 1}

Para o primeiro procedimento adotado conforme citado, estipulou-se a posição de medição conforme esquema abaixo apresentado.

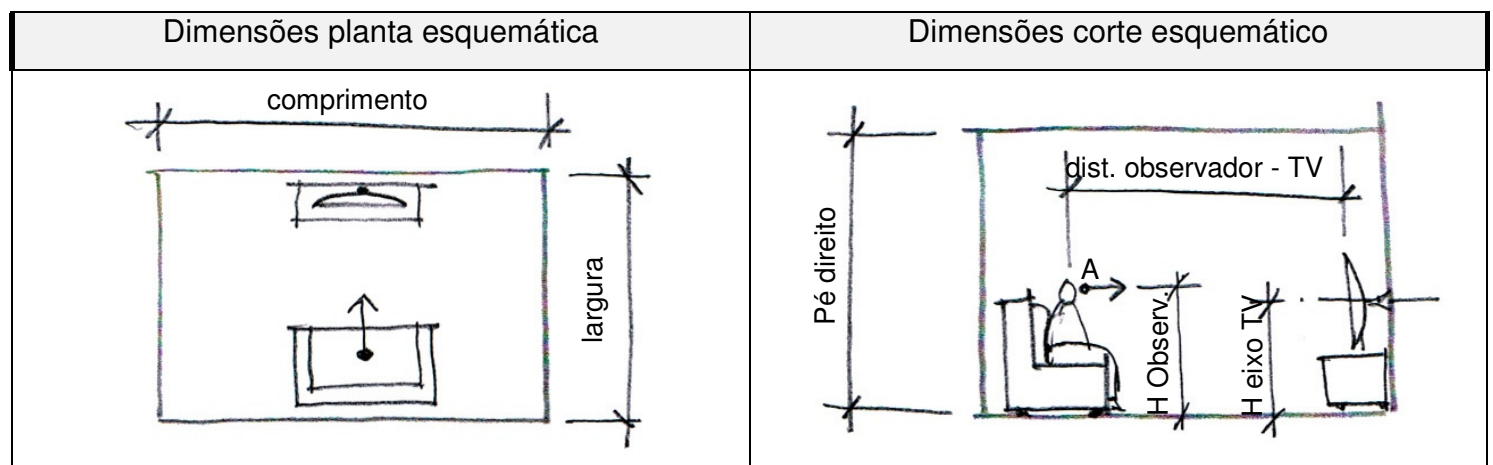

Figura 21 - Esquema de medição de campo adotada no procedimento 1

Os pontos observados foram: os níveis de energia luminosa no olho, as tipologias de fontes de luz e sua temperatura de cor, as dimensões do ambiente e as distâncias do usuário para a TV e o modelo, tamanho e tecnologia luminosa empregada na TV.

Não foram levantadas as posições métricas das luminárias nos ambientes, nem os modelos, marcas e potências das lâmpadas utilizadas, para evitar interpretações superficiais sobre a relação do posicionamento com os resultados obtidos, uma vez que a informação relevante é o quanto de energia chega aos olhos dos usuários.

Foram feitas 3 medições distintas, sendo a primeira com luzes acesas somadas a televisão ligada, a segunda com apenas as luzes acesas e a televisão desligada e a terceira apenas com a televisão ligada e as luzes apagadas.

A seguir tabelas e gráficos das medições realizadas. 


\begin{tabular}{|c|c|c|c|c|c|}
\hline \multicolumn{6}{|c|}{ Luzes Acesas + TV Ligada } \\
\hline Amostra & Equipamentos & Lux Vertical & Tcp K & CLa & CS \\
\hline Residência 1 & $\begin{array}{l}\text { TV Samsung LED de 55" + } \\
\text { 14x GU10 Halógena 50W } 30^{\circ}\end{array}$ & 27,4 & 4093 & 28 & $4,00 \%$ \\
\hline Residência 2 & $\begin{array}{l}\text { TV Samsung CFL 40" + } \\
\text { 3x Fluor. Comp. Tripla 6500K }\end{array}$ & 38,8 & 5870 & 42 & $6,10 \%$ \\
\hline Residência 3 & $\begin{array}{l}\text { TV Samsung CFL } 46 "+ \\
\text { 1x Fluor. Comp. Tripla } 6500 \mathrm{~K}+ \\
\text { 1x LED bulbo } 6500 \mathrm{~K}\end{array}$ & 34,2 & 5145 & 35 & $5,00 \%$ \\
\hline Residência 4 & $\begin{array}{c}\text { TV Samsung LED 55" curva + } \\
\text { 3x Fluor. Comp. } 6500 \mathrm{~K}+ \\
\text { 3x Incand. Bolinha } 2700 \mathrm{~K}\end{array}$ & 31,8 & 3295 & 14 & $2,00 \%$ \\
\hline Residência 5 & $\begin{array}{l}\text { TV Samsung LED } 47 "+ \\
\text { 2x LED Bulbo } 3000 \mathrm{~K}\end{array}$ & 45,2 & 4280 & 44 & $6,30 \%$ \\
\hline Residência 6 & $\begin{array}{l}\text { TV Samsung LED 32" + } \\
\text { 3x Fluor. Comp. 6500K }\end{array}$ & 27,1 & 5950 & 27 & $3,90 \%$ \\
\hline Residência 7 & $\begin{array}{l}\text { TV Samsung LED 42" + } \\
\text { 22x GU10 LED5mm 6500K }\end{array}$ & 30,8 & 5141 & 31 & $4,40 \%$ \\
\hline Residência 8 & $\begin{array}{l}\text { TV Philips LED 47" + } \\
\text { 12x GU10 LED } 3000 \mathrm{~K}\end{array}$ & 59,4 & 2973 & 45 & $6,50 \%$ \\
\hline Residência 9 & $\begin{array}{l}\text { TV Philips 55"LED + } \\
\text { 4x Fluor. Comp. } 6500 \mathrm{~K}\end{array}$ & 57,7 & 5121 & 52 & $7,50 \%$ \\
\hline Residência 10 & $\begin{array}{l}\text { TV Toshiba 42" LED + } \\
\text { 3xLED } 6500 \mathrm{~K}\end{array}$ & 38,6 & 5221 & 37 & $5,30 \%$ \\
\hline Residência 11 & $\begin{array}{l}\text { TV STI 40" LED - } \\
\text { 2x Fluor.Comp. } 6500 \mathrm{~K}\end{array}$ & 36 & 5945 & 39 & $5,70 \%$ \\
\hline Residência 12 & $\begin{array}{l}\text { TV Samsung 52" LCD - } \\
\text { 9x Fluor. Comp. } 2700 \mathrm{~K}\end{array}$ & 85,9 & 2557 & 54 & $7,80 \%$ \\
\hline Residência 13 & $\begin{array}{c}\text { TV LG } 47 " \text { LED + } \\
\text { 2x FC } 6500 \mathrm{~K}+ \\
\text { 16x LED spot } 3000 \mathrm{~K}\end{array}$ & 38 & 3796 & 19 & $2,70 \%$ \\
\hline Residência 14 & $\begin{array}{c}\text { TV Sony 42" LCD + } \\
\text { 4x LED 6500K Spot + } \\
\text { 1x halóg. 50W GU10 } 2700 \mathrm{~K}\end{array}$ & 80,7 & 5137 & 72 & $10,30 \%$ \\
\hline Residência 15 & $\begin{array}{l}\text { TV LG 22" LCD + } \\
3 \times \text { LED } 6500 \mathrm{~K}+ \\
2 \times \text { LED } 6500 \mathrm{~K}\end{array}$ & 17,4 & 6001 & 19 & $2,70 \%$ \\
\hline Residência 16 & $\begin{array}{l}\text { TV LG50" Plasma + } \\
\text { 4x Fluor. Comp. 6500K }\end{array}$ & 32,7 & 5300 & 29 & $4,10 \%$ \\
\hline Residência 17 & $\begin{array}{l}\text { TV LG } 46 " \text { LED + } \\
3 \times \text { LED } 6500 \mathrm{~K}\end{array}$ & 16,2 & 6371 & 19 & $2,70 \%$ \\
\hline Residência 18 & $\begin{array}{l}\text { TV Sony } 40 " \text { LCD + } \\
\text { 2x LED Milho } 6500 \mathrm{~K}\end{array}$ & 29,3 & 5192 & 28 & $4,00 \%$ \\
\hline
\end{tabular}

Tabela 5 - Procedimento 1 Luzes acesas + TV ligada 


\begin{tabular}{|c|c|c|c|c|c|}
\hline \multicolumn{6}{|c|}{ Luzes Acesas + TV Desligada } \\
\hline Amostra & Equipamentos & Lux Vertical & Tcp K & CLa & CS \\
\hline Residência 1 & $\begin{array}{l}\text { TV Samsung LED de 55" + } \\
\text { 14x GU10 Halógena 50W } 30^{\circ}\end{array}$ & 14,1 & 2423 & 11 & $1,50 \%$ \\
\hline Residência 2 & $\begin{array}{l}\text { TV Samsung CFL 40" + } \\
\text { 3x Fluor. Comp. Tripla 6500K }\end{array}$ & 31,7 & 5733 & 33 & $4,70 \%$ \\
\hline Residência 3 & $\begin{array}{l}\text { TV Samsung CFL } 46 "+ \\
\text { 1x Fluor. Comp. Tripla } 6500 \mathrm{~K}+ \\
\text { 1x LED bulbo } 6500 \mathrm{~K}\end{array}$ & 27,2 & 5190 & 26 & $3,70 \%$ \\
\hline Residência 4 & $\begin{array}{c}\text { TV Samsung LED 55" curva + } \\
\text { 3x Fluor. Comp. } 6500 \mathrm{~K}+ \\
\text { 3x Incand. Bolinha } 2700 \mathrm{~K}\end{array}$ & 31 & 3204 & 33 & $4,70 \%$ \\
\hline Residência 5 & $\begin{array}{l}\text { TV Samsung LED } 47 "+ \\
\text { 2x LED Bulbo } 3000 \mathrm{~K}\end{array}$ & 25,8 & 3250 & 25 & $3,60 \%$ \\
\hline Residência 6 & $\begin{array}{l}\text { TV Samsung LED 32" + } \\
\text { 3x Fluor. Comp. } 6500 \mathrm{~K}\end{array}$ & 19,6 & 5436 & 15 & $2,10 \%$ \\
\hline Residência 7 & $\begin{array}{l}\text { TV Samsung LED 42" + } \\
\text { 22x GU10 LED5mm 6500K }\end{array}$ & 31,7 & 4814 & 26 & $3,70 \%$ \\
\hline Residência 8 & $\begin{array}{l}\text { TV Philips LED 47" + } \\
\text { 12x GU10 LED } 3000 \mathrm{~K}\end{array}$ & 58,5 & 2972 & 44 & $6,30 \%$ \\
\hline Residência 9 & $\begin{array}{l}\text { TV Philips 55"LED + } \\
\text { 4x Fluor. Comp. } 6500 \mathrm{~K}\end{array}$ & 52,4 & 4737 & 36 & $5,20 \%$ \\
\hline Residência 10 & $\begin{array}{l}\text { TV Toshiba 42" LED + } \\
\text { 3xLED } 6500 \mathrm{~K}\end{array}$ & 29,3 & 6006 & 33 & $4,70 \%$ \\
\hline Residência 11 & $\begin{array}{l}\text { TV STI 40" LED - } \\
\text { 2x Fluor.Comp. } 6500 \mathrm{~K}\end{array}$ & 31,3 & 5778 & 32 & $4,60 \%$ \\
\hline Residência 12 & $\begin{array}{l}\text { TV Samsung 52" LCD - } \\
\text { 9x Fluor. Comp. } 2700 \mathrm{~K}\end{array}$ & 107 & 2516 & 64 & $9,10 \%$ \\
\hline Residência 13 & $\begin{array}{c}\text { TV LG } 47 " \text { LED + } \\
\text { 2x FC } 6500 \mathrm{~K}+ \\
\text { 16x LED spot } 3000 \mathrm{~K}\end{array}$ & 35,7 & 3718 & 17 & $2,40 \%$ \\
\hline Residência 14 & $\begin{array}{c}\text { TV Sony 42" LCD + } \\
\text { 4x LED 6500K Spot + } \\
\text { 1x halóg. 50W GU10 } 2700 \mathrm{~K}\end{array}$ & 74,8 & 5167 & 64 & $9,10 \%$ \\
\hline Residência 15 & $\begin{array}{l}\text { TV LG 22" LCD + } \\
3 \times \text { LED } 6500 \mathrm{~K}+ \\
2 \times \text { LED } 6500 \mathrm{~K}\end{array}$ & 16,4 & 6072 & 19 & $2,60 \%$ \\
\hline Residência 16 & $\begin{array}{l}\text { TV LG50" Plasma + } \\
\text { 4x Fluor. Comp. 6500K }\end{array}$ & 30,6 & 5612 & 28 & $4,00 \%$ \\
\hline Residência 17 & $\begin{array}{l}\text { TV LG } 46 " \text { LED + } \\
3 \times \text { LED } 6500 \mathrm{~K}\end{array}$ & 10 & 5118 & 8 & $1,10 \%$ \\
\hline Residência 18 & $\begin{array}{l}\text { TV Sony } 40 " \text { LCD + } \\
\text { 2x LED Milho } 6500 \mathrm{~K}\end{array}$ & 23,8 & 5629 & 24 & $3,40 \%$ \\
\hline
\end{tabular}

Tabela 6 - Procedimento 1 Luzes acesas + TV desligada 


\begin{tabular}{|c|c|c|c|c|c|}
\hline \multicolumn{6}{|c|}{ Luzes Apagadas + TV Ligada } \\
\hline Amostra & Equipamentos & Lux Vertical & Tcp K & CLa & CS \\
\hline Residência 1 & $\begin{array}{l}\text { TV Samsung LED de 55" + } \\
\text { 14x GU10 Halógena 50W } 30^{\circ}\end{array}$ & 9,6 & 7046 & 12 & $1,70 \%$ \\
\hline Residência 2 & $\begin{array}{l}\text { TV Samsung CFL 40" + } \\
\text { 3x Fluor. Comp. Tripla 6500K }\end{array}$ & 3,9 & 8230 & 7 & $0,90 \%$ \\
\hline Residência 3 & $\begin{array}{c}\text { TV Samsung CFL } 46 "+ \\
\text { 1x Fluor. Comp. Tripla } 6500 \mathrm{~K}+ \\
\text { 1x LED bulbo } 6500 \mathrm{~K}\end{array}$ & 7,2 & 6790 & 11 & $1,50 \%$ \\
\hline Residência 4 & $\begin{array}{c}\text { TV Samsung LED 55" curva + } \\
\text { 3x Fluor. Comp. } 6500 \mathrm{~K}+ \\
\text { 3x Incand. Bolinha } 2700 \mathrm{~K}\end{array}$ & 2,1 & 9662 & 4 & $0,50 \%$ \\
\hline Residência 5 & $\begin{array}{l}\text { TV Samsung LED 47" + } \\
\text { 2x LED Bulbo } 3000 \mathrm{~K}\end{array}$ & 15,4 & 6378 & 17 & $2,40 \%$ \\
\hline Residência 6 & $\begin{array}{l}\text { TV Samsung LED 32" + } \\
\text { 3x Fluor. Comp. 6500K }\end{array}$ & 3,3 & 8884 & 6 & $0,70 \%$ \\
\hline Residência 7 & $\begin{array}{l}\text { TV Samsung LED 42" + } \\
\text { 22x GU10 LED5mm 6500K }\end{array}$ & 2 & 64791 & 6 & $0,70 \%$ \\
\hline Residência 8 & $\begin{array}{l}\text { TV Philips LED 47" + } \\
\text { 12x GU10 LED } 3000 \mathrm{~K}\end{array}$ & 1,5 & 7601 & 2 & $0,30 \%$ \\
\hline Residência 9 & $\begin{array}{l}\text { TV Philips 55"LED + } \\
\text { 4x Fluor. Comp. } 6500 \mathrm{~K}\end{array}$ & 7,6 & 6937 & 15 & $2,10 \%$ \\
\hline Residência 10 & $\begin{array}{l}\text { TV Toshiba 42" LED + } \\
\text { 3xLED } 6500 \mathrm{~K}\end{array}$ & 2,9 & 8831 & 5 & $0,60 \%$ \\
\hline Residência 11 & $\begin{array}{l}\text { TVSTI 40" LED - } \\
\text { 2x Fluor.Comp. } 6500 \mathrm{~K}\end{array}$ & 1,3 & 0 & 4 & $0,50 \%$ \\
\hline Residência 12 & $\begin{array}{l}\text { TV Samsung 52" LCD - } \\
\text { 9x Fluor. Comp. } 2700 \mathrm{~K}\end{array}$ & 2,3 & 5613 & 3 & $0,30 \%$ \\
\hline Residência 13 & $\begin{array}{c}\text { TV LG } 47 " \text { LED + } \\
\text { 2x FC } 6500 \mathrm{~K}+ \\
\text { 16x LED spot } 3000 \mathrm{~K}\end{array}$ & 9,5 & 19080 & 24 & $3,40 \%$ \\
\hline Residência 14 & $\begin{array}{c}\text { TV Sony 42" LCD + } \\
\text { 4x LED 6500K Spot + } \\
\text { 1x halóg. 50W GU10 2700K }\end{array}$ & 2,9 & 6788 & 4 & $0,50 \%$ \\
\hline Residência 15 & $\begin{array}{l}\text { TV LG 22" LCD + } \\
3 \times \text { LED } 6500 \mathrm{~K}+ \\
2 \times \text { LED } 6500 \mathrm{~K}\end{array}$ & 0,6 & 5795 & 1 & $0,10 \%$ \\
\hline Residência 16 & $\begin{array}{l}\text { TV LG50" Plasma + } \\
\text { 4x Fluor. Comp. 6500K }\end{array}$ & 2,3 & 3765 & 3 & $0,40 \%$ \\
\hline Residência 17 & $\begin{array}{l}\text { TV LG } 46 " \text { LED + } \\
3 \times \text { LED } 6500 \mathrm{~K}\end{array}$ & 4,9 & 13256 & 11 & $1,50 \%$ \\
\hline Residência 18 & $\begin{array}{l}\text { TV Sony } 40 " \text { LCD + } \\
2 x \text { LED Milho 6500K }\end{array}$ & 5 & 3931 & 3 & $0,40 \%$ \\
\hline
\end{tabular}

Tabela 7 - Procedimento 1 Luzes apagadas + TV ligada 

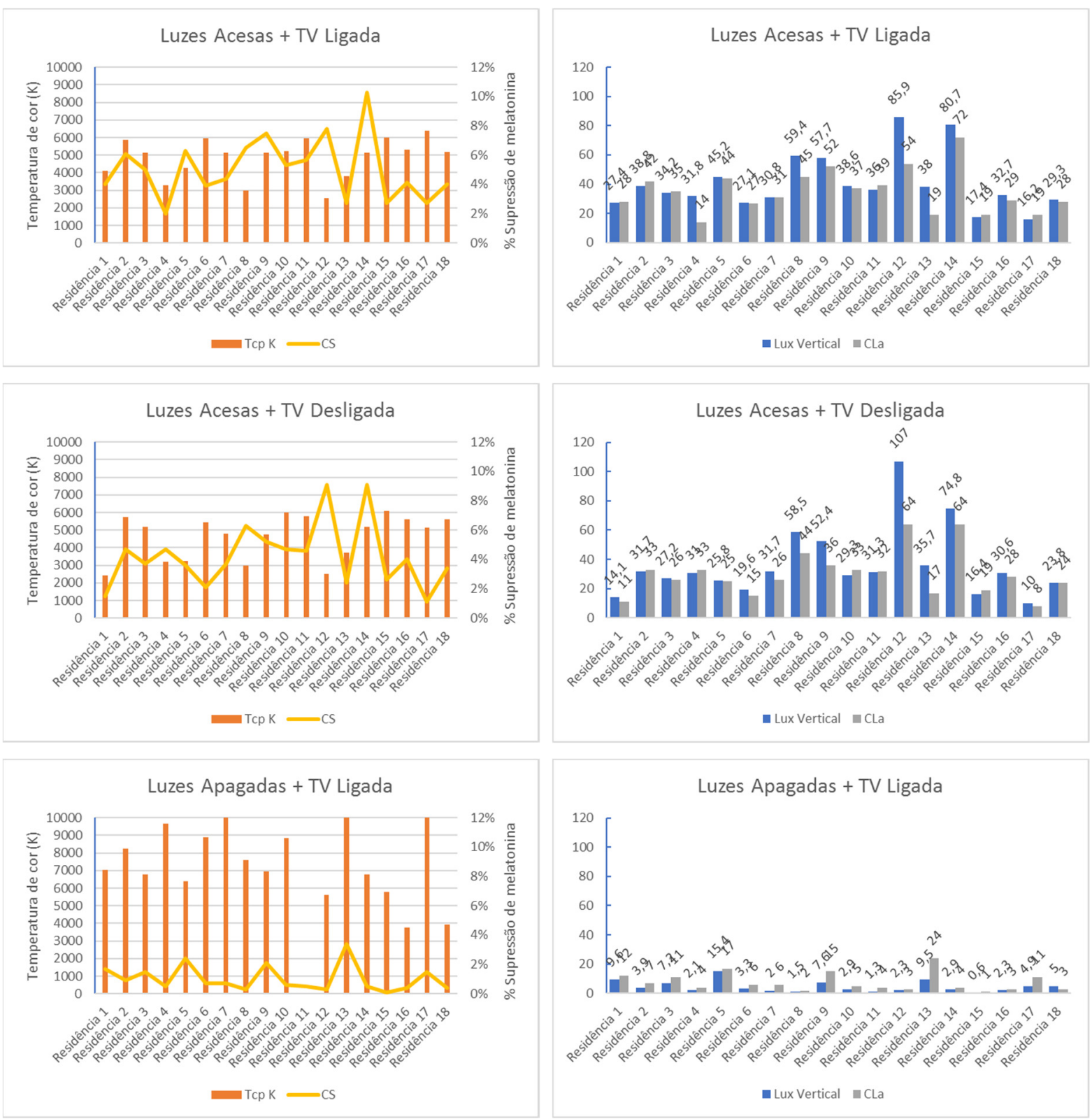

Gráfico 7 - Gráficos de resumo do procedimento 1 - Residências aleatórias

Os resultados foram classificados por ordem de execução das medições, pois as análises devem ser feitas pontualmente para cada residência medida e globalmente avaliando os limites encontrados versus os níveis de iluminância vertical nos olhos dos usuários medidos. 
Dentre os resultados obtidos 12 das 18 residências usam lâmpadas com temperatura de cor acima de $5000 \mathrm{~K}$ que, em níveis mais elevados de iluminância tem um maior impacto na supressão de produção de melatonina.

Apenas 3 das 18 residências obtiveram leituras de lux vertical acima de 50lux e apenas 1 delas acima de 100lux, o que indica que, apesar da maioria das residências terem uma quantidade de luz próximo do indicado pelo Lighting Handbook, em alguns casos o uso exacerbado de luz é praticado, o que acarreta em maiores impactos no sistema circadiano.

\subsubsection{Procedimento 2}

Para o segundo procedimento adotado conforme citado, estipulou-se a posição de medição conforme esquema abaixo apresentado, lembrando que, como neste caso a residência é a mesma para todas as medições, as variações irão ocorrer apenas nas fontes de luz utilizadas conforme será apresentado.

Dimensões planta esquemática




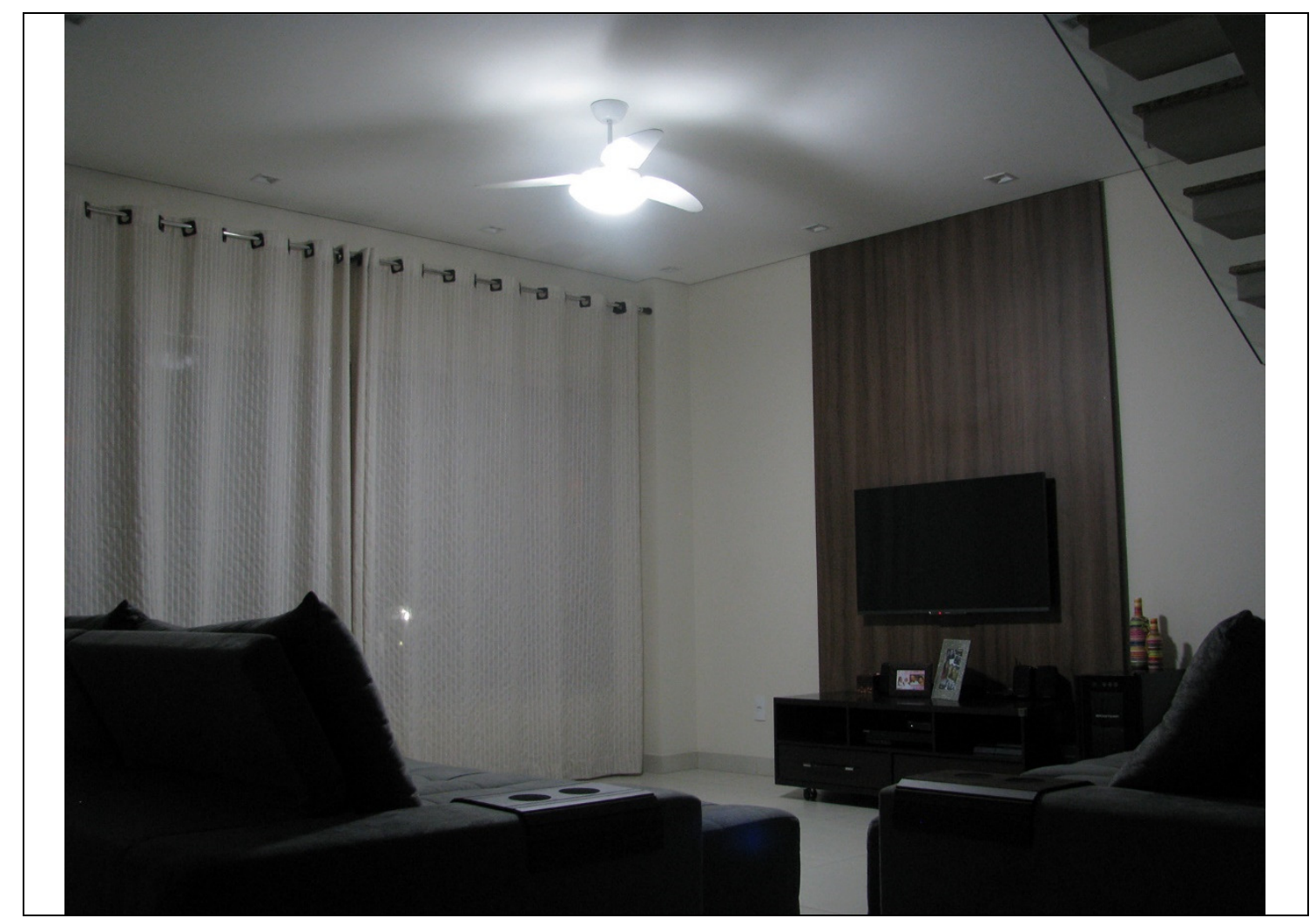

Figura 22 - Dimensões e registro fotogrático da residência adotada como modelo

Também foram feitas 3 medições distintas, sendo a primeira com luzes acesas somadas a televisão ligada, a segunda com apenas as luzes acesas e ainda uma terceira, tirando o vidro difusor contido na luminária, deixando as lâmpadas expostas, visando simular o uso mais simples de uma lâmpada, que é pendurada em um soquete com fio.

Como o ambiente não muda, apenas uma medição com a apenas a televisão ligada foi feita e também uma medição com tudo desligado, para verificar se haveria alguma interferência de luz das vias públicas, as quais usam tecnologia de vapor de sódio de alta pressão.

Abaixo tabelas e gráficos das medições realizadas. 


\begin{tabular}{|c|c|c|c|c|}
\hline \multicolumn{5}{|c|}{ Residência Modelo com TV Philips LED 47" - Luzes Acesas + TV Ligada } \\
\hline Detalhe & Lux Vertical & Tcp K & CLa & CS \\
\hline $6 x$ Velas em altura de candelábro & 4,8 & 4520 & 4 & $0,50 \%$ \\
\hline $\begin{array}{c}\text { 2x Incandescente Philips 60W Soft } \\
127 \mathrm{~V}\end{array}$ & 33 & 2794 & 32 & $4,50 \%$ \\
\hline $\begin{array}{c}\text { 2x Fluorescente Compacta Tripla } \\
\text { Osram } 20 \mathrm{~W} 2700 \mathrm{~K}\end{array}$ & 59,4 & 2703 & 42 & $6,10 \%$ \\
\hline $\begin{array}{l}\text { 2x Fluorescente Compacta Tripla GE } \\
\qquad 22 \mathrm{~W} 6500 \mathrm{~K}\end{array}$ & 79,4 & 6010 & 89 & $12,50 \%$ \\
\hline 2x LED Bulbo Tachibra 4,9W 3000K & 36,2 & 3576 & 16 & $2,30 \%$ \\
\hline 2x LED Bulbo Brilia 9W 6500K & 53,1 & 6098 & 61 & $8,80 \%$ \\
\hline $\begin{array}{l}\text { 2x Philips Hue 600Im 127V } \\
\text { Acendimento Padrão }\end{array}$ & 28,2 & 2933 & 25 & $3,50 \%$ \\
\hline $\begin{array}{l}\text { 2x Philips Hue 600Im 127V } \\
\text { Cena Relaxar }\end{array}$ & 9,7 & 2792 & 9 & $1,20 \%$ \\
\hline $\begin{array}{l}\text { 2x Philips Hue 600Im 127V } \\
\text { Cena Concentrar }\end{array}$ & 33,1 & 4341 & 21 & $2,90 \%$ \\
\hline
\end{tabular}

Tabela 8 - Residência modelo - Luzes acesas + TV ligada 


\begin{tabular}{|c|c|c|c|c|}
\hline \multicolumn{5}{|c|}{ Residência Modelo com TV Philips LED 47" - Luzes Acesas + TV Desligada } \\
\hline Detalhe & Lux Vertical & Tср K & CLa & CS \\
\hline $6 x$ Velas em altura de candelábro & 1,2 & 1915 & 1 & $0,10 \%$ \\
\hline $\begin{array}{l}\text { 2x Incandescente Philips 60W Soft } \\
127 \mathrm{~V}\end{array}$ & 30,4 & 2627 & 26 & $3,70 \%$ \\
\hline $\begin{array}{l}\text { 2x Fluorescente Compacta Tripla } \\
\text { Osram } 20 \mathrm{~W} 2700 \mathrm{~K}\end{array}$ & 50,7 & 2584 & 32 & $4,70 \%$ \\
\hline $\begin{array}{l}\text { 2x Fluorescente Compacta Tripla GE } \\
\qquad 22 \mathrm{~W} 6500 \mathrm{~K}\end{array}$ & 79,4 & 5946 & 86 & $12,10 \%$ \\
\hline 2x LED Bulbo Tachibra 4,9W 3000K & 29 & 2996 & 26 & $3,70 \%$ \\
\hline 2x LED Bulbo Brilia 9W 6500K & 50,6 & 6054 & 58 & $8,30 \%$ \\
\hline $\begin{array}{l}\text { 2x Philips Hue } 600 \mathrm{Im} 127 \mathrm{~V} \\
\text { Acendimento Padrão }\end{array}$ & 24,2 & 2660 & 18 & $2,50 \%$ \\
\hline $\begin{array}{l}\text { 2x Philips Hue 600Im 127V } \\
\text { Cena Relaxar }\end{array}$ & 7,2 & 2223 & 4 & $0,50 \%$ \\
\hline $\begin{array}{l}\text { 2x Philips Hue 600Im 127V } \\
\text { Cena Concentrar }\end{array}$ & 30 & 4124 & 16 & $2,20 \%$ \\
\hline
\end{tabular}

Tabela 9 - Residência modelo - Luzes acesas + TV desligada 


\begin{tabular}{|c|c|c|c|c|}
\hline \multicolumn{5}{|c|}{ Residência Modelo com TV Philips LED 47" - Luzes Acesas s/ vidro + TV Desligada } \\
\hline Detalhe & Lux Vertical & Tcp K & CLa & CS \\
\hline $\begin{array}{l}\text { 2x Incandescente Philips 60W Soft } \\
127 \mathrm{~V}\end{array}$ & 34,1 & 2618 & 29 & $4,20 \%$ \\
\hline $\begin{array}{l}\text { 2x Fluorescente Compacta Tripla } \\
\text { Osram 20W } 2700 \mathrm{~K}\end{array}$ & 64,3 & 2601 & 41 & $6,00 \%$ \\
\hline $\begin{array}{l}\text { 2x Fluorescente Compacta Tripla GE } \\
22 \mathrm{~W} 6500 \mathrm{~K}\end{array}$ & 88,8 & 6032 & 99 & $13,80 \%$ \\
\hline 2x LED Bulbo Tachibra 4,9W 3000K & 31,7 & 2991 & 29 & $4,10 \%$ \\
\hline 2x LED Bulbo Brilia 9W 6500K & 55,4 & 6122 & 65 & $9,30 \%$ \\
\hline $\begin{array}{l}\text { 2x Philips Hue 600lm } 127 \mathrm{~V} \\
\text { Acendimento Padrão }\end{array}$ & 27,1 & 2646 & 20 & $2,80 \%$ \\
\hline $\begin{array}{l}\text { 2x Philips Hue 600Im 127V } \\
\text { Cena Relaxar }\end{array}$ & 8,1 & 2214 & 5 & $0,60 \%$ \\
\hline $\begin{array}{l}\text { 2x Philips Hue } 600 \mathrm{Im} 127 \mathrm{~V} \\
\text { Cena Concentrar }\end{array}$ & 33,7 & 4120 & 19 & $2,60 \%$ \\
\hline
\end{tabular}

Tabela 10 - Residência modelo - Luzes acesas + TV ligada - sem o vidro da luminária (lâmpadas expostas)

\begin{tabular}{|ccccc|}
\hline \multicolumn{5}{c|}{ Residência Modelo com TV Philips LED 47" - TV Ligada / TV Desligada (escuro) } \\
\hline Detalhe & Lux Vertical & Tcp K & CLa & CS \\
\hline Apenas a TV Ligada & 1,5 & 7601 & 2 & $0,30 \%$ \\
\hline Tudo escuro (análise de luz externa) & 0,1 & 1868 & 0 & $0,00 \%$ \\
\hline
\end{tabular}

Tabela 11 - Residência modelo - Luzes apagadas + TV ligada e condição de tudo desligado. 

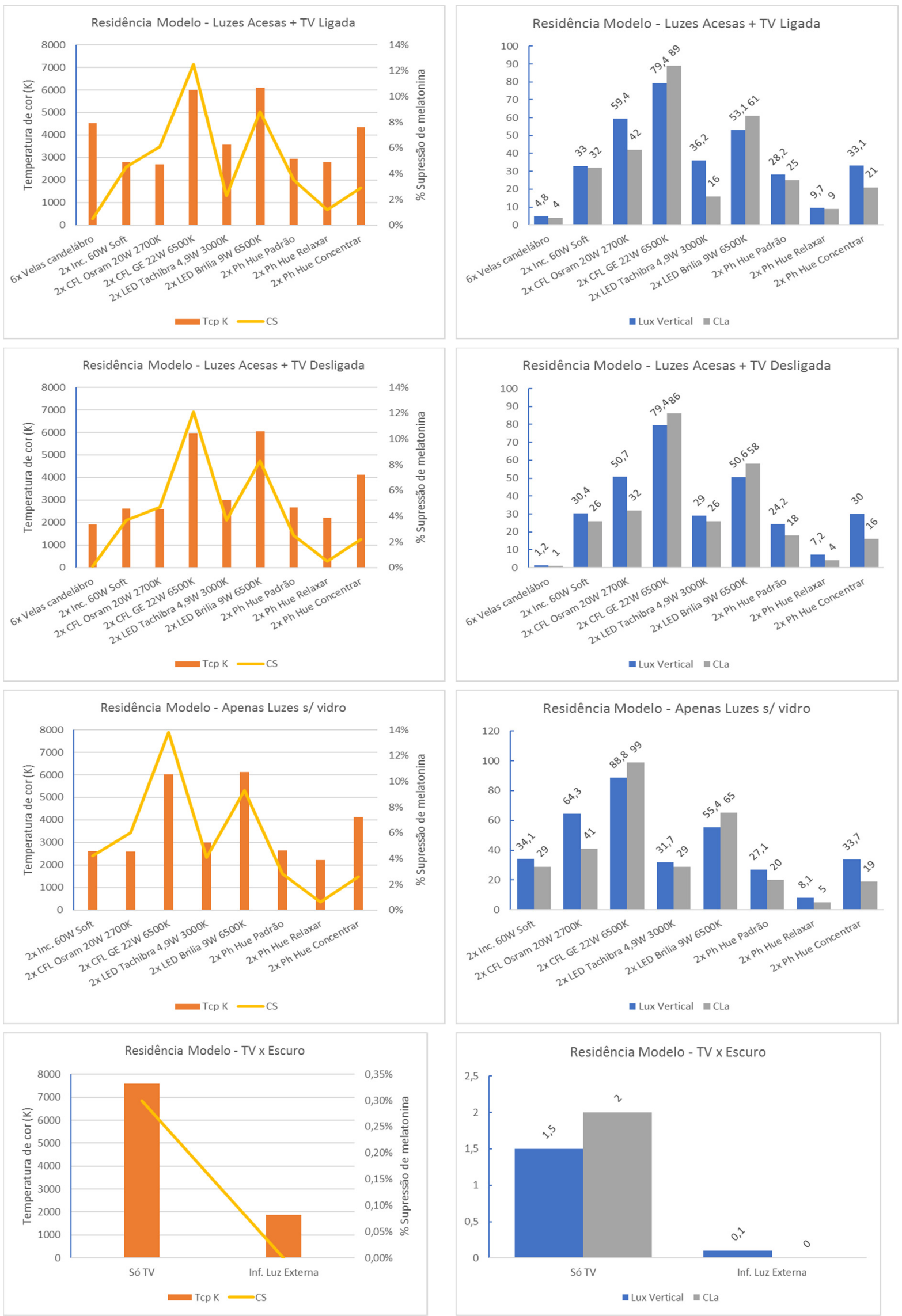

Gráfico 8 - Gráficos de resumo do procedimento 2 - residência modelo 
As medições foram apresentadas em ordem de tecnologia.

Foram feitas medições também de velas iluminando o ambiente, simulando a ideia de um candelabro para fazer uma análise, mesmo que pouco grosseira, de como seria a energia resultante no olho do observador antes da luz elétrica. Abaixo ilustrado como foi feito tal simulação e posicionamento das velas.

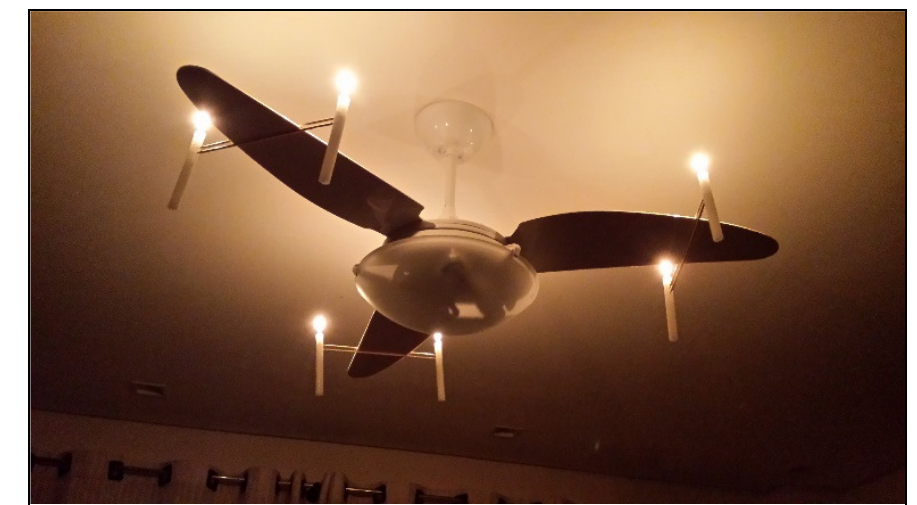

Figura 23 - Registro fotográfico do candelabro simulado na residência modelo

As lâmpadas consideradas mais econômicas resultaram em leituras mais elevadas dos níveis de iluminância, sendo assim entendemos que elas não apenas proporcionam economia de energia, mas também podem elevar a quantidade de luz na casa das pessoas.

As fontes de luz com temperatura de cor de $6500 \mathrm{~K}$ tem leituras de CLa mais elevadas do que a quantidade de lux.

As fontes de luz com temperatura de cor mais quentes, próximos dos $3000 \mathrm{~K}$ tem impactos similares nos diferentes tipos de tecnologia.

As leituras para o candelabro simulado têm níveis baixos de lux e CLa, mostrando que a quantidade de luz utilizando a tecnologia do fogo eram claramente mais baixas. Inclusive a luz do fogo tem impacto menor que a leitura de apenas a TV ligada.

As fontes de luz com tecnologia LED RGB têm impactos menores em qualquer cena utilizada, mesmo as cenas de cor aparentemente mais frias, denominada cena de concentração. 


\subsection{EQUALIZAÇÃO DO PROCEDIMENTO 2}

Conforme observado, o procedimento 2 adotou tecnologias diferentes que proporcionaram valores de medições diferentes devido a alteração de potência e fluxo luminoso emitido pelas fontes de luz selecionadas.

Por conta disso, decidiu-se usar a medição de apenas as luzes acesas com a TV desligada, para simular como seriam os resultados, caso todas as fontes de luz tivessem o mesmo resultado de medição de iluminância. Decidimos por 4 níveis distintos, sendo 30, 60 e 901x respectivamente. A primeira embasada pelo Lighting Handbook que traz uma recomendação para "living room" (sala de estar) de 30lx vertical, a segunda por parte das medições práticas terem apresentado tais níveis próximos a esse valor, $901 x$ devido a um dos testes realizados na residência modelo também terem apresentado valores próximos e o último de 120lx por extrapolação possível.

Nestes gráficos, classificou-se as fontes de luz por temperatura de cor, para agora sim fazer uma relação não apenas entre tecnologias, mas também se as diferentes temperaturas teriam variações representativas.

A seguir tabelas e gráficos dos resultados. 


\begin{tabular}{|c|c|c|c|c|}
\hline \multicolumn{5}{|c|}{ Residência Modelo - Luzes Acesas com equalização de níveis 30lx } \\
\hline Detalhe & Lux Vertical & Tcp K & CLa & CS \\
\hline 6x Velas em altura de candelábro & 30 & 1915 & 14 & $2,00 \%$ \\
\hline $\begin{array}{l}\text { 2x Philips Hue 600lm 127V } \\
\text { Cena Relaxar }\end{array}$ & 30 & 2223 & 18 & $2,50 \%$ \\
\hline $\begin{array}{l}\text { 2x Fluorescente Compacta Tripla } \\
\text { Osram 20W } 2700 \mathrm{~K}\end{array}$ & 30 & 2584 & 19 & $2,70 \%$ \\
\hline $\begin{array}{c}\text { 2x Incandescente Philips 60W Soft } \\
127 \mathrm{~V}\end{array}$ & 30 & 2627 & 25 & $3,60 \%$ \\
\hline $\begin{array}{l}\text { 2x Philips Hue } 600 \mathrm{Im} 127 \mathrm{~V} \\
\text { Acendimento Padrão }\end{array}$ & 30 & 2660 & 22 & $3,10 \%$ \\
\hline 2x LED Bulbo Tachibra 4,9W 3000K & 30 & 2996 & 27 & $3,80 \%$ \\
\hline $\begin{array}{l}\text { 2x Philips Hue 600Im 127V } \\
\text { Cena Concentrar }\end{array}$ & 30 & 4124 & 16 & $2,20 \%$ \\
\hline $\begin{array}{l}\text { 2x Fluorescente Compacta Tripla GE } \\
\text { 22W 6500K }\end{array}$ & 30 & 5946 & 32 & $4,70 \%$ \\
\hline 2x LED Bulbo Brilia 9W 6500K & 30 & 6054 & 34 & $4,90 \%$ \\
\hline
\end{tabular}

Tabela 12 - Residência modelo equalização de níveis de iluminância (lux) Luzes acesas + TV desligada para $301 x$

\begin{tabular}{|c|c|c|c|c|}
\hline \multicolumn{5}{|c|}{ Residência Modelo - Luzes Acesas com equalização de níveis 60lx } \\
\hline Detalhe & Lux Vertical & Tcp K & CLa & CS \\
\hline $6 x$ Velas em altura de candelábro & 60 & 1915 & 29 & $4,10 \%$ \\
\hline $\begin{array}{l}\text { 2x Philips Hue 600lm 127V } \\
\text { Cena Relaxar }\end{array}$ & 60 & 2223 & 35 & $5,10 \%$ \\
\hline $\begin{array}{c}\text { 2x Fluorescente Compacta Tripla } \\
\text { Osram 20W } 2700 \mathrm{~K}\end{array}$ & 60 & 2584 & 38 & $5,50 \%$ \\
\hline $\begin{array}{l}\text { 2x Incandescente Philips 60W Soft } \\
127 \mathrm{~V}\end{array}$ & 60 & 2627 & 51 & $7,30 \%$ \\
\hline $\begin{array}{l}\text { 2x Philips Hue } 600 \mathrm{Im} 127 \mathrm{~V} \\
\text { Acendimento Padrão }\end{array}$ & 60 & 2660 & 44 & $6,40 \%$ \\
\hline 2x LED Bulbo Tachibra 4,9W 3000K & 60 & 2996 & 54 & $7,70 \%$ \\
\hline $\begin{array}{l}\text { 2x Philips Hue 600Im 127V } \\
\text { Cena Concentrar }\end{array}$ & 60 & 4124 & 32 & $4,60 \%$ \\
\hline $\begin{array}{l}\text { 2x Fluorescente Compacta Tripla GE } \\
22 \mathrm{~W} 6500 \mathrm{~K}\end{array}$ & 60 & 5946 & 65 & $9,30 \%$ \\
\hline 2x LED Bulbo Brilia 9W 6500K & 60 & 6054 & 69 & $9,80 \%$ \\
\hline
\end{tabular}

Tabela 13 - Residência modelo equalização de níveis de iluminância (lux) Luzes acesas + TV desligada para $601 x$ 


\begin{tabular}{|c|c|c|c|c|}
\hline \multicolumn{5}{|c|}{ Residência Modelo - Luzes Acesas com equalização de níveis $901 x$} \\
\hline Detalhe & Lux Vertical & Tcp K & CLa & cs \\
\hline 6x Velas em altura de candelábro & 90 & 1915 & 43 & $6,20 \%$ \\
\hline $\begin{array}{l}\text { 2x Philips Hue 600lm 127V } \\
\text { Cena Relaxar }\end{array}$ & 90 & 2223 & 53 & $7,60 \%$ \\
\hline $\begin{array}{l}\text { 2x Fluorescente Compacta Tripla } \\
\text { Osram 20W } 2700 \mathrm{~K}\end{array}$ & 90 & 2584 & 58 & $8,30 \%$ \\
\hline $\begin{array}{c}\text { 2x Incandescente Philips 60W Soft } \\
127 \mathrm{~V}\end{array}$ & 90 & 2627 & 76 & $10,80 \%$ \\
\hline $\begin{array}{l}\text { 2x Philips Hue } 600 \mathrm{Im} 127 \mathrm{~V} \\
\text { Acendimento Padrão }\end{array}$ & 90 & 2660 & 66 & $9,50 \%$ \\
\hline 2x LED Bulbo Tachibra 4,9W 3000K & 90 & 2996 & 80 & $11,40 \%$ \\
\hline $\begin{array}{l}\text { 2x Philips Hue } 600 \mathrm{Im} 127 \mathrm{~V} \\
\text { Cena Concentrar }\end{array}$ & 90 & 4124 & 49 & $7,00 \%$ \\
\hline $\begin{array}{l}\text { 2x Fluorescente Compacta Tripla GE } \\
\text { 22W 6500K }\end{array}$ & 90 & 5946 & 98 & $13,60 \%$ \\
\hline 2x LED Bulbo Brilia 9W 6500K & 90 & 6054 & 103 & $14,20 \%$ \\
\hline
\end{tabular}

Tabela 14 - Residência modelo equalização de níveis de iluminância (lux) Luzes acesas + TV desligada para $901 \mathrm{x}$

\begin{tabular}{|c|c|c|c|c|}
\hline \multicolumn{5}{|c|}{ Residência Modelo - Luzes Acesas com equalização de níveis $1201 x$} \\
\hline Detalhe & Lux Vertical & Tcp K & CLa & CS \\
\hline 6x Velas em altura de candelábro & 120 & 1915 & 57 & $8,20 \%$ \\
\hline $\begin{array}{l}\text { 2x Philips Hue 600lm 127V } \\
\text { Cena Relaxar }\end{array}$ & 120 & 2223 & 70 & $10,10 \%$ \\
\hline $\begin{array}{c}\text { 2x Fluorescente Compacta Tripla } \\
\text { Osram 20W } 2700 \mathrm{~K}\end{array}$ & 120 & 2584 & 77 & $10,90 \%$ \\
\hline $\begin{array}{c}\text { 2x Incandescente Philips 60W Soft } \\
127 \mathrm{~V}\end{array}$ & 120 & 2627 & 102 & $14,10 \%$ \\
\hline $\begin{array}{l}\text { 2x Philips Hue } 600 \mathrm{Im} 127 \mathrm{~V} \\
\text { Acendimento Padrão }\end{array}$ & 120 & 2660 & 88 & $12,40 \%$ \\
\hline 2x LED Bulbo Tachibra 4,9W 3000K & 120 & 2996 & 107 & $14,70 \%$ \\
\hline $\begin{array}{l}\text { 2x Philips Hue 600Im 127V } \\
\text { Cena Concentrar }\end{array}$ & 120 & 4124 & 65 & $9,30 \%$ \\
\hline $\begin{array}{l}\text { 2x Fluorescente Compacta Tripla GE } \\
\text { 22W } 6500 \mathrm{~K}\end{array}$ & 120 & 5946 & 131 & $17,40 \%$ \\
\hline 2x LED Bulbo Brilia 9W 6500K & 120 & 6054 & 138 & $18,20 \%$ \\
\hline
\end{tabular}

Tabela 15 - Residência modelo equalização de níveis de iluminância (lux) Luzes acesas + TV desligada para $1201 x$ 

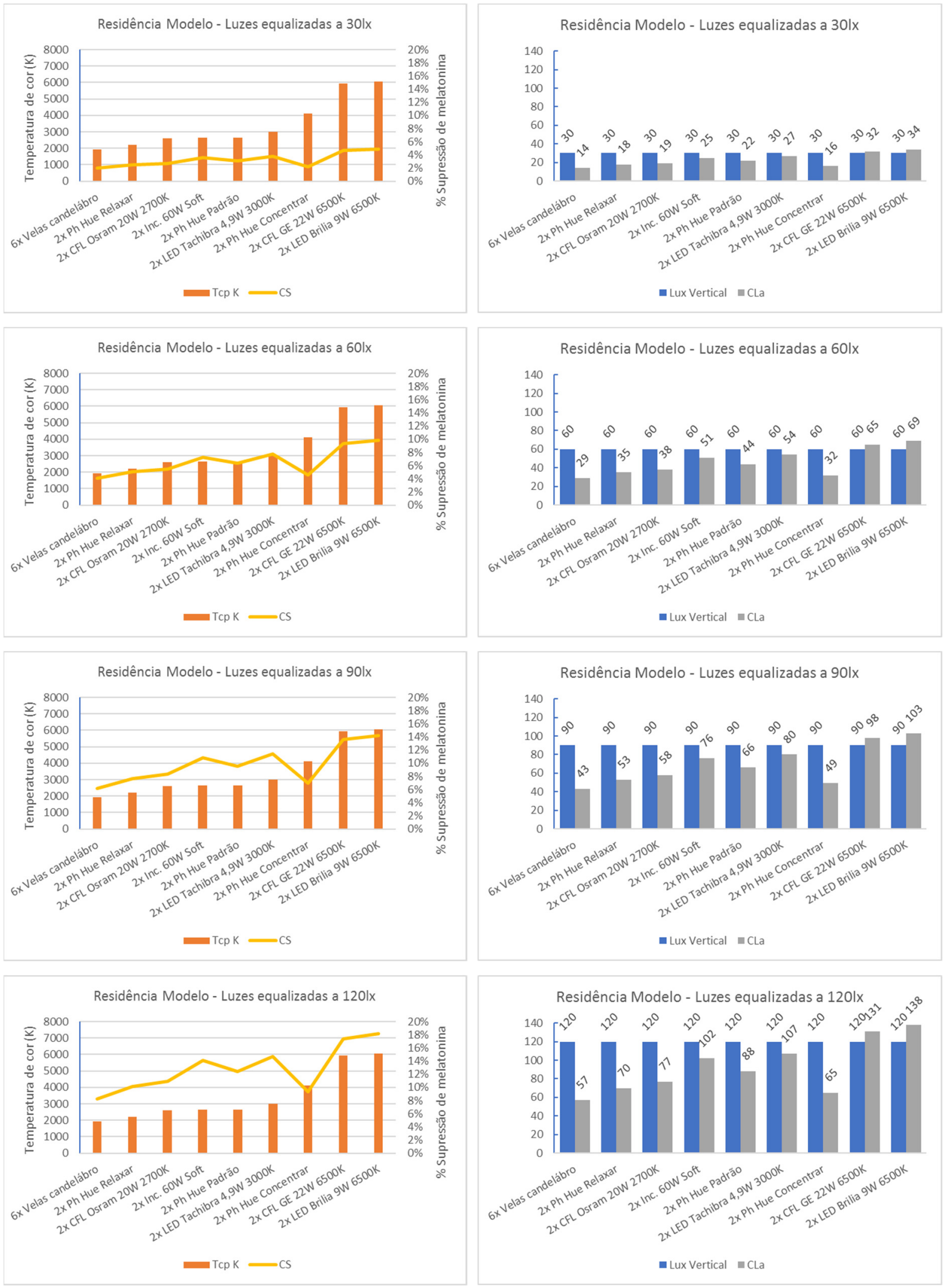

Gráfico 9 - Gráficos de resumo da equalização de níveis de iluminância para a residência modelo. 
Podemos entender das leituras acima realizadas que, as temperaturas de cor acima de $6500 \mathrm{~K}$ tem um impacto até $50 \%$ maior do que temperaturas de cor abaixo de $3000 \mathrm{~K}$.

Porém, cruzando os resultados entendemos que a variação da quantidade de luz tem impacto direto nesses resultados. Se compararmos a supressão de uma fonte de luz CFL $2700 \mathrm{~K}$ em 90 lux com outra CFL de $6500 \mathrm{~K}$ em 30 lux, a primeira tem chega a quase $9 \%$ e a segunda a quase $5 \%$ na primeira hora, ou seja, mesmo tendo temperatura de cor mais alta e potencial de supressão maior, a quantidade de luz tem papel determinante no resultado final.

\subsection{DiscussõES}

A utilização de dois procedimentos com aplicação similar, porém com objetivos distintos , busca, por um lado, a investigação das variações arbitrárias dos ambientes e suas relações com os tipos de emissores de luz, além de uma amostra dos níveis de energia encontrados nos ambientes e, por outro, a compreensão das variações dos emissores de luz dentro de um mesmo cenário.

Após a equalização dos níveis de iluminância, o resultado nos traz uma visão balanceada das fontes de luz em relação ao seu potencial de supressão da produção de melatonina dentro da primeira hora de exposição, conforme método adotado.

Apesar das aparentes pequenas variações entre os resultados, devemos entender que este método analisa a supressão em indivíduos que já estejam produzindo melatonina e apenas entre a primeira e segunda hora. Certamente os resultados acumulativos sugerem $\mathrm{o}$ aumento das variações entre as diferentes amostras. 
A vasta bibliografia disponível para o tema deste trabalho assim como a amostra aqui discutida e escolhida para suportar a hipótese levantada estão relacionados a um universo multidisciplinar onde, cada qual está incumbida de estudar seus meandros e aplicações, sugerem e aplicam métodos tangíveis para a aplicação profissional e acadêmica dos resultados obtidos.

A metodologia aqui aplicada é a tentativa da aproximação prática do projeto de iluminação com o embasamento científico proporcionado pelos estudos realizados por diversos laboratórios na área de neurofisiologia, eletrofisiologia e genética.

Dentre os resultados obtidos através da linha de raciocínio lógico abordado, se questiona não apenas maturidade do método escolhido, questão abordada pelo próprio desenvolvedor que, apesar de saber que o método está bem evoluído, sabe que existem lacunas que poderão ser preenchidas em um futuro breve para uma melhor equalização do processo.

As variações de leituras obtidas através dos procedimentos em diferentes tipos de residência e a equalização do segundo procedimento aplicado em uma residência modelo nos dá uma visão de comparação entre tecnologias, porém as leituras originais mostram que, diferentes temperaturas de cor com diferentes níveis de iluminância podem resultar em divergências acentuadas no resultado final, apontando que, não apenas a cor da luz influencia demasiadamente na supressão de produção de melatonina, mas sim a quantidade de luz encontrada nas medições.

Estudos científicos mostram os impactos da supressão de melatonina, tendo impacto direto em funções cardiovasculares, disfunções do sono, obesidade, diabetes, câncer, distúrbios de humor, degeneração macular, etc. Mesmo em baixos níveis de supressão, existem estudos que mostram níveis de disfunções cognitivas em cobaias laboratoriais. (Yvan Touitou, 2017).

Apesar dos baixos níveis de supressão indicados e deste predizer que isso ocorrerá após 1hora de exposição, outros estudos indicam que a supressão é cumulativa. Sendo assim o acumulo na supressão por mais uma ou duas horas podem ser significativos é provável que devam ser evitados. 
O objetivo inicial desse trabalho não é gerar conclusões determinantes e sim levantar hipóteses e indicar possíveis caminhos para a pesquisa futura.

Mesmo com metodologias distintas, pesquisadores do mundo inteiro estão olhando para as influências que a luz tem diretamente nos organismos vivos e com isso ajudando a melhorar a preocupação, não apenas com o consumo de energia que, apesar de tema importante e crucial para o futuro da humanidade deve ser sempre avaliado em conjunto ao bem-estar social, cultural e biológico dos indivíduos.

Sugere-se que, até que todos os estudos estejam suficientemente maduros e haja nível de consenso suficiente para a elaboração de parâmetros seguros de utilização da luz para que esta não influencie negativamente no ciclo circadiano, o uso de fontes de luz e níveis de iluminância com menor impacto na ativação da melanopsina contida nas ipRGCs.

Pelos resultados obtidos, as fontes de luz abaixo de $3000 \mathrm{~K}$ tem impactos muito similares ao sistema circadiano através dos métodos abordados, porém entende-se que, o parâmetro utilizado, a iluminância (lux), está baseado na curva de resposta do olho humano desenvolvido pela CIE em 1931, na região da fóvea com ângulo de análise de $2^{\circ}$, ou seja, zona na qual a existência de cones curtos é extremamente baixa, além da concentração de melanopsina estar distribuída através da retina. Por isso, as tecnologias que visam economia de energia, em particular o LED, devem procurar evolução para suprimir cada vez mais a porção de luz azul contida nessas fontes, zona de comprimento já citado anteriormente, de maior impacto na supressão de melatonina.

Dentre as 3 fontes de luz que sempre foram o objetivo deste estudo, as lâmpadas incandescentes, fluorescentes e LED, a lâmpada incandescente está sendo descontinuada no mercado, não podendo ser mais comercializada e, as lâmpadas fluorescentes e de LED tem impactos similares no ciclo circadiano. Desta forma recomenda-se o uso da tecnologia LED, em temperaturas de cor abaixo de $3000 \mathrm{~K}$, com níveis de iluminância baixos (abaixo dos 30lx). O uso exagerado de luz, em 
especial em temperaturas de cor mais elevadas (acima de 5000K) tem maiores impactos no ciclo circadiano e devem ser evitados.

O uso de televisores que deem a opção de controle de emissão de luz branca é bem-vindo, apesar das pesquisas realizadas aqui, mostram que a TV tem baixo impacto quando comparados com a iluminação artificial, o ideal é que o impacto chegue a zero. Vale lembrar que, celulares e tablets também merecem atenção pois emitem luz embasada na tecnologia LED com alta temperatura de cor, sendo assim 0 uso de aplicativos de controle de emissão de quantidade de luz é bem-vindo. Vale salientar que, esses equipamentos têm emissão dinâmica de cores e que podem, mesmo com baixas intensidade de luz, estarem próximos da zona de supressão da produção de melatonina ( 440 a 500nm). 
APPLEMAN, Kenneth; FIGUEIRO, Mariana G., REA, Mark S. Controlling light-dark exposure patterns rather than sleep schedules determines circadian phase. Sleep Medicine, v. 14 p. 456-461, 2013.

BELLIA, L.; BISEGNA, F.; SPADA, G. Lighting in indoor environments: visual and non-visual effects of light sources with different spectral power distributions. Building and Environment, v. 46, p. 1984-1992, dez 2011.

BELLIA, L.; PEDACE, A.; BARBATO, G. Indoor artificial lighting: Prediction of the circadian effects of different spectral power distributions. Lighting Res. Technology, v. 46, p. 650-660, 2014.

BELLIA, L.; PEDACE, A.; SPADA, G, FRAGLIASSOA, F. Methods to evaluate lighting quality in educational environments. Energy Procedia, v. 78, p. 3138-3143, 2015.

BOWMAN, David M. J. S.;BALCH, Jennifer K.;ARTAXO, Paulo; BOND,William J.; CARLSON,Jean M.; COCHRANE,Mark A.; D'ANTONIO,Carla M.; DEFRIES Ruth S.; DOYLE , John C.; HARRISON, Sandy P. ; JOHNSTON Fay H.; KEELEY, Jon E.; KRAWCHUK, Meg A. ; KULL, Christian A.; MARSTON, J. Brad; MORITZ, Max A.; PRENTICE, I. Colin; ROOS, Christopher I.; SCOTT, Andrew C.; SWETNAM, Thomas W.; WERF, Guido R. van der; PYNE, Stephen J. Fire in the Earth System. Science, 24, v. 324, no 5926, p. 481-484, abril 2009. Disponível em: http://www.sciencemag.org/content/324/5926/481 >. Acessado em: dezembro 2014.

BRAINARD, George C.; HANIFIN, John P.; GREESON, Jeffrey M.; BYRNE, Brenda; GLICKMAN, Gena. Action Spectrum for Melatonin Regulation in Humans: Evidence for a Novel Circadian Photoreceptor. The Journal of Neuroscience, 21(16), p. 6405-6412, Agosto 2001.

BRAINARD, George C.; WARFIELD, Benjamin; LOCKLEY, Steven W.; COYLE, William; MAIDA, James; HANIFIN, John P.; AYERS, Melissa; BOWEN, Charles; KEMP, John; BERNECKER, Craig. Solid-state lighting for the International Space Station: Tests of visual performance and melatonin regulation. Acta Astronautica, 92, p. 21-28, novembro 2013.

BUXTON, Orfeu M.; CHANG, Anne-Marie; SPILSBURY, James C.; BOS, Taylor; BM, EMSELLEM, Helene; KNUTSON, Kristen L. Sleep in the modern family: protective family routines for child and adolescent sleep. Sleep Health, v. 1, p. 15-27, 2015.

CHEN, S.-K.; BADEA T. C.; HATTAR S. Photoentrainment and pupillary light reflex are mediated by distinct populations of ipRGCs. Letter Research. Nature, 2011.

CLAUSTRAT, B.; LESTONB, J. Melatonin: Physiological effects in humans. Neurochirurgie, v. 61, p. 77-84, abril-junho 2015. 
CREE. Eye Safety With LED Components. Technical Article. Disponível em: <http://www.cree.com/ /media/Files/Cree/LED\%20Components\%20and\%20Modules /XLamp/XLamp\%20Application\%20Notes/XLamp_EyeSafety.pdf>. Acessado em: janeiro 2017.

CROWLEY, Stephanie J.; EASTMAN, Charmane I. Phase advancing human circadian rhythms with morning bright light, afternoon melatonin, and gradually shifted sleep: can we reduce morning bright-light duration? Sleep Medicine, 16, p. 288-297, fevereiro 2015.

CROWLEY, Stephanie J.; EASTMAN, Charmane I. Phase advancing human circadian rhythms with morning bright light, afternoon melatonin, and gradually shifted sleep: can we reduce morning bright-light duration? Sleep Medicine, v. 16 , p. 288-297, 2015.

DACEY, Dennis M.; LIAO, Hsi-Wen; PETERSON, Beth B.; ROBINSON, Farrel R.; SMITH, Vivianne C.; POKORNY, Joel; YAU, King-Wai; GAMLIN, Paul D.. Melanopsin-expressing ganglion cells in primate retina signal colour and irradiance and project to the LGN. Nature, v. 433, 749-754, fevereiro 2005.

EISMANN, Emily A.; LUSH, Elizabeth; SEPHTON, Sandra E. Circadian effects in cancer-relevant psychoneuroendocrine and immune pathways. Psychoneuroendocrinology, v. 35, p. 963-976, 2010.

FAVEROA, Gaia; FRANCESCHETTI, Lorenzo; BUFFOLI, Barbara; MOGHADASIANB, Mohammed H.; REITER, Russel J., RODELLAA, Luigi F., REZZANI, Rita. Melatonin: Protection against age-related cardiac pathology. Ageing Research Reviews, 2016.

FIGUEIRO, M.; OVERINGTON, D. Self-luminous devices and melatonin suppression in adolescents. Lighting Res. Technology, v. 47, p. 01-10, abril 2015.

FIGUEIRO, Mariana G.; BIERMAN, Andrew; REA, Mark S. Retinal mechanisms determine the subadditive response to polychromatic light by the human circadian system. Neuroscience Letters, 438, p. 242-245, junho 2008.

FIGUEIRO, Mariana G.; REA, Mark S.; BULLOUGH,John D., Circadian effectiveness of two polychromatic lights insuppressing human nocturnal melatonin. Neuroscience Letters 406, p. 293-297, julho 2006

FIGUEIRO, Mariana; LESNIAK, Natalia; REA, Mark S. Implications of controlled shortwavelength light exposure for sleep in older adults. BMC Research Notes, v. 04, p. 01-08, set 2011.

FIGUEIRO, Mariana; WOOD, Brittany; PLITNICK, Barbara; REA, Mark S. The impact of light from computer monitors on melatonin levels in college students. Biogenic Amines, v. 25, p. 106-116, 2011

ILLUMINATING ENGINEERING SOCIETY (IES). Lighting Handbook, Reference and Application. 10 ed. New York: IESNA, 2011. 
ISKRA-GOLEC, IM.; WAZNA, A; SMITH, L. Effects of blue-enriched light on the daily course of mood, sleepiness and light perception: A fied experiment. Lighting Res. Technology, v. 44, p. 506-513, dez 2012.

KORT, Yvonne A.W. de. From blind spot into the spotlight Introduction to the special issue 'Light, lighting, and human behaviour'. Journal of Environmental PSYCHOLOGY, v 39, p. 1-4, 2014.

KUBOTA, Tomio; UCHIYAMA, Makoto; SUZUKI, Hiroyuki; SHIBUI, Kayo; KIM, Keiko, TAN, Xin; TAGAYA, Hirokuni; OKAWA, Masako; INOUE, Shojiro. Effects of nocturnal bright light on saliva melatonin, core body temperature and sleep propensity rhythms in human subjects. Neuroscience Research, v.42, p. 115-122, 2002.

Lucas , Robert J.; Peirson, Stuart N.; Berson, David M.; Brown, Timothy M.; Cooper , Howard M.; Czeisler, Charles A.; Figueiro, Mariana G.; Gamlin, Paul D.; Lockley, Steven W.; O'Hagan, John B.; Price, Luke L.A.; Provencio, Ignacio; Skene, Debra J.; Brainard, George $C$. Measuring and using light in the melanopsin age Trends in Neurosciences, Vol. 37, No. 1 p.1-9, janeiro 2014

LUCAS, Robert J.; PEIRSON, Stuart N.; BERSON, David M.; COOPER, Howard M.; LOCKLEY, Steven W.; SKENE, Debra J.; BRAINARD, George C.; CZEISLER, Charles A.; O'HAGAN, John B.; FIGUEIRO, Mariana G.; PRICE, Luke L.A.; BROWN, Timothy M.; GAMLIN, Paul D.; PROVENCIO, Ignacio. Measuring and using light in the melanopsin age. Trends in Neurosciences, v. 37, p. 1-9, janeiro 2014.

Martau, Betina Tschiedel. A luz além da visão: iluminação e sua relação com a saúde e bem-estar de funcionárias de lojas de rua e de shopping centers em Porto Alegre. Tese de doutorado Campinas, 2009.

Ministério de Minas e Energia. Empresa de Pesquisa Energética. Brasília: MME/EPE, Plano Decenal de Expansão de Energia 2024. 2015

PAUL, Michel A.; ARENDT, Josephine; LOVE, Ryan J., HAWTON, Andrea; BRETT, Kaighley; Donald R. Sleep deficits in the High Arctic summer in relation to light exposure and behaviour: use of melatonin as a countermeasure. Sleep Medicine, 16, p. 406-413, 2015.

Paul, Michel A.; Love, Ryan J.; Hawton, Andrea; Brett, Kaighley; McCreary, Donald R.; Arendt, Josephine. Sleep deficits in the High Arctic summer in relation to light exposure and behaviour: use of melatonin as a countermeasure. Sleep Medicine 16 p. 406-413, janeiro 2015.

Portnov, Boris A.; Stevens, Richard G.; Samociuk, Holly; Wakefield, Daniel; Gregorio, David I. Light at night and breast cancer incidence in Connecticut: An ecological study of age group effects Science of the Total Environment 572 p. 1020-1024, Agosto 2016.

Rea, Mark S. A natural view of artificial light. Sleep Health 1 p. 88-89, 2015 
Rea, Mark S. The lumen seen in a new light: Making distinctions between light, lighting and neuroscience. Lighting Res. Technol.; Vol. 47: p. 259-280, 2015

REA, Mark S.; BULLOUGH, John D., FIGUEIRO, Mariana G. Human melatonin suppression by light: a case for scotopic eficiency. Neuroscience Letters, 299, p. 45-48, fevereiro 2001.

Rea, Mark S.; Figueiro, Mariana G. The NICU Lighted Environment. Newborn \& Infant Nursing Reviews 16 p. 195-202, 2016

REA, Mark S.; FIGUEIRO, Mariana G.; BULLOUGH, John D.; BIERMAN, Andrew. A model of phototransduction by the human circadian system. Science Direct, Brain Research Reviews, 50, p. 213-228, 2005.

Rea, Mark S.; Figueiro, Mariana G.; Bullough, John D.; Bierman, Andrew. Corrigendum to "A model of phototransduction by the human circadian system" [Brain Res. Rev. 50/2 (2005) 213-228]. Brain Research Reviews 56 p.270, 2007

Rea, MS; Figueiro MG; Bierman, A; Hamner, R. Modelling the spectral sensitivity of the human circadian system, Lighting Res. Technol. 44: p.386-396, outubro 2011

Rea, MS; Figueiro MG; Bierman, A; Hamner, R. Corrigendum to "Modelling the spectral sensitivity of the human circadian system" [Lighting Research and Technology 2012; 44(4): 386-396], Lighting Res. Technol. 44: p.386-396, 2012

Rea, MS; Figueiro MG. Light as a circadian stimulus for architectural lighting. Lighting Res. Technol. 0: p. 1-14, Novembro 2016

ROBERTS, Joan E. Circadian Rhythm and Human Health. Julho 2010. Disponível em: < http://www.photobiology.info/Roberts-CR.html>. Acessado em: janeiro 2015.

ROBERTS, Joan E. Photobiology of the Human Lens. Setembro 2011. Disponível em: <http://www.photobiology.info/Roberts.html>. Acessado em: janeiro 2015.

ROBERTS, Joan E. Update on the Positive Effects of Light in Humans. Fordham University Department of Natural Sciences. Disponível em: http://faculty.fordham.edu/jroberts/Joan.pdf>. Acessado em: novembro 2014.

Roecklein, Kathryn A.; Wong, Patricia M.; Miller, Megan A.; Donofry, Shannon D.; Kamarck, Marissa L.; Brainard, George C. Melanopsin, photosensitive ganglion cells, and seasonal affective disorder Neuroscience and Biobehavioral Reviews 37 p. 229-239, Dezembro 2012

Sahin, Levent; Wood, Brittany M.; Plitnick, Barbara; Figueiro, Mariana G. Daytime light exposure: Effects on biomarkers, measures of alertness, and performance. Behavioural Brain Research 274 p. 176-185, Agosto 2014

Selmaoui, Brahim; Touitou, Yvan. Reproducibility of the circadian rhythms of serum cortisol and melatonin in healthy subjects: a study of three different 24-h cycles over six weeks. Life Sciences 73 p.3339-3349, Maio 2003 
Sharkey, Katherine M.; Carskadon, Mary A.; Figueiro, Mariana G.; Zhu, Yong; Rea, Mark S. Effects of an advanced sleep schedule and morning short wavelength light exposure on circadian phase in young adults with late sleep schedules Sleep Medicine 12 p. 685-692, Junho 2011

STEVENS, Richard G., BRAINARD, George C.; BLASK, David E.; LOCKLEY, Steven W.; MOTTA, Mario E. Adverse Health Effects of Nighttime Lighting Comments on American Medical Association Policy Statement. American Journal of Preventive Medicine, 45 (3), p. 343-346, 2013.

Touitou, Yvan; Reinberg, Alain; Touitou, David. Association between light at night, melatonin secretion, sleep deprivation, and the internal clock: Health impacts and mechanisms of circadian disruption Life Sciences 173 p. 94-106, Fevereiro 2017

Veitch, J. A.; Galasiu, A. D. The Physiological and Psychological Effects of Windows, Daylight, and View at Home: Review and Research Agenda NRC-IRC Research Report RR-325, Fevereiro 2012.

Veitch, J.A. Psychological processes influencing lighting quality. NRCC-42469 Journal of the Illuminating Engineering Society, 30(1), p.124-140., 2001

Wiechmann, Allan F.; Chignell; Colin F.; Roberts; Joan E. Influence of dietary melatonin on photoreceptor survival in the rat retina: An ocular toxicity study Experimental Eye Research 86 p. 241e250, Novembro 2007

Winzen, J; Albers, F; Marggraf-Micheel, C. The influence of coloured light in the aircraft cabin on passenger thermal comfort. Lighting Res. Technol. Vol. 46: p. 465-475, março 2013

WOOD, Brittany; REA, Mark S.; PLITNICK, Barbara; FIGUEIRO, Mariana G. Light level and duration of exposure determine the impact of self-luminous tablets on melatonin suppression. Applied Ergonomics, 44, p. 237-240, 2013.

Young, Martin E.; Bray, Molly S. Potential role for peripheral circadian clock dyssynchrony in the pathogenesis of cardiovascular dysfunction Sleep Medicine 8 p.656-667, março 2007

Zhu, Yong; Fu, Alan; Hoffman, Aaron E.; Figueiro, Mariana G.; Carskadon, Mary A.; Sharkey, Katherine M.; Rea, Mark S. Advanced sleep schedules affect circadian gene expression in young adults with delayed sleep schedules Sleep Medicine 14 p.449-455, abril 2013 
9 AnEXos 


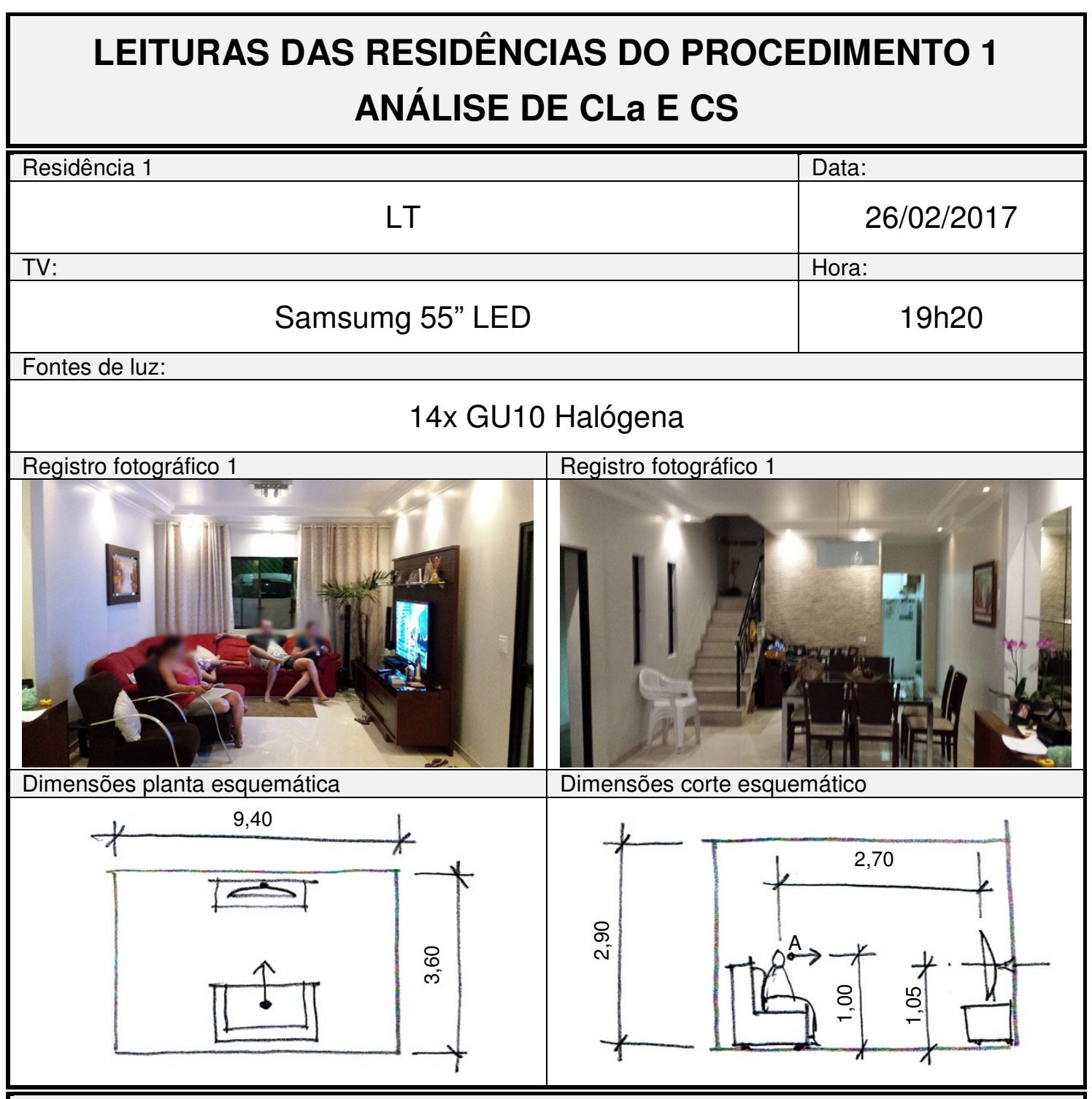

\begin{tabular}{|c|c|c|c|c|c|}
\hline \multicolumn{6}{|c|}{ Leituras e cálculos para o ponto $\mathrm{A}$} \\
\hline \multicolumn{2}{|c|}{ Luzes acesas e TV ligados } & \multicolumn{2}{|c|}{ Luzes acesas e TV desligada } & \multicolumn{2}{|c|}{ Luzes desligadas e TV ligada } \\
\hline \multirow{2}{*}{\multicolumn{2}{|c|}{ 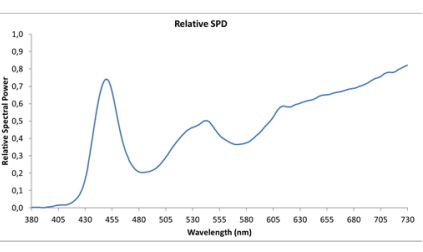 }} & \multirow{2}{*}{\multicolumn{2}{|c|}{ 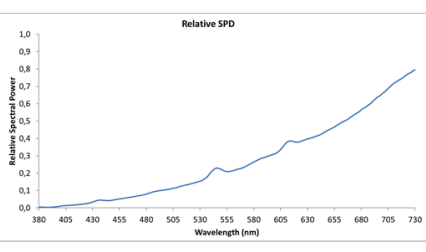 }} & \multirow{2}{*}{\multicolumn{2}{|c|}{ 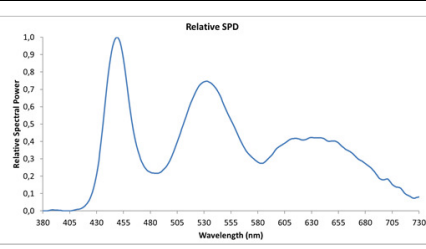 }} \\
\hline & & & & & \\
\hline $\operatorname{lux}$ & tcp & $\operatorname{lux}$ & tcp & $\operatorname{lux}$ & tcp \\
\hline $27,41 x$ & $4093 \mathrm{~K}$ & $14,1 \mid x$ & $2423 \mathrm{~K}$ & $9,61 x$ & $7046 \mathrm{~K}$ \\
\hline CLa & CS & CLa & CS & CLa & CS \\
\hline 28 & $4,00 \%$ & 11 & $1,50 \%$ & 12 & $1,70 \%$ \\
\hline
\end{tabular}

Observações:

As leituras, medições e fotografias foram feitas com consentimento dos moradores, utilizando espectrofotômetro Konica Minolta CL500A + Trena Bosch eletrônica GLM50 + Celular (fotos). Gráficos, CS e CLa calculados através de tabela do Lighting Research Center 


\section{LEITURAS DAS RESIDÊNCIAS DO PROCEDIMENTO 1 ANÁLISE DE CLa E CS}

\begin{tabular}{|l|l|}
\hline Residência 2 & Data: \\
\hline TV: & $26 / 02 / 2017$ \\
\hline Samsung 40" LCD & Hora: \\
\hline 3x Fluorescente Compacta 6500K \\
\hline Registro fotográfico 1
\end{tabular}

\begin{tabular}{|c|c|c|c|c|c|}
\hline \multicolumn{6}{|c|}{ Leituras e cálculos para o ponto $\mathrm{A}$} \\
\hline \multicolumn{2}{|c|}{ Luzes acesas e TV ligados } & \multicolumn{2}{|c|}{ Luzes acesas e TV desligada } & \multicolumn{2}{|c|}{ Luzes desligadas e TV ligada } \\
\hline 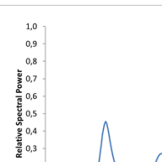 & & 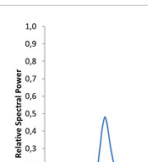 & & 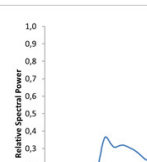 & \\
\hline $\operatorname{lux}$ & tcp & $\operatorname{lux}$ & tcp & lux & tcp \\
\hline $38,81 x$ & $5870 \mathrm{~K}$ & $31,7 \mid x$ & $5733 \mathrm{~K}$ & $3,91 x$ & $8230 \mathrm{~K}$ \\
\hline CLa & CS & CLa & CS & CLa & CS \\
\hline 42 & $6,10 \%$ & 33 & $4,70 \%$ & 7 & $0,90 \%$ \\
\hline
\end{tabular}

Observações:

As leituras, medições e fotografias foram feitas com consentimento dos moradores, utilizando espectrofotômetro Konica Minolta CL500A + Trena Bosch eletrônica GLM50 + Celular (fotos). Gráficos, CS e CLa calculados através de tabela do Lighting Research Center 


\section{LEITURAS DAS RESIDÊNCIAS DO PROCEDIMENTO 1 ANÁLISE DE CLa E CS}

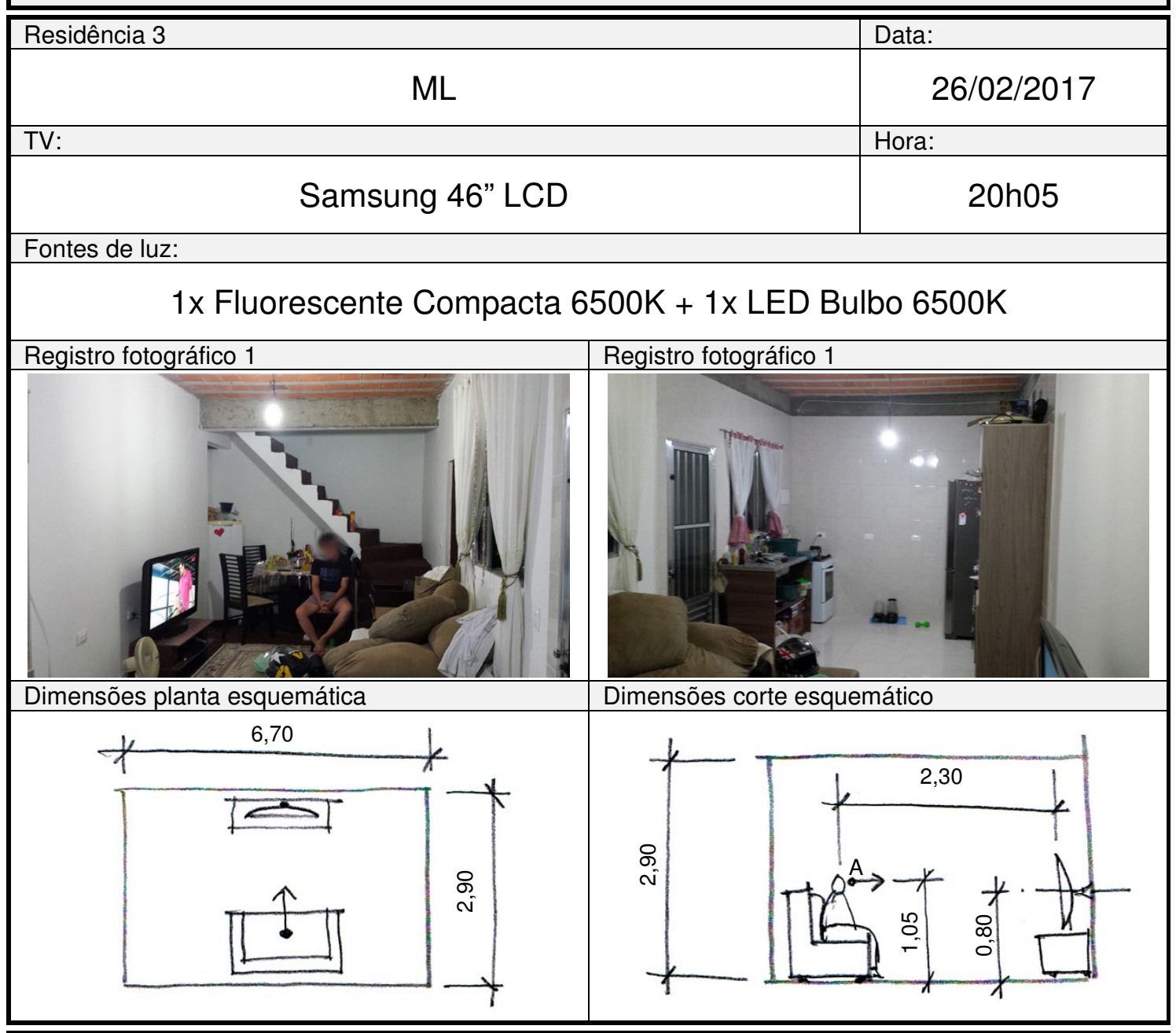

\begin{tabular}{|c|c|c|c|c|c|}
\hline \multicolumn{6}{|c|}{ Leituras e cálculos para o ponto A } \\
\hline \multicolumn{2}{|c|}{ Luzes acesas e TV ligados } & \multicolumn{2}{|c|}{ Luzes acesas e TV desligada } & \multicolumn{2}{|c|}{ Luzes desligadas e TV ligada } \\
\hline 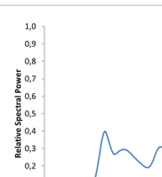 & $\Lambda$ & 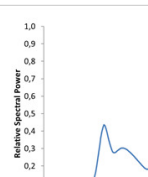 & & 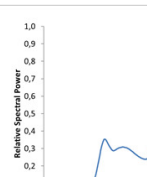 & \\
\hline $\operatorname{lux}$ & $\operatorname{tcp}$ & $\operatorname{lux}$ & $\operatorname{tcn}$ & Jux & $\operatorname{tcn}$ \\
\hline $34,21 x$ & $5145 K$ & $27,21 x$ & $5190 \mathrm{~K}$ & $7,21 x$ & $6790 \mathrm{~K}$ \\
\hline CLa & CS & CLa & CS & CLa & CS \\
\hline 35 & $5.00 \%$ & 26 & $3,70 \%$ & 11 & $1,50 \%$ \\
\hline
\end{tabular}

Observações:

As leituras, medições e fotografias foram feitas com consentimento dos moradores, utilizando espectrofotômetro Konica Minolta CL500A + Trena Bosch eletrônica GLM50 + Celular (fotos). Gráficos, CS e CLa calculados através de tabela do Lighting Research Center 


\section{LEITURAS DAS RESIDÊNCIAS DO PROCEDIMENTO 1 ANÁLISE DE CLa E CS}

\begin{tabular}{|l|l|}
\hline Residência 4 EP & Data: \\
\hline TV: & $26 / 02 / 2017$ \\
\hline Fontes de luz: & Hora: \\
\hline 3x incandescente bolinha + 3x fluorescente compacta 6500K \\
\hline Registro fotográfico 1 \\
\hline
\end{tabular}

\begin{tabular}{|c|c|c|c|c|c|}
\hline \multicolumn{6}{|c|}{ Leituras e cálculos para o ponto $\mathrm{A}$} \\
\hline \multicolumn{2}{|c|}{ Luzes acesas e TV ligados } & \multicolumn{2}{|c|}{ Luzes acesas e TV desligada } & \multicolumn{2}{|c|}{ Luzes desligadas e TV ligada } \\
\hline 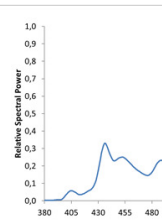 & 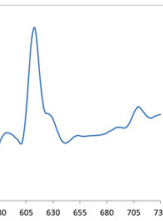 & 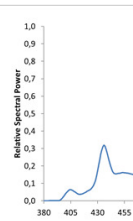 & & 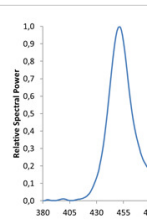 & \\
\hline $\operatorname{lux}$ & tcp & $\operatorname{lux}$ & tcp & $\operatorname{lux}$ & tcp \\
\hline $31,81 x$ & $3295 K$ & $311 x$ & 3204 & $2,11 x$ & $9662 \mathrm{~K}$ \\
\hline CLa & CS & CLa & CS & CLa & CS \\
\hline 14 & $2,00 \%$ & 33 & $4,70 \%$ & 4 & $0,50 \%$ \\
\hline
\end{tabular}

Observações:

As leituras, medições e fotografias foram feitas com consentimento dos moradores, utilizando espectrofotômetro Konica Minolta CL500A + Trena Bosch eletrônica GLM50 + Celular (fotos). Gráficos, CS e CLa calculados através de tabela do Lighting Research Center 


\section{LEITURAS DAS RESIDÊNCIAS DO PROCEDIMENTO 1 ANÁLISE DE CLa E CS}

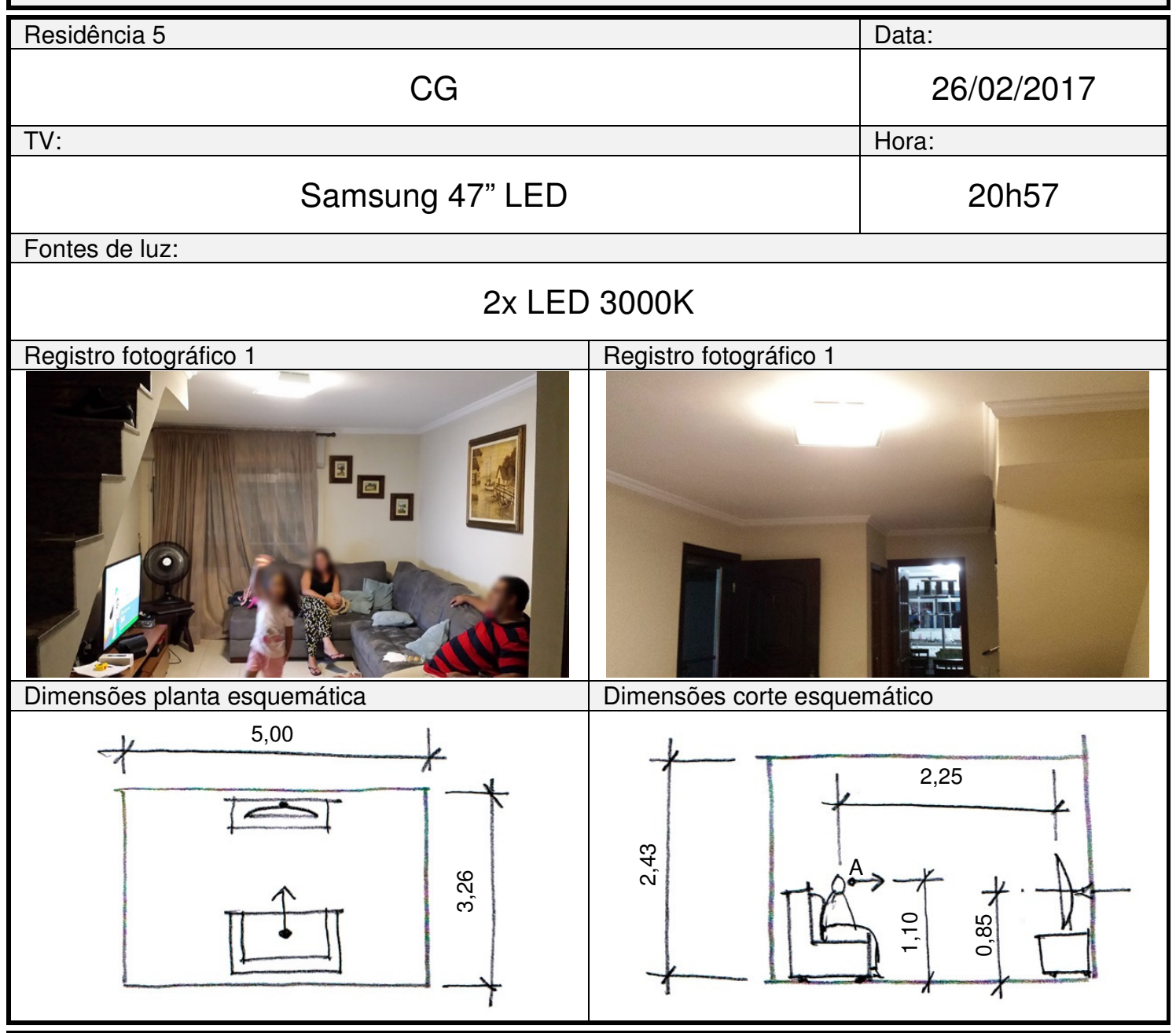

\begin{tabular}{|c|c|c|c|c|c|}
\hline \multicolumn{6}{|c|}{ Leituras e cálculos para o ponto $\mathrm{A}$} \\
\hline \multicolumn{2}{|c|}{ Luzes acesas e TV ligados } & \multicolumn{2}{|c|}{ Luzes acesas e TV desligada } & \multicolumn{2}{|c|}{ Luzes desligadas e TV ligada } \\
\hline 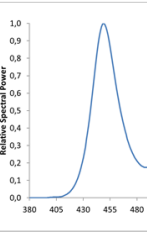 & - & 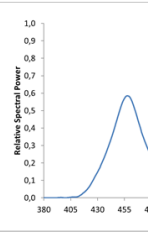 & & 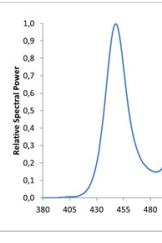 & \\
\hline $\operatorname{lux}$ & tcp & $\operatorname{lux}$ & tcp & $\operatorname{lux}$ & tcp \\
\hline $45,21 x$ & $4280 \mathrm{~K}$ & $25,81 x$ & $3250 \mathrm{~K}$ & $15,4 \mid x$ & $6378 \mathrm{~K}$ \\
\hline CLa & CS & CLa & CS & CLa & CS \\
\hline 44 & $6,30 \%$ & 25 & $3,60 \%$ & 17 & $2,40 \%$ \\
\hline
\end{tabular}

Observações:

As leituras, medições e fotografias foram feitas com consentimento dos moradores, utilizando espectrofotômetro Konica Minolta CL500A + Trena Bosch eletrônica GLM50 + Celular (fotos). Gráficos, CS e CLa calculados através de tabela do Lighting Research Center 


\section{LEITURAS DAS RESIDÊNCIAS DO PROCEDIMENTO 1 ANÁLISE DE CLa E CS}

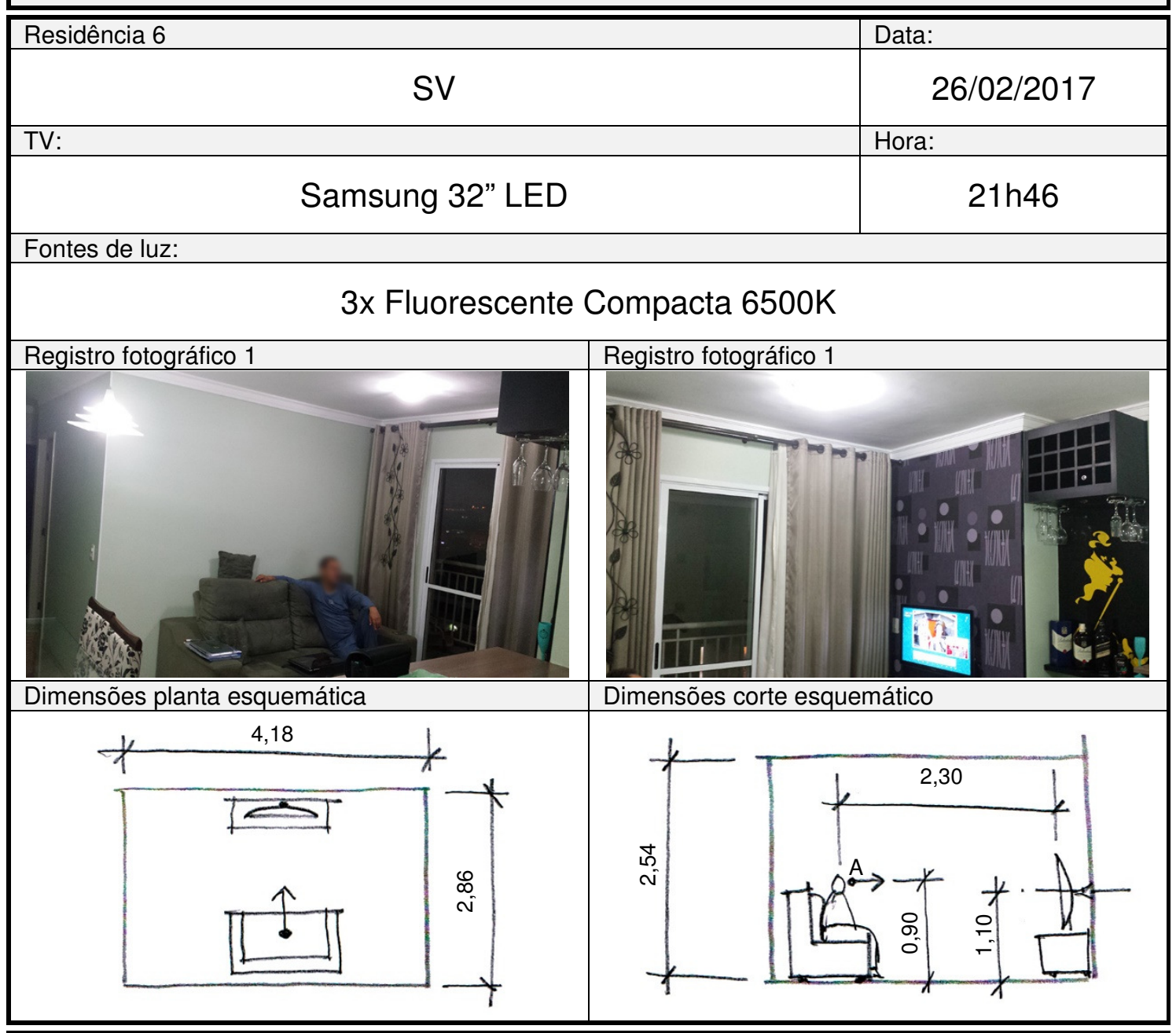

\begin{tabular}{|c|c|c|c|c|c|}
\hline \multicolumn{6}{|c|}{ Leituras e cálculos para o ponto $\mathrm{A}$} \\
\hline \multicolumn{2}{|c|}{ Luzes acesas e TV ligados } & \multicolumn{2}{|c|}{ Luzes acesas e TV desligada } & \multicolumn{2}{|c|}{ Luzes desligadas e TV ligada } \\
\hline 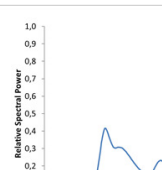 & & 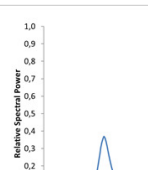 & & 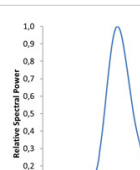 & \\
\hline $\operatorname{lux}$ & tcp & $\operatorname{lux}$ & tcp & $\operatorname{lux}$ & tcp \\
\hline $27,1 \mid x$ & $5950 \mathrm{~K}$ & $19,61 x$ & $5436 \mathrm{~K}$ & $3,31 x$ & $8884 \mathrm{~K}$ \\
\hline CLa & $\mathrm{CS}$ & CLa & CS & CLa & $\mathrm{CS}$ \\
\hline 27 & $3,90 \%$ & 15 & $2,10 \%$ & 6 & $0,70 \%$ \\
\hline
\end{tabular}

Observações:

As leituras, medições e fotografias foram feitas com consentimento dos moradores, utilizando espectrofotômetro Konica Minolta CL500A + Trena Bosch eletrônica GLM50 + Celular (fotos). Gráficos, CS e CLa calculados através de tabela do Lighting Research Center 


\section{LEITURAS DAS RESIDÊNCIAS DO PROCEDIMENTO 1 ANÁLISE DE CLa E CS}

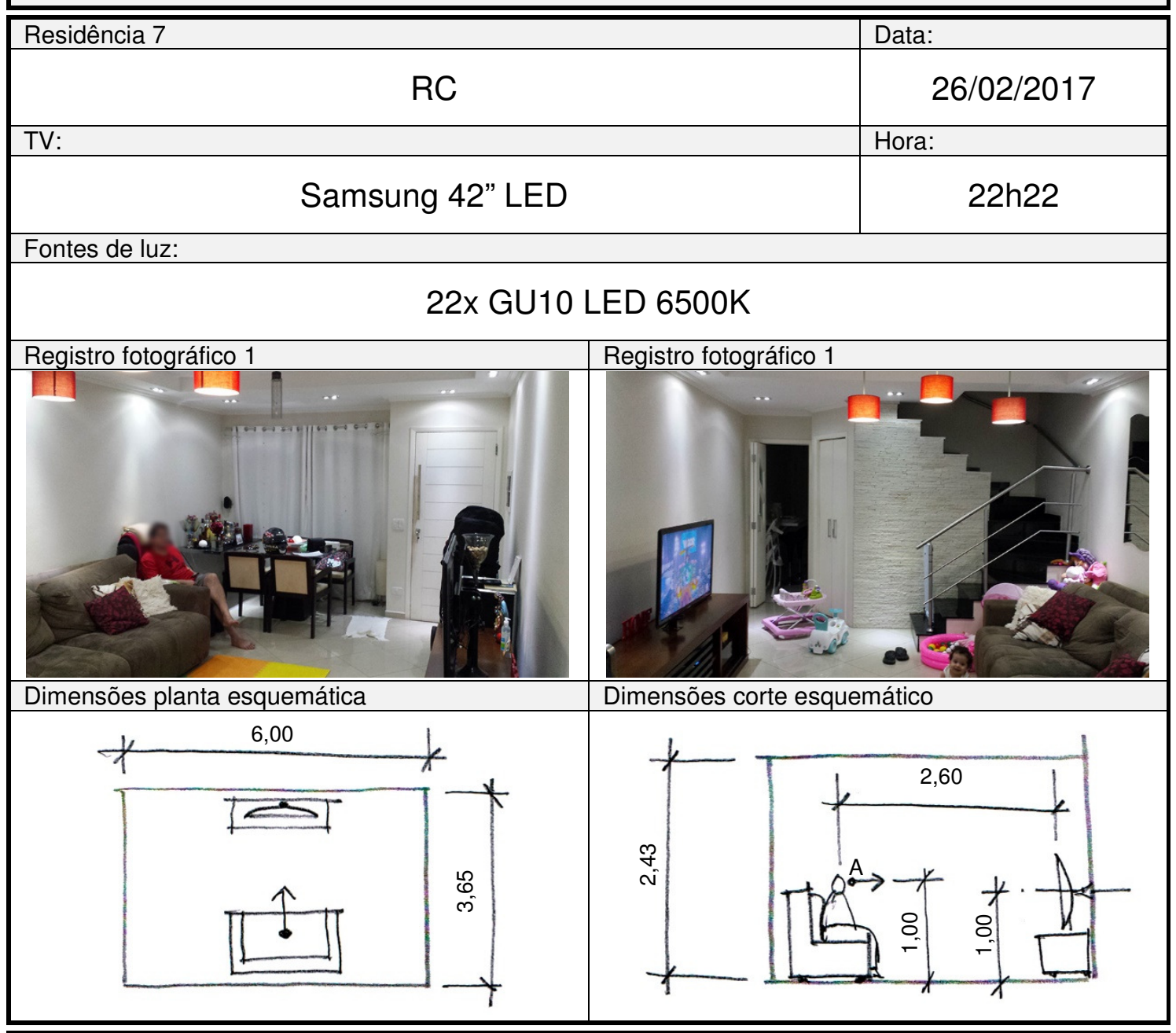

\begin{tabular}{|c|c|c|c|c|c|}
\hline \multicolumn{6}{|c|}{ Leituras e cálculos para o ponto $\mathrm{A}$} \\
\hline \multicolumn{2}{|c|}{ Luzes acesas e TV ligados } & \multicolumn{2}{|c|}{ Luzes acesas e TV desligada } & \multicolumn{2}{|c|}{ Luzes desligadas e TV ligada } \\
\hline 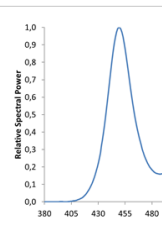 & & 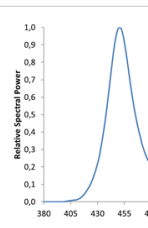 & & 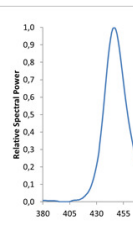 & \\
\hline $\operatorname{lux}$ & tcp & $\operatorname{lux}$ & tcp & $\operatorname{lux}$ & tcp \\
\hline $30,81 x$ & $5141 \mathrm{~K}$ & $31,7 \mathrm{~lx}$ & $4814 \mathrm{~K}$ & $21 x$ & $64791 \mathrm{~K}$ \\
\hline CLa & CS & CLa & CS & CLa & CS \\
\hline 31 & $4,40 \%$ & 26 & $3,70 \%$ & 6 & $0,70 \%$ \\
\hline
\end{tabular}

Observações:

As leituras, medições e fotografias foram feitas com consentimento dos moradores, utilizando espectrofotômetro Konica Minolta CL500A + Trena Bosch eletrônica GLM50 + Celular (fotos). Gráficos, CS e CLa calculados através de tabela do Lighting Research Center 


\section{LEITURAS DAS RESIDÊNCIAS DO PROCEDIMENTO 1 ANÁLISE DE CLa E CS}

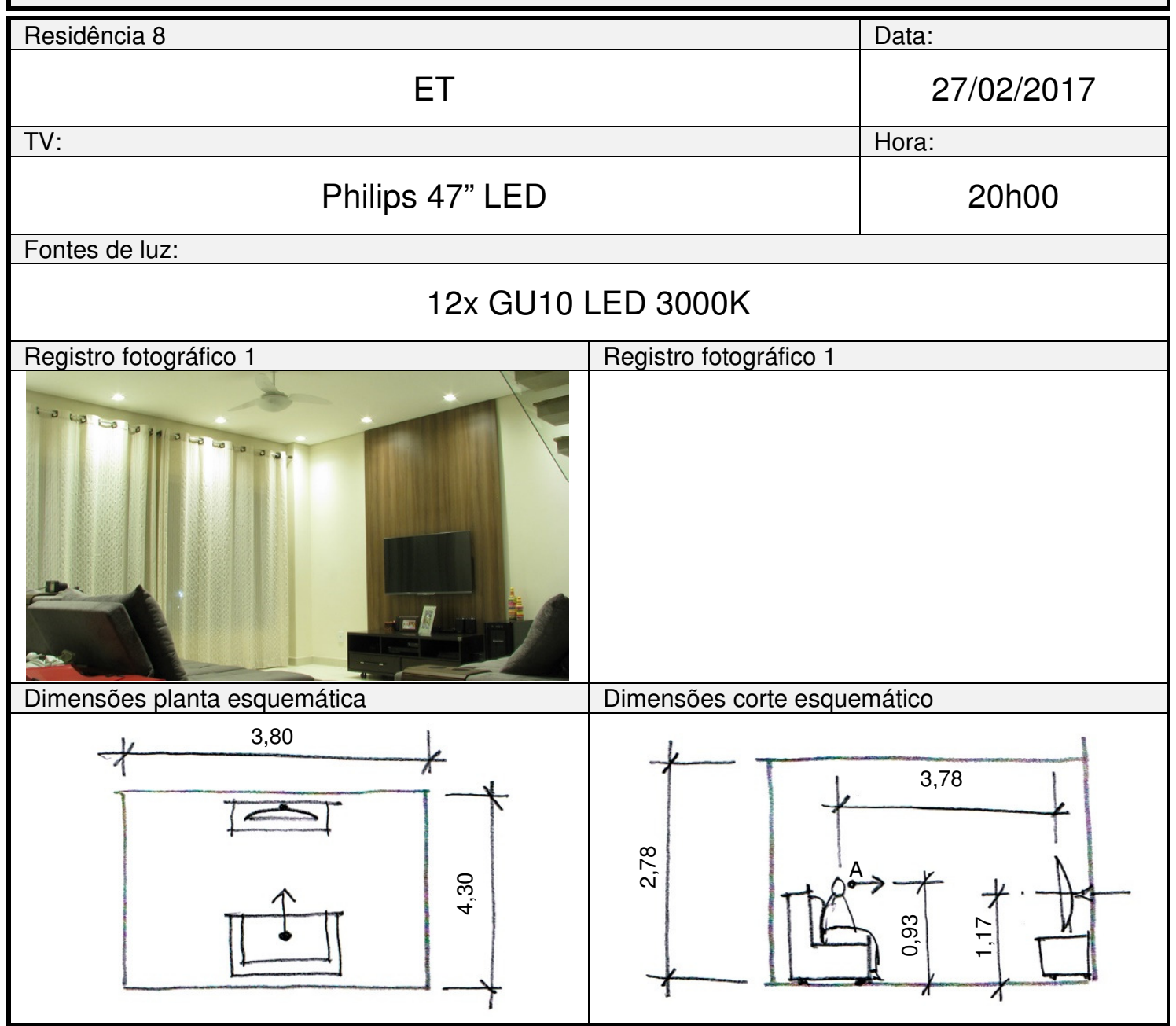

\begin{tabular}{|c|c|c|c|c|c|}
\hline \multicolumn{6}{|c|}{ Leituras e cálculos para o ponto $\mathrm{A}$} \\
\hline \multicolumn{2}{|c|}{ Luzes acesas e TV ligados } & \multicolumn{2}{|c|}{ Luzes acesas e TV desligada } & \multicolumn{2}{|c|}{ Luzes desligadas e TV ligada } \\
\hline 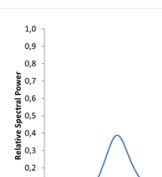 & & 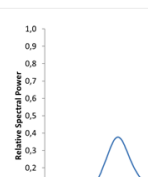 & & 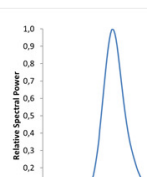 & \\
\hline $\operatorname{lux}$ & tcp & $\operatorname{lux}$ & tcp & $\operatorname{lux}$ & tcp \\
\hline $59,41 x$ & 2973K & $58,51 x$ & 2972 & $1,5 \mid x$ & $7601 \mathrm{~K}$ \\
\hline $\mathrm{CLa}$ & CS & $\mathrm{CLa}$ & CS & $\mathrm{CLa}$ & CS \\
\hline 45 & $6,50 \%$ & 44 & $6,30 \%$ & 2 & $0,30 \%$ \\
\hline
\end{tabular}

Observações:

As leituras, medições e fotografias foram feitas com consentimento dos moradores, utilizando espectrofotômetro Konica Minolta CL500A + Trena Bosch eletrônica GLM50 + Celular (fotos). Gráficos, CS e CLa calculados através de tabela do Lighting Research Center 


\section{LEITURAS DAS RESIDÊNCIAS DO PROCEDIMENTO 1 ANÁLISE DE CLa E CS}

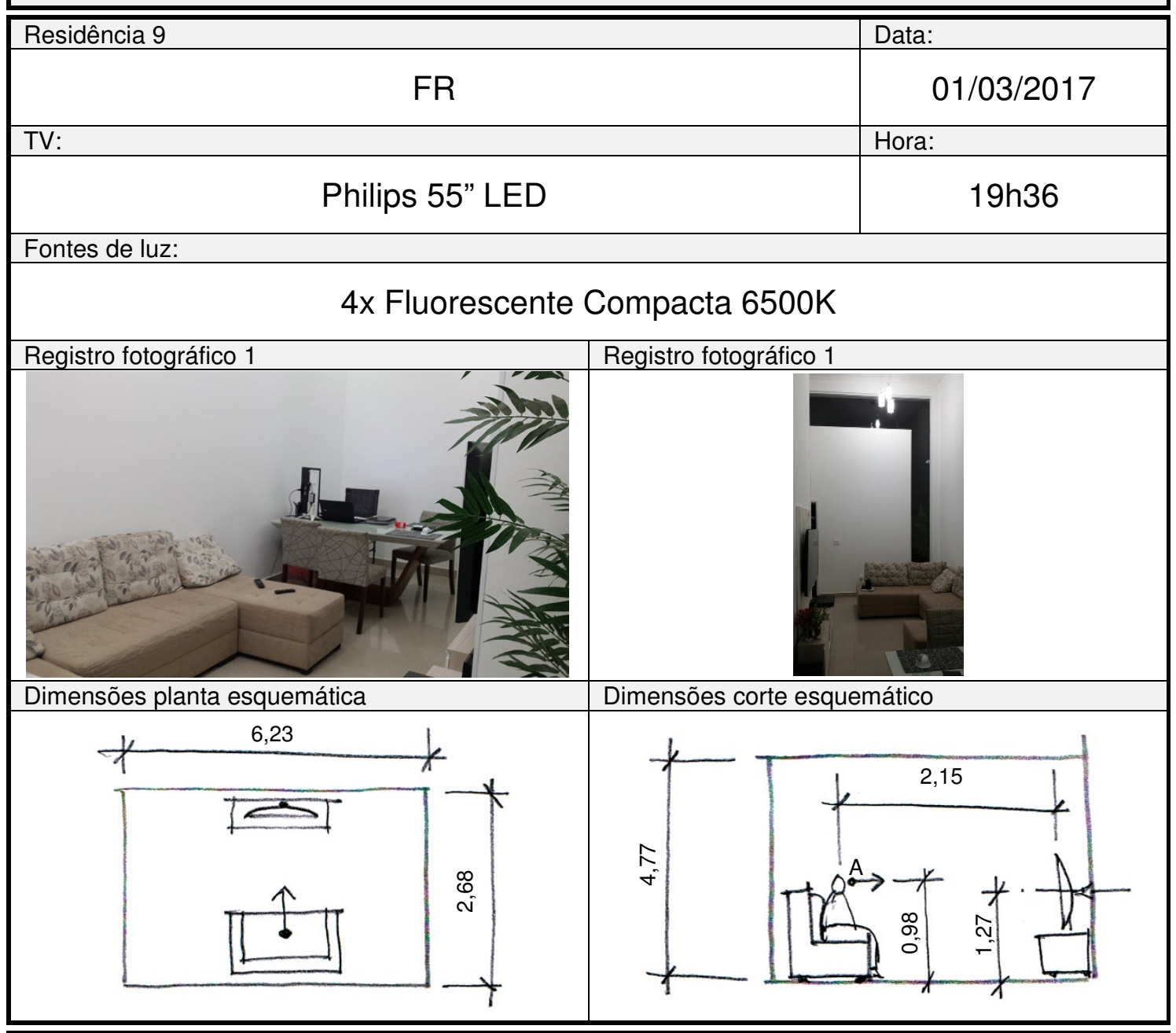

\begin{tabular}{|c|c|c|c|c|c|}
\hline \multicolumn{6}{|c|}{ Leituras e cálculos para o ponto $\mathrm{A}$} \\
\hline \multicolumn{2}{|c|}{ Luzes acesas e TV ligados } & \multicolumn{2}{|c|}{ Luzes acesas e TV desligada } & \multicolumn{2}{|c|}{ Luzes desligadas e TV ligada } \\
\hline 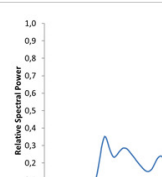 & & 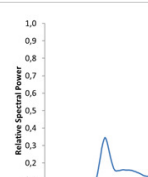 & & 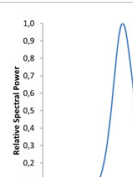 & \\
\hline $\operatorname{lux}$ & tcp & lux & tcp & $\operatorname{lux}$ & tcp \\
\hline $57,71 x$ & 5121 & $52,41 x$ & 4737 & $7,61 x$ & 6937 \\
\hline CLa & CS & CLa & CS & CLa & CS \\
\hline 52 & $7,50 \%$ & 36 & $5,20 \%$ & 15 & $2,10 \%$ \\
\hline
\end{tabular}

Observações:

As leituras, medições e fotografias foram feitas com consentimento dos moradores, utilizando espectrofotômetro Konica Minolta CL500A + Trena Bosch eletrônica GLM50 + Celular (fotos). Gráficos, CS e CLa calculados através de tabela do Lighting Research Center 


\section{LEITURAS DAS RESIDÊNCIAS DO PROCEDIMENTO 1 ANÁLISE DE CLa E CS}

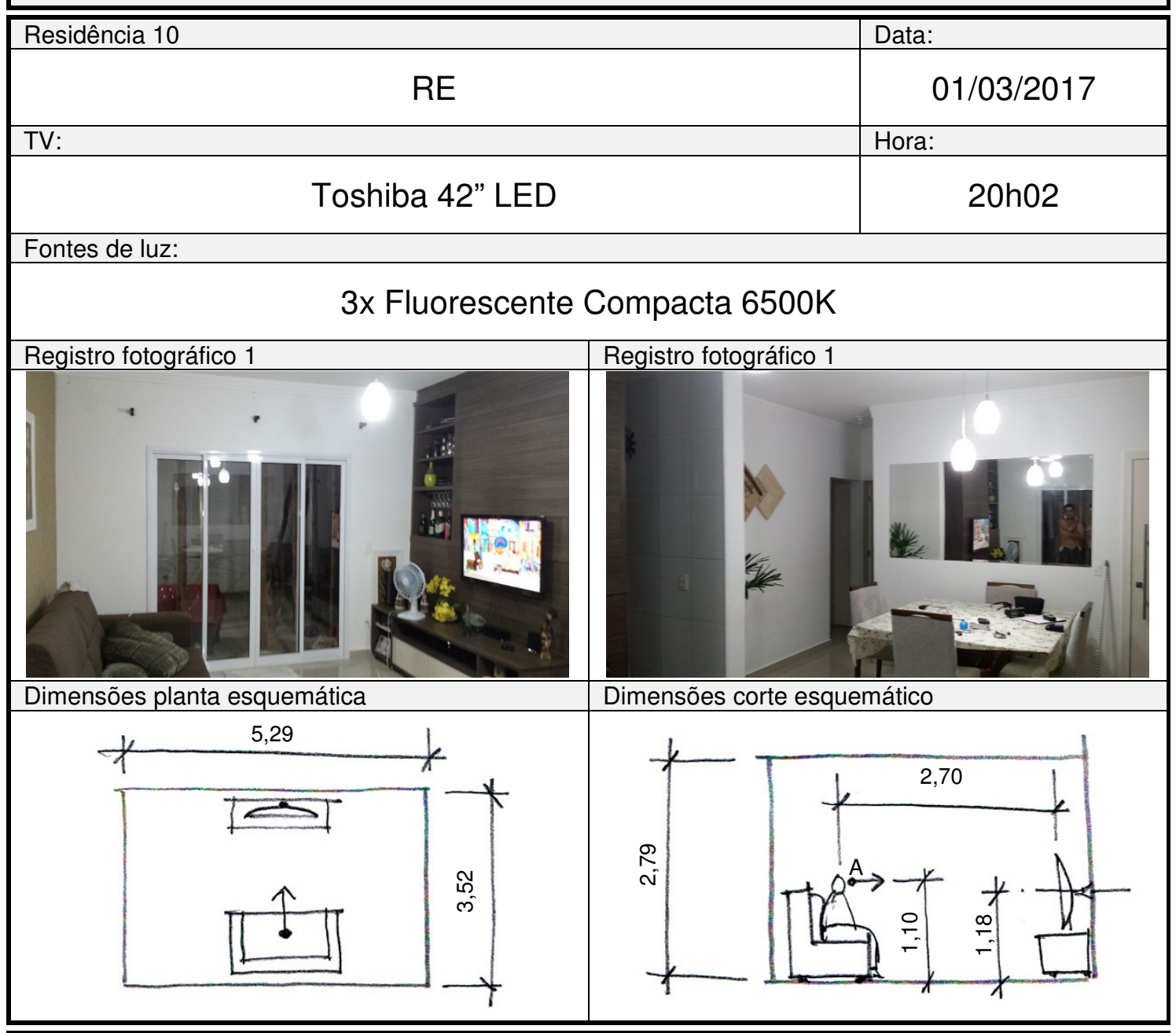

\begin{tabular}{|c|c|c|c|c|c|}
\hline \multicolumn{6}{|c|}{ Leituras e cálculos para o ponto $\mathrm{A}$} \\
\hline \multicolumn{2}{|c|}{ Luzes acesas e TV ligados } & \multicolumn{2}{|c|}{ Luzes acesas e TV desligada } & \multicolumn{2}{|c|}{ Luzes desligadas e TV ligada } \\
\hline 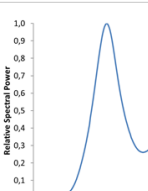 & & 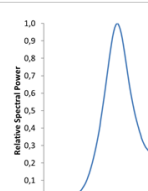 & & 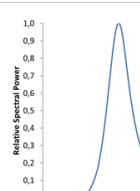 & \\
\hline $\operatorname{lux}$ & tcp & $\operatorname{lux}$ & tcp & $\operatorname{lux}$ & tcp \\
\hline $38,61 x$ & $5221 \mathrm{~K}$ & $29,31 x$ & $6006 \mathrm{~K}$ & $2,91 x$ & $8831 \mathrm{~K}$ \\
\hline CLa & CS & CLa & CS & CLa & CS \\
\hline 37 & $5,30 \%$ & 33 & $4,70 \%$ & 5 & $0,60 \%$ \\
\hline
\end{tabular}

Observações:

As leituras, medições e fotografias foram feitas com consentimento dos moradores, utilizando espectrofotômetro Konica Minolta CL500A + Trena Bosch eletrônica GLM50 + Celular (fotos). Gráficos, CS e CLa calculados através de tabela do Lighting Research Center 


\section{LEITURAS DAS RESIDÊNCIAS DO PROCEDIMENTO 1 ANÁLISE DE CLa E CS}

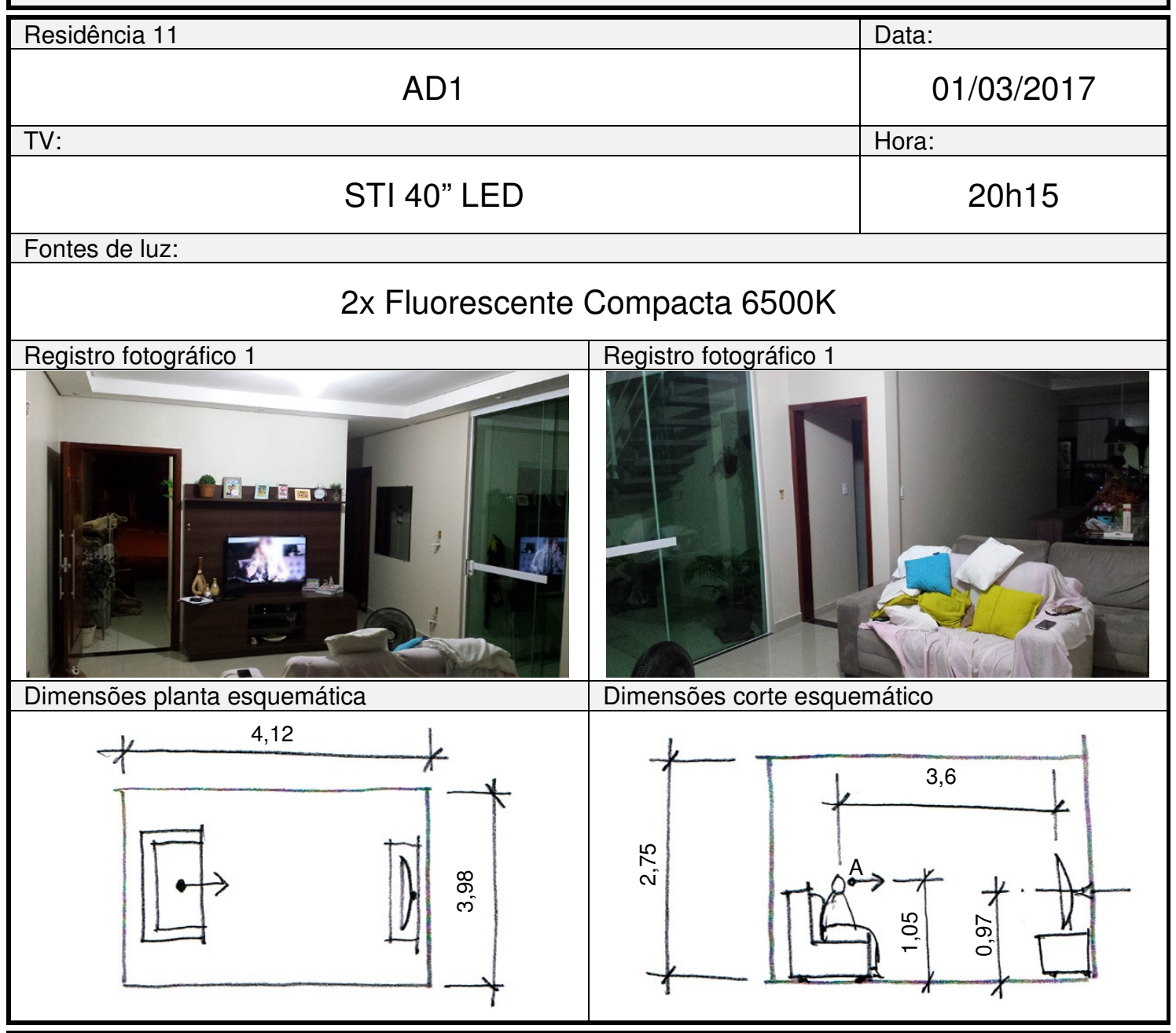

\begin{tabular}{|c|c|c|c|c|c|}
\hline \multicolumn{6}{|c|}{ Leituras e cálculos para o ponto $\mathrm{A}$} \\
\hline \multicolumn{2}{|c|}{ Luzes acesas e TV ligados } & \multicolumn{2}{|c|}{ Luzes acesas e TV desligada } & \multicolumn{2}{|c|}{ Luzes desligadas e TV ligada } \\
\hline 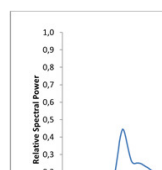 & & 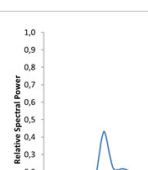 & & 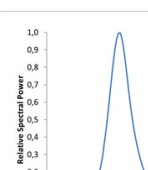 & \\
\hline lux & tcp & \multicolumn{2}{|r|}{$t c 0$} & $\operatorname{lux}$ & tcp \\
\hline $361 x$ & $5945 \mathrm{~K}$ & $31,31 x$ & $5778 \mathrm{~K}$ & $1,31 x$ & $0^{*}$ \\
\hline CLa & CS & CLa & CS & $\mathrm{CLa}$ & CS \\
\hline 39 & $5,70 \%$ & 32 & $4,60 \%$ & 4 & $0,50 \%$ \\
\hline \multicolumn{6}{|c|}{$\begin{array}{l}\text { Observações: } \\
\text { *aparelho não apresentou a temperatura de cor. }\end{array}$} \\
\hline
\end{tabular}




\section{LEITURAS DAS RESIDÊNCIAS DO PROCEDIMENTO 1 ANÁLISE DE CLa E CS}

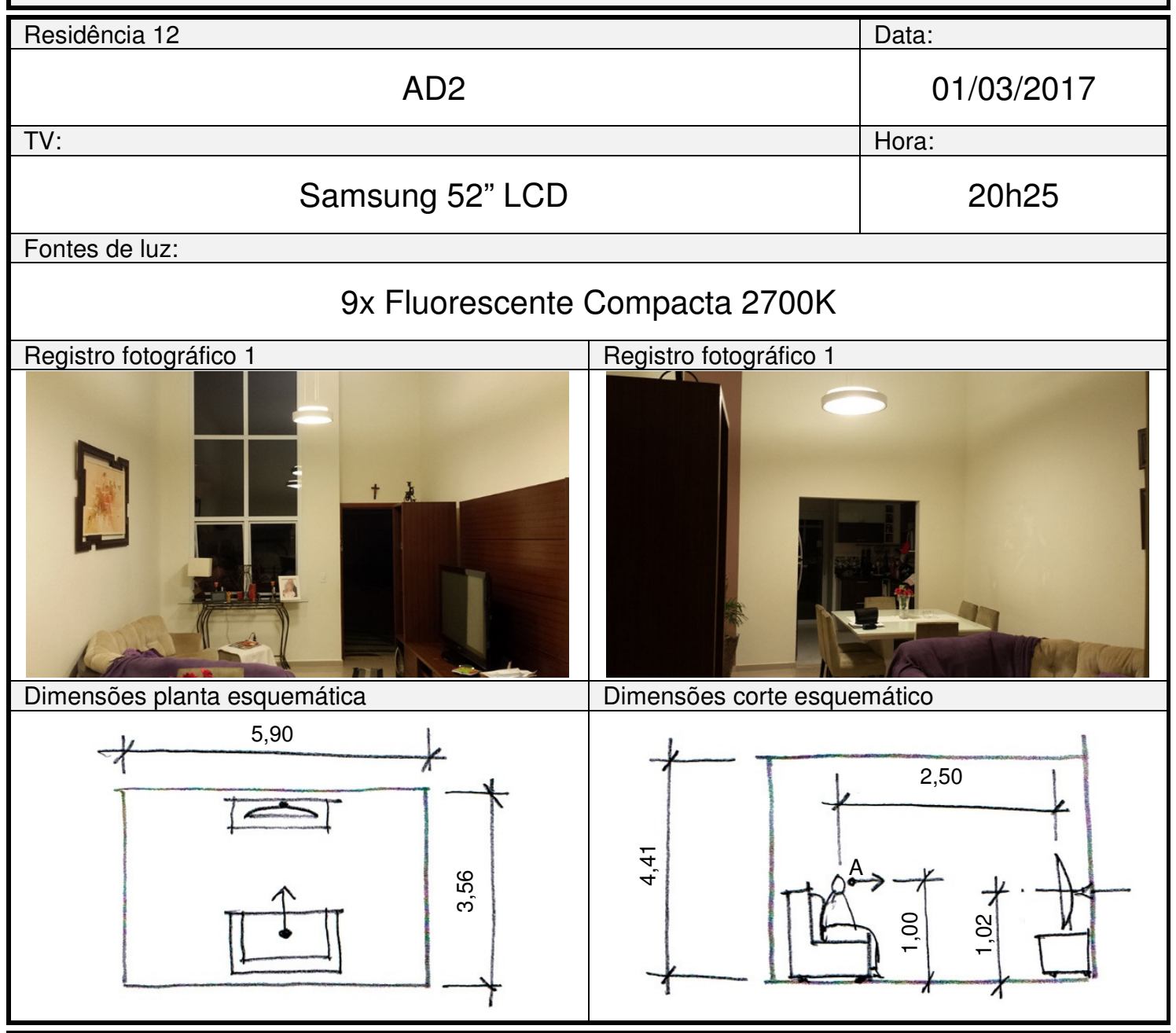

\begin{tabular}{|c|c|c|c|c|c|}
\hline \multicolumn{6}{|c|}{ Leituras e cálculos para o ponto $\mathrm{A}$} \\
\hline \multicolumn{2}{|c|}{ Luzes acesas e TV ligados } & \multicolumn{2}{|c|}{ Luzes acesas e TV desligada } & \multicolumn{2}{|c|}{ Luzes desligadas e TV ligada } \\
\hline 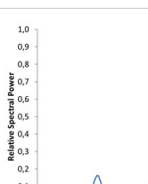 & & 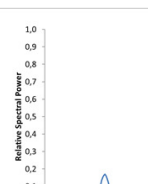 & & 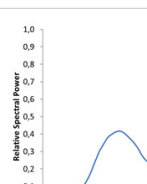 & \\
\hline $\operatorname{lux}$ & tcp & $\operatorname{lux}$ & tcp & $\operatorname{lux}$ & tcp \\
\hline $85,91 x$ & 2557K & $107 \mid x^{*}$ & $2516 K$ & $2,31 x$ & $5613 \mathrm{~K}$ \\
\hline CLa & CS & CLa & CS & CLa & CS \\
\hline 54 & $7,80 \%$ & 64 & $9,10 \%$ & 3 & $0,30 \%$ \\
\hline
\end{tabular}

Observações:

*estranhou-se a leitura do nível de iluminância estar acima de com a tv ligada. Supõe-se que as lâmpadas fluorescentes estavam aquecendo na medição 1

As leituras, medições e fotografias foram feitas com consentimento dos moradores, utilizando espectrofotômetro Konica Minolta CL500A + Trena Bosch eletrônica GLM50 + Celular (fotos). Gráficos, CS e CLa calculados através de tabela do Lighting Research Center 


\section{LEITURAS DAS RESIDÊNCIAS DO PROCEDIMENTO 1 ANÁLISE DE CLa E CS}

\begin{tabular}{|l|l|}
\hline Residência 13 & Data: \\
\hline LG: & $01 / 03 / 2017$ \\
\hline Fontes de luz: & Hora: \\
\hline 2x Fluorescente Compacta 6500K + 16x LED spot 3000K \\
\hline Registro fotográfico 1 \\
\hline Dimensões planta esquemática
\end{tabular}

\begin{tabular}{|c|c|c|c|c|c|}
\hline \multicolumn{6}{|c|}{ Leituras e cálculos para o ponto $\mathrm{A}$} \\
\hline \multicolumn{2}{|c|}{ Luzes acesas e TV ligados } & \multicolumn{2}{|c|}{ Luzes acesas e TV desligada } & \multicolumn{2}{|c|}{ Luzes desligadas e TV ligada } \\
\hline 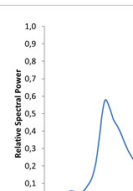 & & 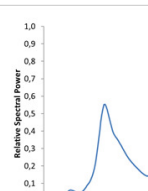 & & 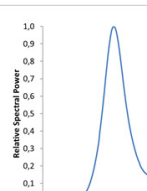 & \\
\hline $\operatorname{lux}$ & tcp & $\operatorname{lux}$ & tcp & $\operatorname{lux}$ & tcp \\
\hline $381 x$ & $3796 \mathrm{~K}$ & $35,7 \mathrm{~lx}$ & $3718 \mathrm{~K}$ & $9,51 x$ & $19080 \mathrm{~K}$ \\
\hline CLa & CS & CLa & CS & CLa & CS \\
\hline 19 & $2,70 \%$ & 17 & $2,40 \%$ & 24 & $3,40 \%$ \\
\hline
\end{tabular}

Observações:

As leituras, medições e fotografias foram feitas com consentimento dos moradores, utilizando espectrofotômetro Konica Minolta CL500A + Trena Bosch eletrônica GLM50 + Celular (fotos). Gráficos, CS e CLa calculados através de tabela do Lighting Research Center 


\section{LEITURAS DAS RESIDÊNCIAS DO PROCEDIMENTO 1 ANÁLISE DE CLa E CS}

\begin{tabular}{|l|l|}
\hline Residência 14 & Data: \\
\hline SV: & $01 / 03 / 2017$ \\
\hline Fontes de luz: & Hora: \\
\hline 4x LED spot 6500K + 1x GU10 Halógena 3000K \\
\hline Registro fotográfico 1
\end{tabular}

\begin{tabular}{|c|c|c|c|c|c|}
\hline \multicolumn{6}{|c|}{ Leituras e cálculos para o ponto $\mathrm{A}$} \\
\hline \multicolumn{2}{|c|}{ Luzes acesas e TV ligados } & \multicolumn{2}{|c|}{ Luzes acesas e TV desligada } & \multicolumn{2}{|c|}{ Luzes desligadas e TV ligada } \\
\hline 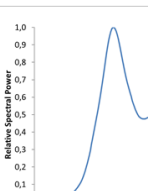 & & 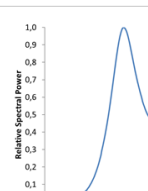 & & & \\
\hline $\operatorname{lux}$ & tcp & $\operatorname{lux}$ & tcp & $\operatorname{lux}$ & tcp \\
\hline $80,7 \mathrm{~lx}$ & $5137 \mathrm{~K}$ & $74,81 x$ & $5167 \mathrm{~K}$ & $2,91 x$ & $6788 \mathrm{~K}$ \\
\hline CLa & CS & CLa & CS & CLa & CS \\
\hline 72 & $10,30 \%$ & 64 & $9,10 \%$ & 4 & $0,50 \%$ \\
\hline
\end{tabular}

Observações:

As leituras, medições e fotografias foram feitas com consentimento dos moradores, utilizando espectrofotômetro Konica Minolta CL500A + Trena Bosch eletrônica GLM50 + Celular (fotos). Gráficos, CS e CLa calculados através de tabela do Lighting Research Center 


\section{LEITURAS DAS RESIDÊNCIAS DO PROCEDIMENTO 1 ANÁLISE DE CLa E CS}

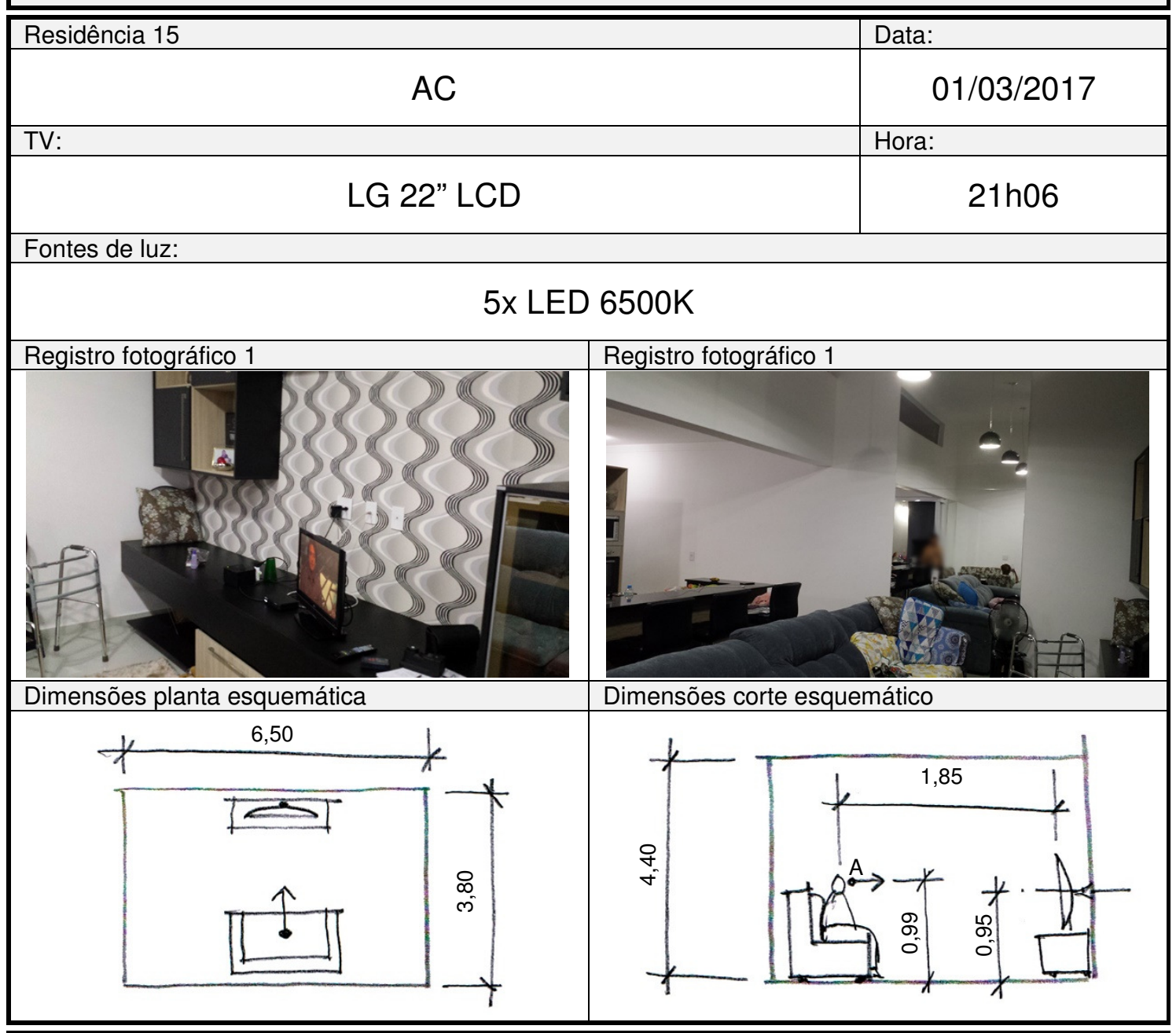

\begin{tabular}{|c|c|c|c|c|c|}
\hline \multicolumn{6}{|c|}{ Leituras e cálculos para o ponto $\mathrm{A}$} \\
\hline \multicolumn{2}{|c|}{ Luzes acesas e TV ligados } & \multicolumn{2}{|c|}{ Luzes acesas e TV desligada } & \multicolumn{2}{|c|}{ Luzes desligadas e TV ligada } \\
\hline 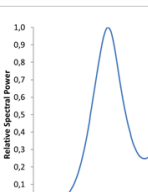 & & 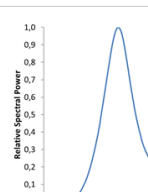 & & 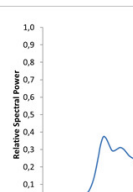 & \\
\hline $\operatorname{lux}$ & tcp & $\operatorname{lux}$ & tcp & $\operatorname{lux}$ & tcp \\
\hline $17,4 \mathrm{Ix}$ & $6001 \mathrm{~K}$ & $16,4 \mid x$ & $6072 \mathrm{~K}$ & $0,6 l x$ & $5795 \mathrm{~K}$ \\
\hline CLa & CS & CLa & CS & CLa & CS \\
\hline 19 & $2,70 \%$ & 19 & $2,60 \%$ & 1 & $0,10 \%$ \\
\hline
\end{tabular}

Observações:

As leituras, medições e fotografias foram feitas com consentimento dos moradores, utilizando espectrofotômetro Konica Minolta CL500A + Trena Bosch eletrônica GLM50 + Celular (fotos). Gráficos, CS e CLa calculados através de tabela do Lighting Research Center 


\section{LEITURAS DAS RESIDÊNCIAS DO PROCEDIMENTO 1 ANÁLISE DE CLa E CS}

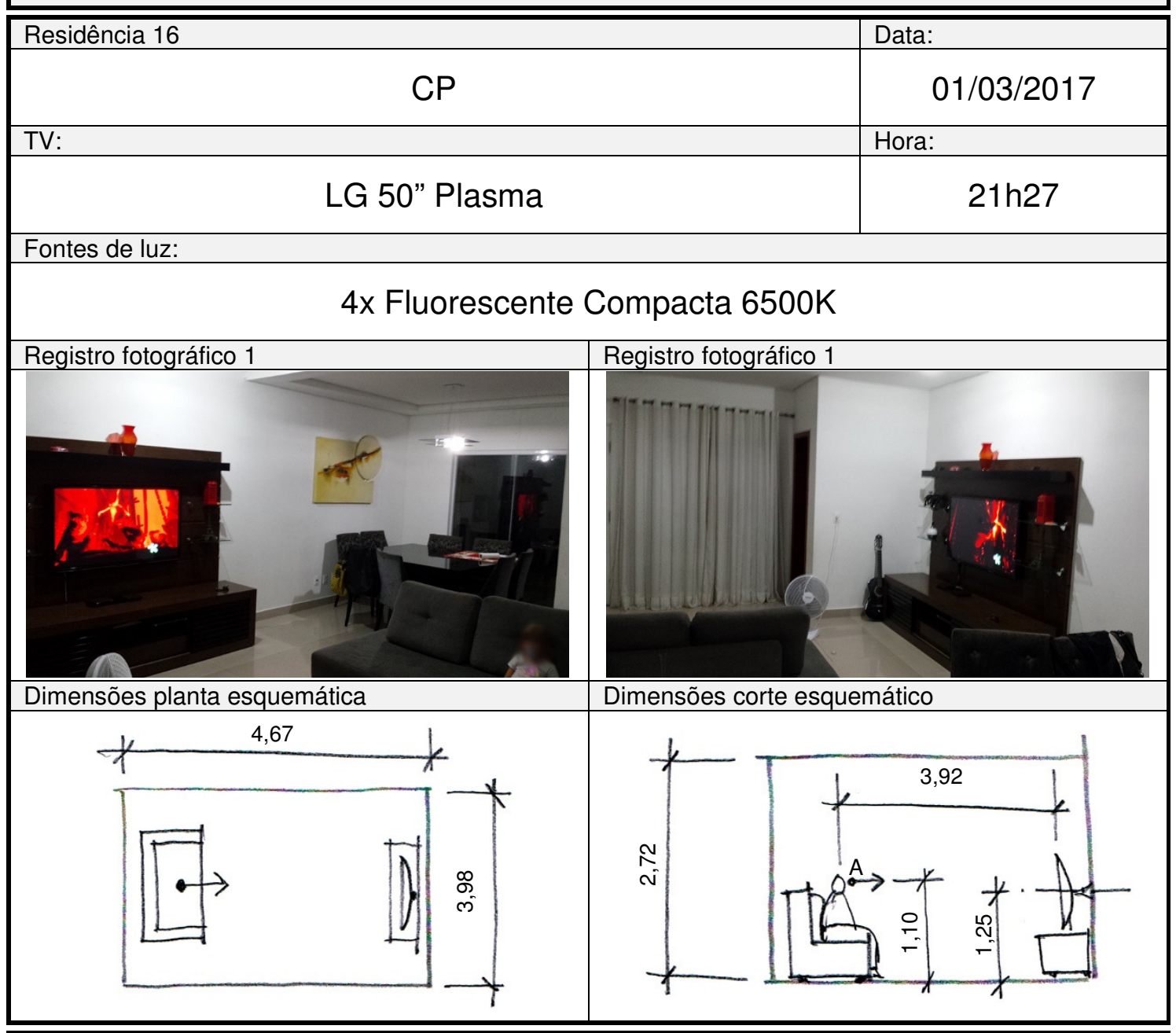

\begin{tabular}{|c|c|c|c|c|c|}
\hline \multicolumn{6}{|c|}{ Leituras e cálculos para o ponto $\mathrm{A}$} \\
\hline \multicolumn{2}{|c|}{ Luzes acesas e TV ligados } & \multicolumn{2}{|c|}{ Luzes acesas e TV desligada } & \multicolumn{2}{|c|}{ Luzes desligadas e TV ligada } \\
\hline 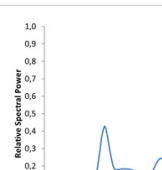 & & 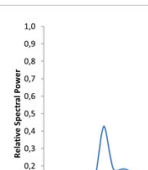 & & 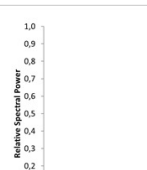 & \\
\hline lux & tcp & lux & tcp & lux & tcp \\
\hline $32,71 x$ & $5300 \mathrm{~K}$ & $30,6 l x$ & $5612 K$ & $2,31 x$ & $3765 K$ \\
\hline CLa & CS & CLa & CS & CLa & CS \\
\hline 29 & $4,10 \%$ & 28 & $4,00 \%$ & 3 & $0,40 \%$ \\
\hline
\end{tabular}

Observações:

As leituras, medições e fotografias foram feitas com consentimento dos moradores, utilizando espectrofotômetro Konica Minolta CL500A + Trena Bosch eletrônica GLM50 + Celular (fotos). Gráficos, CS e CLa calculados através de tabela do Lighting Research Center 


\section{LEITURAS DAS RESIDÊNCIAS DO PROCEDIMENTO 1 ANÁLISE DE CLa E CS}

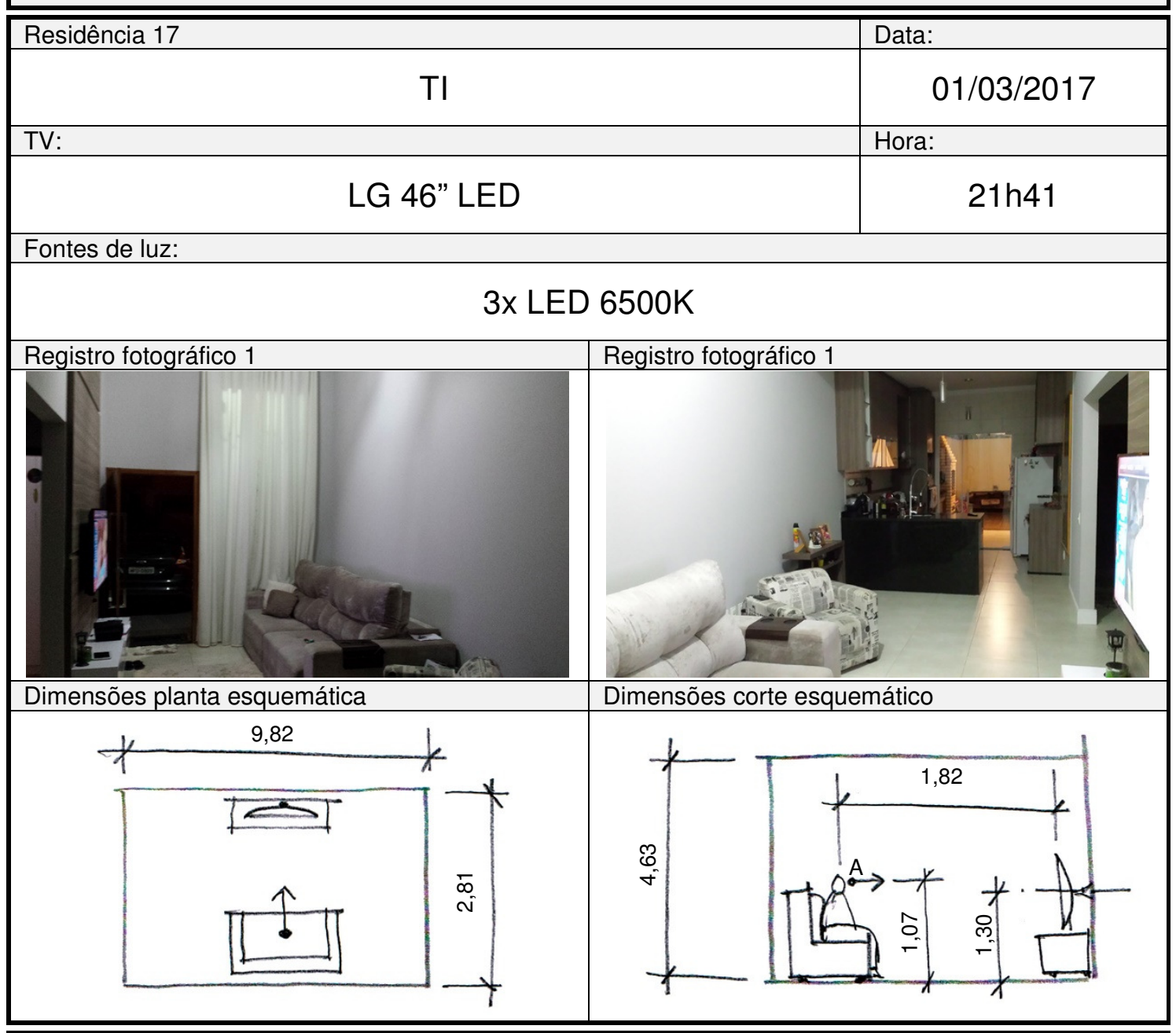

\begin{tabular}{|c|c|c|c|c|c|}
\hline \multicolumn{6}{|c|}{ Leituras e cálculos para o ponto $\mathrm{A}$} \\
\hline \multicolumn{2}{|c|}{ Luzes acesas e TV ligados } & \multicolumn{2}{|c|}{ Luzes acesas e TV desligada } & \multicolumn{2}{|c|}{ Luzes desligadas e TV ligada } \\
\hline 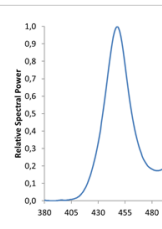 & 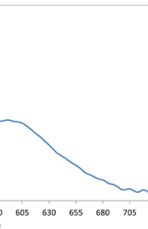 & 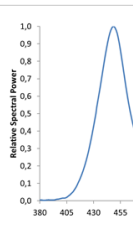 & & 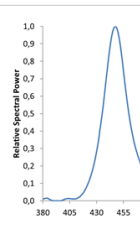 & \\
\hline $\operatorname{lux}$ & tcp & $\operatorname{lux}$ & tcp & $\operatorname{lux}$ & tcp \\
\hline $16,21 \mathrm{x}$ & $6371 \mathrm{~K}$ & $101 x$ & $5118 \mathrm{~K}$ & $4,91 x$ & $13256 \mathrm{~K}$ \\
\hline CLa & CS & CLa & CS & CLa & CS \\
\hline 19 & $2,70 \%$ & 8 & $1,10 \%$ & 11 & $1,50 \%$ \\
\hline
\end{tabular}

Observações:

As leituras, medições e fotografias foram feitas com consentimento dos moradores, utilizando espectrofotômetro Konica Minolta CL500A + Trena Bosch eletrônica GLM50 + Celular (fotos). Gráficos, CS e CLa calculados através de tabela do Lighting Research Center 


\section{LEITURAS DAS RESIDÊNCIAS DO PROCEDIMENTO 1 ANÁLISE DE CLa E CS}

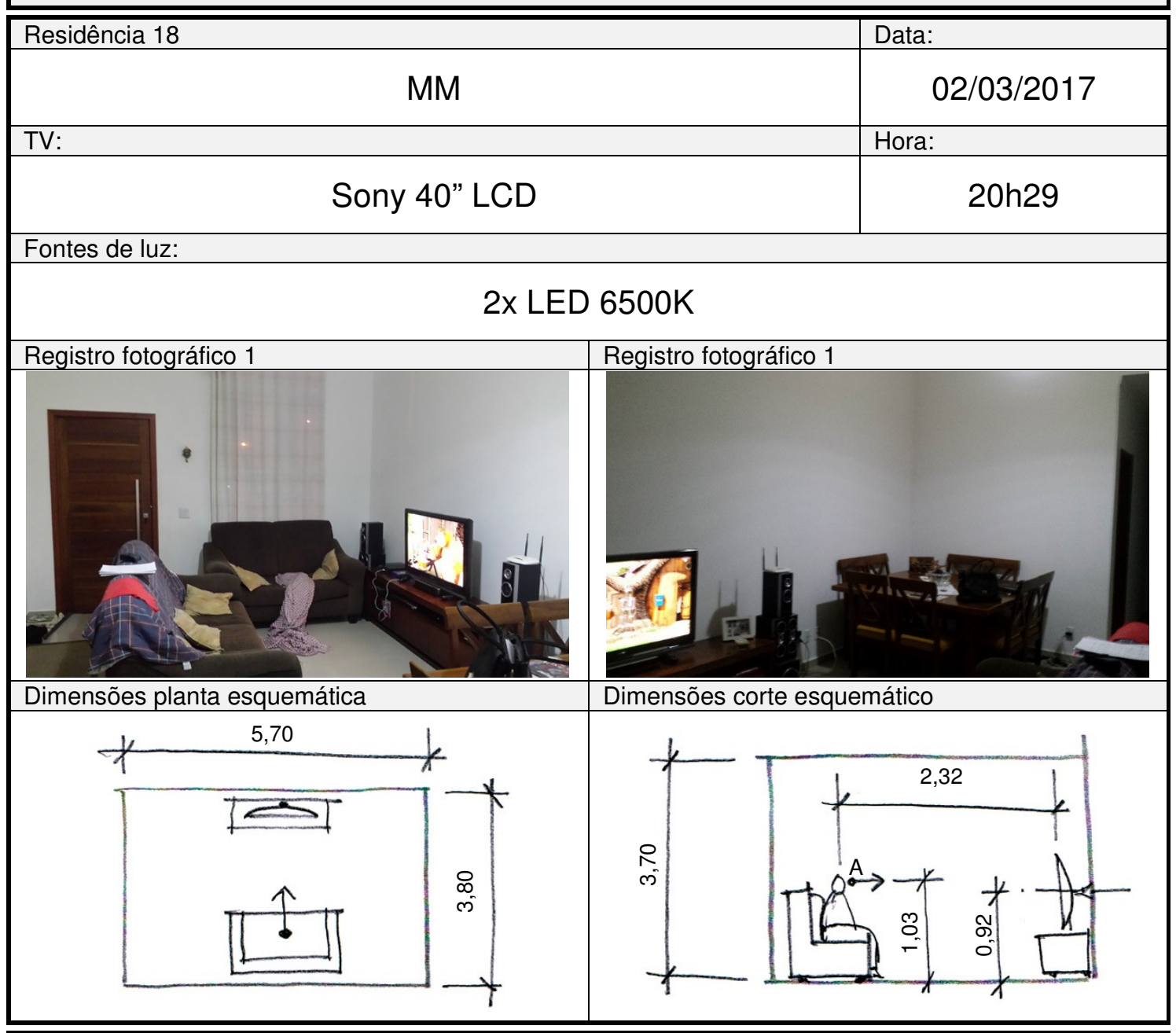

\begin{tabular}{|c|c|c|c|c|c|}
\hline \multicolumn{6}{|c|}{ Leituras e cálculos para o ponto $\mathrm{A}$} \\
\hline \multicolumn{2}{|c|}{ Luzes acesas e TV ligados } & \multicolumn{2}{|c|}{ Luzes acesas e TV desligada } & \multicolumn{2}{|c|}{ Luzes desligadas e TV ligada } \\
\hline 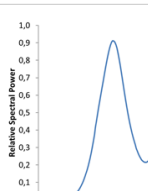 & & 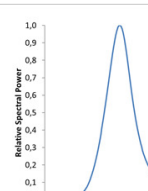 & & 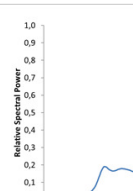 & 1 \\
\hline $\operatorname{lux}$ & tcp & $\operatorname{lux}$ & tcp & lux & tcp \\
\hline $29,31 x$ & $5192 K$ & $23,81 x$ & $5629 K$ & $51 x$ & $3931 \mathrm{~K}$ \\
\hline CLa & CS & CLa & CS & CLa & CS \\
\hline 28 & $4,00 \%$ & 24 & $3,40 \%$ & 3 & $0,40 \%$ \\
\hline
\end{tabular}

Observações:

As leituras, medições e fotografias foram feitas com consentimento dos moradores, utilizando espectrofotômetro Konica Minolta CL500A + Trena Bosch eletrônica GLM50 + Celular (fotos). Gráficos, CS e CLa calculados através de tabela do Lighting Research Center 